\title{
DETERMINANTES SOCIOECONÓMICOS E INSTITUCIONALES PARA PROMOVER EL DESARROLLO ECONÓMICO LOCAL EN NARIÑO, CUNDINAMARCA, MUNICIPIO DE SEXTA CATEGORÍA EN COLOMBIA
}

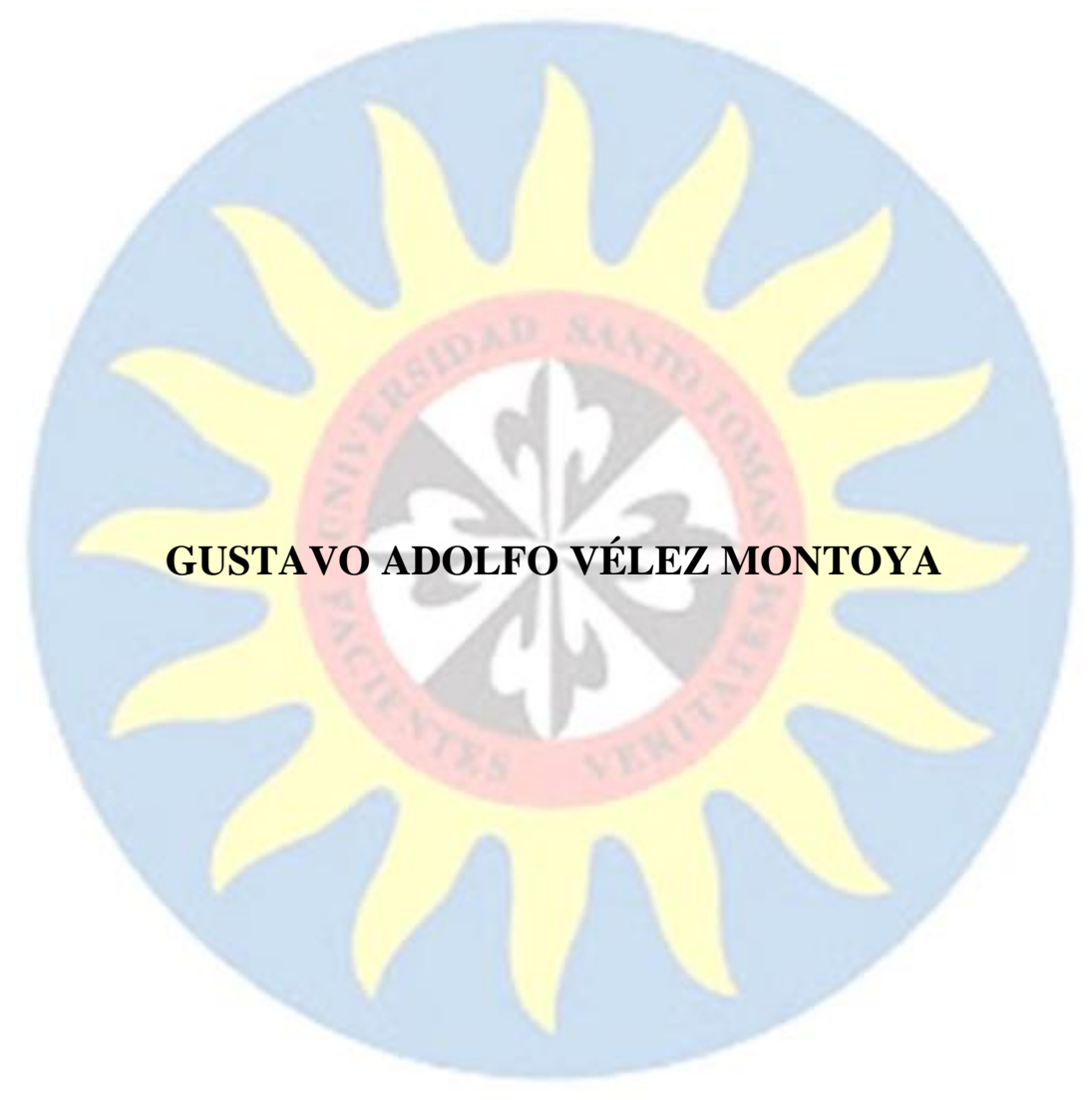

UNIVERSIDAD SANTO TOMÁS

DIVISIÓN DE CIENCIAS ECONÓMICAS Y ADMINISTRATIVAS

FACULTAD DE ECONOMÍA

MAESTRÍA EN CIENCIAS ECONÓMICAS

BOGOTÁ D.C., COLOMBIA 


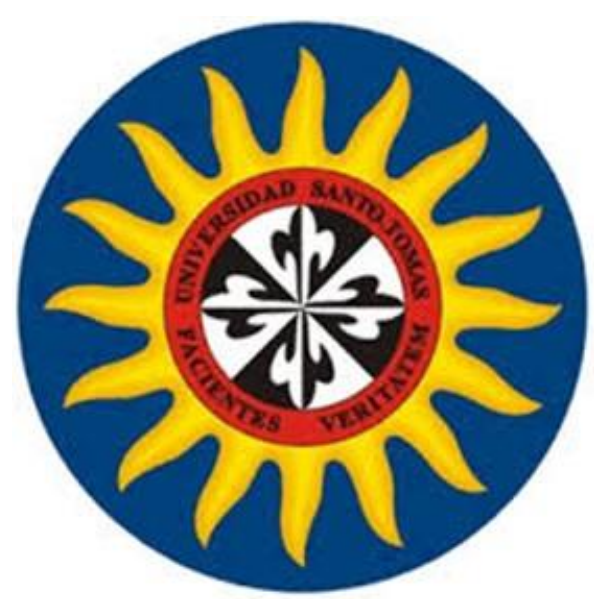

Determinantes Socioeconómicos e Institucionales para Promover el Desarrollo Económico Local en Nariño, Cundinamarca, Municipio de Sexta Categoría en Colombia Gustavo Adolfo Vélez Montoya Universidad Santo Tomás

Nota del autor:

Gustavo Adolfo Vélez Montoya, estudiante de la Maestría en Ciencias Económicas, Facultad de Economía, Universidad Santo Tomás, Bogotá, 2015.

Tesis presentada como requisito parcial para optar al título de Magister en Ciencias Económicas.

Director: Ph.D. Olga Marina García Norato, Economista. 


\section{DETERMINANTES SOCIOECONÓMICOS E INSTITUCIONALES}

\section{Agradecimientos}

A mi esposa Gloria Nancy y mi hija Laura Sofía, por su amor, paciencia y apoyo incondicional.

A mi Tía María, por su amor infinito y compañía aún desde el cielo. A mis amigos de Pereira, Bogotá y de maestría por apoyarme y transmitir la motivación necesaria para cumplir con este objetivo.

A los profesores de maestría y directora de tesis que me apoyaron y fueron fundamentales para hacer realidad este logro. 


\section{DETERMINANTES SOCIOECONÓMICOS E INSTITUCIONALES}

\section{Resumen}

La división político administrativa de Colombia, registra que el país cuenta con un $88,6 \%{ }^{1}$ de municipios categoría $\operatorname{sexta}^{2}$, los cuales presentan condiciones propicias para implementar procesos de desarrollo económico local, entendido este como el liderazgo y protagonismo de los actores locales para la formulación de estrategias y toma de decisiones, haciendo posible la implementación de nuevos proyectos con iniciativas novedosas que potencien los recursos existentes para el aumento las capacidades productivas locales para promover su propio desarrollo y bienestar socioeconómico. Sin embargo, para lograr la implementación de estos procesos, se hace necesario la identificación de los principales determinantes sociales, económicos y políticos para hacer posible que las diversas metodologías o iniciativas para el desarrollo económico local tengan resultados más eficientes.

Por lo anterior, este trabajo presenta una propuesta para motivar la construcción de una herramienta que apoye la identificación de los determinantes socioeconómicos e institucionales que inciden en la implementación de procesos de desarrollo económico local, a partir de las percepciones mismas de la comunidad sobre el estado del desarrollo local (índice de confianza). No se pretende imponer una metodología, pero si orientar la necesidad de crear instrumentos para tomar decisiones en la posible intervención, previendo el menor riesgo y la optimización de recursos que las comunidades e instituciones (agentes) deben incurrir.

Palabras clave: desarrollo local, desarrollo económico local, dimensiones del desarrollo.

\footnotetext{
${ }^{1}$ Datos de la Contaduría General de la Nación para el 2014 (975 municipios categoría sexta de 1.101).

${ }^{2}$ Población igual o menor a 10.000 habitantes y con ingresos corrientes de libre destinación anuales no superiores a quince mil (15.000) salarios mínimos legales mensuales vigentes.
} 


\title{
DETERMINANTES SOCIOECONÓMICOS E INSTITUCIONALES
}

\begin{abstract}
The political and administrative division of Colombia, records that the country has $88.6 \%$ of sixth class municipalities, which present conditions for implementing processes of local economic development, understood as the leadership and involvement of local actors in the formulation strategies and decision making, enabling the implementation of new projects with new initiatives that enhance existing resources to increase local production capacity to promote their own development and socioeconomic welfare. However, to achieve the implementation of these processes, identifying key social, economic and political determinants is necessary to enable the various methodologies and initiatives for local economic development with more efficient results.

Therefore, this work presents a proposal to encourage the construction of a tool to support the identification of socio-economic and institutional determinants that affect the implementation of local economic development processes, from the same community perceptions about the state local development (Confidence Index). It is not intended to impose a methodology, but guide the need for tools to make decisions on possible intervention, providing the lowest risk and optimize resources that communities and institutions (agents) must incur.
\end{abstract}

Keywords: local development, local economic development, dimensions of development. 


\section{Contenido}

pág.

$\begin{array}{ll}\text { Introducción } & 12\end{array}$

Percepciones Teóricas del Desarrollo Económico y el Desarrollo Local 18

Desarrollo Económico Local $\quad 21$

$\begin{array}{ll}\text { Desarrollo Endógeno } & 23\end{array}$

$\begin{array}{ll}\text { Institucionalidad } & 24\end{array}$

Dimensiones del Desarrollo Local 25

Caracterización de las Dimensiones del Desarrollo en el Municipio de Nariño, Cundinamarca

$\begin{array}{ll}\text { Generalidades } & 29\end{array}$

Dimensión Social

Dimensión Económica $\quad 39$

Dimensión Institucional $\quad 48$

Índice de Confianza Municipal a partir de las Percepciones del Desarrollo Local y Económico

$\begin{array}{ll}\text { Local } & 55\end{array}$

Proceso de Elaboración del Índice de Confianza 55

Cálculo para Hallar el Índice de Confianza $\quad 58$

$\begin{array}{ll}\text { Índice de Confianza Municipal } & 67\end{array}$

Determinantes Socioeconómicos e Institucionales para el Desarrollo Económico Local 70

Bases Teóricas de los Determinantes del Desarrollo Local 70

Determinantes Endógenos para el Desarrollo Económico Local 72

Incidencia de Variables en el Desarrollo Económico Local 76 


\section{DETERMINANTES SOCIOECONÓMICOS E INSTITUCIONALES}

Perspectivas que Promueven el Desarrollo Económico Local 85

$\begin{array}{ll}\text { Conclusiones } & 93\end{array}$

Referencias Bibliográficas 996

$\begin{array}{ll}\text { ANEXOS } & 102\end{array}$ 


\section{DETERMINANTES SOCIOECONÓMICOS E INSTITUCIONALES}

\section{Lista de Gráficas}

pág.

Gráfica 1. Población por genero Proyección a 2014

Gráfica 2. Porcentaje población con NBI 2005

Gráfica 3. Aseguramiento de salud (Población a 2012) 34

Gráfica 4. Porcentaje de cobertura de servicios públicos (según Sisbén) 37

Gráfica 5. Ingresos totales de Nariño, Cundinamarca $\quad 51$

Gráfica 6. Determinantes y dimensiones del desarrollo local 76

Gráfica 7. Resultados de desempeño de variables Dimensión Social 81

Gráfica 8. Resultados de desempeño de variables Dimensión Económica 82

Gráfica 9. Resultados de desempeño de variables Dimensión Institucional 84

Gráfica 10. Resultados desempeño general por Dimensión 85

Gráfica 11. Conocimiento en los temas de Desarrollo Local 89

Gráfica 12. Conocimiento en los temas de Desarrollo Económico Local 90

Gráfica 13. Comparación de resultados en Desarrollo Local y Económico 91

Gráfica 14. Comparación de resultados para la promoción del Desarrollo Local

y Económico 


\section{DETERMINANTES SOCIOECONÓMICOS E INSTITUCIONALES}

\section{Lista de Tablas}

pág.

Tabla 1. Indicadores de calidad de vida $\quad 31$

Tabla 2. Cálculo de fiabilidad variables Dimensión Social 59

Tabla 3. Cálculo de fiabiliadad variables Dimensión Económica 60

Tabla 4. Cálculo de fiabiliadad variables Dimensión Institucional 61

Tabla 5. Cálculo del ponderado de variables en la Dimensión Social 65

Tabla 6. Cálculo del ponderado de variables en la Dimensión Económica 66

Tabla 7. Cálculo del ponderado de variables en la Dimensión Institucional 67

Tabla 8. Cálculo del ponderado de Índice General $\quad 68$

$\begin{array}{ll}\text { Tabla 9. Valoración del desempeño por variable } & 77\end{array}$

Tabla 10. Porcentaje de participación de cada variable por dimensión 78 
DETERMINANTES SOCIOECONÓMICOS E INSTITUCIONALES

\section{Lista de Figuras}

pág.

Figura 1. Pasos para calcular el índice $\quad 58$

Figura 2. Esquema de cálculo de ponderados Dimensión Social 63

Figura 3. Esquema de cálculo de ponderados Dimensión Económica 63

Figura 4. Esquema de cálculo de ponderados Dimensión Institucional 64

Figura 5. Esquema para el cálculo del Índice de Confianza $\quad 67$ 


\section{Lista de Anexos}

pág.

Anexo A. Índice de Pobreza Multidimensional (IPM-Colombia)

Anexo B. Diseño de Encuesta de Percepción sobre las Dimensiones del Desarrollo y el Desarrollo Económico Local

Anexo C. Formulario de Encuesta

Anexo D. Tabulación de Respuestas

Anexo E. Cálculos de Cronbach (Fiabilidad Variables Dimensión Social)

Anexo F. Cálculos de Cronbach (Fiabilidad Variables Dimensión Económica)

Anexo G. Cálculos de Cronbach (Fiabilidad Variables Dimensión Institucional)

Anexo H. Cálculos CATPCA Ponderados Dimensión Social

Anexo I. Cálculos CATPCA Ponderados Dimensión Económica

Anexo J. Cálculos CATPCA Ponderados Dimensión Institucional

Anexo K. Consolidado de los Cálculos Ponderados para cada Dimensión

Anexo L. Consolidado Conocimiento en Desarrollo Local y Desarrollo Económico Local 


\section{Introducción}

El artículo 311 de la Constitución Política de Colombia de 1991 define que al municipio como:

(...) entidad fundamental de la división político-administrativa del Estado le corresponde prestar los servicios públicos que determine la ley, construir las obras que demande el progreso local, ordenar el desarrollo de su territorio, promover la participación comunitaria, el mejoramiento social y cultural de sus habitantes y cumplir las demás funciones que le asignen la Constitución y las leyes (Congreso de la República, 1991).

Y en la Ley 136 de 1994 sobre las normas tendientes a modernizar la organización y el funcionamiento de los municipios, define a los municipios "con autonomía política, fiscal y administrativa, dentro de los límites que señalen la Constitución y la ley y cuya finalidad es el bienestar general y el mejoramiento de la calidad de vida de la población en su respectivo territorio" (Congreso de la República, 1994).

De acuerdo con la anterior nominación, los municipios asumen obligaciones y responsabilidades para direccionar con autonomía y en el marco de la Ley el desarrollo y bienestar de su comunidad; sin embargo, la autonomía del gobierno local queda plenamente condicionada en los municipios categorizados con bajo nivel de ingresos y poca población (categoría sexta) ${ }^{3}$, quienes están directamente subordinados a las decisiones del gobierno regional y nacional (centralismo). En consecuencia, las posibilidades para lograr un mejor desarrollo en la dimensión social, económica e institucional, están asociadas a determinantes externos e internos; los primeros provenientes de las decisiones centralistas del Estado; y los segundos, a las acciones locales motivadas por el liderazgo propio de la comunidad con el buen uso de los recursos físicos, humanos y financieros. De esta manera, los determinantes que se asocian en el segundo aspecto,

\footnotetext{
${ }^{3}$ Los municipios de sexta categoría en Colombia registran una población igual o menor a 10.000 habitantes y con ingresos corrientes de libre destinación anuales no superiores a quince mil (15.000) salarios mínimos legales mensuales.
} 
son el propósito directo del presente trabajo, con el fin de establecer determinantes socioeconómicos e institucionales que promuevan el desarrollo local en Nariño, Cundinamarca municipio de sexta categoría en Colombia.

El trabajo se fundamenta en las experiencias y referentes que hay en Colombia sobre procesos de desarrollo económico local, los cuales han venido aumentando a partir de acciones de gestión territorial promovidos por el Programa de las Naciones Unidas para el Desarrollo -PNUDcon el propósito de generar capacidades locales que optimicen eficientemente la disponibilidad de recursos e incrementen la producción local, los ingresos en la población y por tanto mejoramiento de las necesidades básicas de la comunidad.

Pese a ello, en la mayoría de municipios colombianos no hay una clara promoción de acciones para que los entes territoriales o los actores locales impulsen modelos de desarrollo local con las metodologías promovidas por la cooperación internacional como el mismo caso del PNUD y la Agencia de Cooperación Internacional del Japón -JICA-; aunque las experiencias son limitadas, en Colombia se identifica el trabajo de 10 Agencias de Desarrollo Económico Local ADEL- que cubren alrededor de 230 municipios $^{4}$; para el caso de Cundinamarca no se ha establecido a la fecha ADEL alguna, aunque hay una experiencia de Desarrollo Económico Local -DEL- promovida por la gobernación en convenio con un ente gremial $^{5}$, en veintinueve municipios, denominados del milenio, entre ellos Nariño. El balance final de la intervención fue diverso, con mejores resultados en unos que en otros, sin encontrar una causa o determinante común para establecer las diferencias entre los resultados. Por tal razón, el origen del trabajo radica

\footnotetext{
${ }^{4}$ Municipios de los departamentos de Nariño (Adel Nariño); Antioquia y Chocó (Adra, Adeproa, Adel Urabá, Darién Caribe); Boyacá y Santander (Gal Valletenzano, Adel Dinosaurios, Adel Vélez, Adel Metropolitana); Cesar y Magdalena (Adel Zapatosa); Arauca (Aprodel); Cauca (Asociación Casa del Agua).

${ }^{5}$ Convenio de asociación entre la Gobernación de Cundinamarca y Fenalco seccional Bogotá - Cundinamarca, con el objeto de "Aunar esfuerzos administrativos, técnicos y económicos para el apoyo a la implementación de una estrategia subregional de desarrollo local, innovadora y social, mediante la identificación y desarrollo del potencial competitivo de un núcleo de productores de un sector - cadena productiva".
} 
en la necesidad de identificar los determinantes que llevan a obtener mejores resultados con disminución de riesgo y costos, en los procesos de autogestión con suficiencia institucional, productiva y económica (o procesos de desarrollo económico local); de esta manera, se pretende identificar condiciones socioeconómicas e institucionales que motivan a los actores locales y comunidad a implementar estrategias comunes y solidarias de desarrollo local.

El planteamiento del problema se basa en el hecho de que los municipios de menor categoría carecen de reconocidos y eficientes modelos de desarrollo local con resultados significativos que sean objeto de réplica; generación e impulso de las dinámicas productivas internas con crecimiento, autonomía y sostenibilidad; y el aprovechamiento de las potencialidades locales con articulación de los actores públicos y privados con incidencia en lo regional y visibilizados a nivel nacional. Pese a que los pequeños territorios son propicios para realizar procesos de desarrollo local, por la posibilidad de unificar propósitos de bienestar colectivo, en la práctica la falta de unidad comunitaria y política fracturan conscientemente las oportunidades de mejora socioeconómica para estos municipios.

Por lo anterior es necesario que los procesos de Desarrollo Local se asuman con el liderazgo y protagonismo de los actores locales para la formulación de estrategias y toma de decisiones, haciendo posible la implementación de nuevos proyectos con iniciativas novedosas que potencien los recursos existentes para el aumento las capacidades productivas locales.

El presente trabajo no pretende describir detalladamente las teorías y los orígenes (sinopsis) ${ }^{6}$ del Desarrollo Económico Local, y tampoco requiere describir directamente las teorías económicas o citar las escuelas de pensamiento económico, por tratarse de un trabajo ubicado en

\footnotetext{
${ }^{6}$ El profesor Mario D. Tello presenta una valiosa reseña histórica de las teorías de desarrollo local en el documento de trabajo 247 Departamento de Economía y Centrum Católica "Las teorías del desarrollo económico local y la teoría y práctica del proceso de descentralización en los países en desarrollo", julio de 2006.
} 
la realidad y pragmatismo con que actúan los actores en el contexto social, económico, político e institucional propios de las poblaciones y municipios de menor categoría en Colombia (proyectado a territorios tipificados por la vulnerabilidad económica en Latinoamérica); para ello, el soporte teórico se fundamenta en los trabajos de los principales autores de las teorías del desarrollo local y desarrollo económico local, quienes han incorporado los planteamientos de la economía normativa y positiva.

El desarrollo metodológico de la investigación se basa en lo descriptivo analítico. Las etapas están determinadas secuencialmente con los propósitos específicos de la propuesta que son: (a) Caracterizar las condiciones socioeconómicas e institucionales de Nariño, Cundinamarca, municipio de sexta categoría; (b) Establecer un índice de confianza municipal - ICM para Nariño, Cundinamarca, como municipio de sexta categoría; y, (c) Identificar determinantes socioeconómicos e institucionales, para la gestión de iniciativas participativas y la promoción del desarrollo local en Nariño, Cundinamarca.

El levantamiento de información se obtuvo de fuentes secundarías con información estadística (la cual es limitada y desactualizada), y se complementó con los resultados de percepción obtenidos a los representantes y líderes de la municipalidad, mediante un instrumento de encuesta.

De manera particular se ha seleccionado para el trabajo un municipio de Cundinamarca que cumple con todas las características de la categoría seis en Colombia, como lo es el municipio de Nariño, este hace parte de la Provincia del Alto Magdalena, a 149 km de Bogotá, comparte frontera con el departamento de Tolima pero separados por del Rio Magdalena. Es un municipio pequeño de 2.189 habitantes y de estos el 68,2 \% vive en la pobreza (Secretaría de Planeación de 
Cundinamarca, 2015); se estima un $50 \%$ de desempleo; indicadores que evidencian el bajo nivel de desarrollo socioeconómico que caracteriza estos municipios.

El trabajo está estructurado en cuatro capítulos. El primero contiene la información de respaldo teórico y conceptual, el cual se desarrolla partiendo de lo general (conceptualización de desarrollo), hasta finalizar con las dimensiones del desarrollo económico local, para ello, se abordó previamente los elementos teóricos de desarrollo endógeno e institucionalismo. La información teórica se constituyó en un insumo técnico importante, para soportar durante los demás capítulos aspectos relacionados con el índice de confianza y la identificación de determinantes.

El segundo capítulo sobre la caracterización del municipio, recoge información estadística y se confronta cada variable por dimensión social, económica e institucional, con cada uno de los resultados de percepción obtenida en las encuestas. Para realizar el levantamiento de información, se efectuó bajo el sistema de "bola de nieve" para identificar a los representantes y líderes de los sectores más representativos del municipio.

El tercer capítulo contiene la propuesta para hallar el Índice de Confianza Municipal ICM, en éste se describen los parámetros para validar la fiabilidad de la información recopilada a través del sistema de Cronbach, posteriormente se calcularon los ponderadores para hallar el peso de cada variable dentro de cada dimensión con el método CATPCA - Análisis de Componentes principales Categórico (CATPCA, del inglés Categorical Principal Components Analysis). Finalmente se obtiene el índice de confianza municipal con la ponderación de las tres dimensiones.

El último capítulo finaliza con la identificación de los determinantes propuestos, a partir del análisis de la información procesada en el segundo capítulo y los valores resultantes en el tercer capítulo con el Índice de Confianza Municipal. 
Como conclusión principal, el trabajo es un referente para el diseño de instrumentos que apoyen la identificación de determinantes que permitan el cumplimiento de los propósitos DEL, pero disminuyendo el riesgo y los costos que un mal proceso puede derivar.

Por lo anterior el trabajo con alcance correlacional, pretende motivar en las comunidades de menor desarrollo como son los municipios de sexta categoría en Colombia, la implementación de acciones participativas y solidarias en comunidad, promovidas por sus líderes y dirigentes a partir del reconocimiento de las capacidades locales hacia un desarrollo socio económico para el bienestar y la cohesión social. 


\section{Percepciones Teóricas del Desarrollo Económico y el Desarrollo Local}

El PNUD define el desarrollo económico como:

(...) un proceso donde las condiciones de bienes y servicios se encuentran en estado creciente y al alcance de todos los grupos sociales que conforman la comunidad. Una sociedad donde existe un buen desarrollo económico presenta características de integración económica y social y tendría menos personas viviendo en la marginalidad.

Pero en tiempos modernos el desarrollo es mucho más que bienestar económico, y por ello debe ser integral e incluyente con el bienestar mismo de las personas, a lo que se le llama el desarrollo humano. Sin embargo, otra perspectiva como la de Alberto Gago (1993), quien define el desarrollo como:

(...) un proceso de cambio estructural global (económico, político, social, cultural y del medio ambiente), tendiente a aumentar la calidad de vida de todos los miembros integrantes de la sociedad, de forma de alcanzar una más completa satisfacción de las necesidades colectivas básicas (Gago, 1993).

Esta suma de concepciones del desarrollo integral en lo económico y en el bienestar social, se han convertido en un mensaje social e institucional, que en teoría es un ideal, pero no es fácil alcanzarlo, pues generar desarrollo integral en lo económico involucrando lo humano, en gran parte depende de la misma capacidad que tiene una sociedad para apropiarse de sus diversos recursos en busca de su bienestar, que por supuesto, deriva en mejor calidad de vida para la comunidad, tanto en el presente como en el futuro.

En un marco más específico, los aportes significativos que han realizado muchos autores en el campo del desarrollo, suman continuamente elementos ${ }^{7}$ que ayudan a valorar el tipo de desarrollo que una sociedad espera alcanzar. En este sentido, algunos exponentes del desarrollo

\footnotetext{
${ }^{7}$ El término “elementos", se cita para indicar teorías, conceptos, postulados sobre el desarrollo.
} 
como Manfred Max-Neef, presenta una perspectiva de desarrollo a escala humana (Max-Neef, 1993, pág. 30), sustentado en tres pilares como son, las necesidades humanas (diferencia a los satisfactores de las necesidades humanas, que son iguales en cualquier población, cultura y tiempo histórico, pues lo que diferencia el desarrollo humano de una comunidad es la calidad y cantidad de sus satisfactores), los niveles crecientes de auto dependencia, y las articulaciones orgánicas (entre los seres humanos con la naturaleza y la tecnología). Para Max-Neef, estos principios están basados en el "reconocimiento y protagonismo de las personas, quienes son los sujetos de sus propias aspiraciones" (Max-Neef, 1993).

Para Amartya Sen (2000), el desarrollo es concebido "como un proceso de expansión de las libertades reales de que disfrutan los individuos" (Sen, 2000, pág. 19), reconociendo que estas libertades deben estar acompañadas por las instituciones sociales y económicas; que a su vez, dichas instituciones podrán ser aprovechadas en la medida que los mismos individuos tenga libertad para "participar de las decisiones sociales y en la elaboración de las decisiones públicas" (Sen, 2000). Esta perspectiva del desarrollo, incorpora un elemento a tener en cuenta en los resultados DEL, relacionado con el rol y la determinación del individuo frente al papel que debe asumir en el desarrollo.

En la misma línea, pero con mayor anticipación al mismo Sen, se reconoce al economista español José Luis Sampedro como un pionero y vanguardista en el estudio del desarrollo (Domínguez, 2013), promulgando el "desarrollo humano como libertad”, que lo llevó a mantener un reclamo permanente por la "humanización del desarrollo" (Sampedro, 2009), incorporándole posteriormente el componente ecológico; siendo sus postulados un referente para ubicar al hombre como eje mismo del desarrollo. 
Otra visión del desarrollo que se enfoca en el hombre, la presenta el economista francés Francois Perroux, quien lo define:

(...) como la combinación de los cambios mentales y sociales de una población que la vuelven apta a hacer crecer, cumulativa y durablemente su producto real global. // Perroux agrega que el desarrollo remite a las estructuras, particularmente a las sociales y mentales; bajo sus formas más eficaces consiste en un arrastre reciproco y cumulativo de las poblaciones por el aparato productivo y del aparato productivo por las poblaciones: los gustos de los consumidores y de los productores extendiéndose y afinándose requieren un aparato productivo más poderoso y más complejo: recíprocamente, este aparato, mejorado, exige trabajadores más competitivos y eficaces, es decir, mejor formados. De ahí la consecuencia de que no haya desarrollo económico sin desarrollo social y cultural, y recíprocamente (Guillén Romo, 2007, pág. 15).

El elemento productivo incorporado en esta perspectiva de desarrollo, no puede ser menos importante, frente a las teorías actuales, más aún cuando está ligado a las capacidades del mismo hombre para responder al entorno económico.

Finalmente antes de abordar los elementos más específicos para el DEL, es importante considerar una nueva perspectiva del desarrollo económico o por lo menos nuevos valores para la economía, el cual ha tomado fuerza - en especial por empresarios europeos-, en lo que se ha denominado "la Economía del Bien Común” propuesto por el economista austriaco y activista político Felber, el cual trata de:

(...) un proceso participativo, de desarrollo abierto que busca sinergia en procesos similares como: economía solidaria, economía social, movimiento de bienes comunes, economía del post crecimiento o democracia económica. Juntando sus esfuerzos, una gran cantidad de personas y actores son capaces de crear algo fundamentalmente nuevo (Felber, 2011). 
Este nuevo elemento como los ya señalados, refuerzan los planteamientos que le son comunes al Desarrollo Económico Local, los cuales se han visto desde una perspectiva integral, incorporando lo social y lo económico a partir de la propia identidad y caracterización cultural del sujeto para lograr dimensiones propias de bienestar. Por eso una comunidad, aunque pequeña y pobre que sea, no debe condicionar las posibilidades del desarrollo a las limitaciones económicas que le son propias, sin que haya explorado las potencialidades, que el mismo factor humano organizado le puede otorgar. Bajo esta dimensión, al ubicar el discurso del desarrollo, se hace necesario involucrar la participación de actores sociales, económicos e institucionales, hacia cambios estructurales que impacten el interés social, en función de lo económico, lo cultural y lo organizacional; éste último, es factor determinante al entender el rol e interés político de líderes y representantes, para beneficiar el interés general.

\section{Desarrollo Económico Local}

Los anteriores planteamientos ya empiezan a derivar responsabilidades en los actores locales, como un factor intrínseco para apropiar el sentido humano en el desarrollo; incitando a que los mismos actores asuman procesos específicos de bienestar; actúa además como mecanismo para entender desde la misma comunidad, a qué tipo de desarrollo le apuestan y cómo llegar a él.

En línea con lo anterior, acudir a las teorías de Desarrollo Económico Local-DEL-, como lo señala institucionalmente La Organización Internacional del Trabajo -OIT-, permite la presentación de elementos que proponen y motivan la implementación de acciones como alternativa para generar capacidades locales de bienestar:

(...) es un proceso de desarrollo participativo que fomenta los acuerdos de colaboración entre los principales actores públicos y privados de un territorio, posibilitando el diseño y la puesta en práctica de una estrategia de desarrollo común a base de aprovechar los recursos y ventajas 
competitivas locales en el contexto global, con el objetivo final de crear empleo decente y estimular la actividad económica (Rodríguez-Pose, 2002).

Para Vázquez Barquero ${ }^{8}$ el desarrollo económico local se define como:

(...) un proceso de crecimiento y cambio estructural que, mediante la utilización del potencial de desarrollo existente en el territorio, conduce a elevar el bienestar de la población de una localidad o una región. Cuando la comunidad local es capaz de liderar el proceso de cambio estructural, nos encontramos ante un proceso de desarrollo local endógeno. La hipótesis de partida es que las localidades y territorios tienen un conjunto de recursos (económicos, humanos, institucionales y culturales) y de economías de escala no explotadas que constituyen su potencial de desarrollo. Cada localidad o territorio se caracteriza, por ejemplo, por una determinada estructura productiva, un mercado de trabajo, una capacidad empresarial y tecnológica, una dotación de recursos naturales e infraestructuras, un sistema social y político, y una tradición y cultura, sobre los cuales se articulan los procesos de desarrollo económico local (Vásquez Barquero, 2000).

Este criterio se expone como un instrumento de acción, que motiva a las comunidades a realizar una apropiación concertada de cómo será y cómo deben buscar su propio bienestar; es una búsqueda a la no exclusiva dependencia de las políticas centralistas. De esta manera, Antonio Vázquez Barquero en su trabajo con la CEPAL/GTZ ${ }^{9}$ define planteamientos sobre las líneas de actuación que favorecen la competitividad de las economías locales en un sistema de intercambio abierto, globalizado y cada vez más competido.

\footnotetext{
${ }^{8}$ Antonio Vázquez Barquero es Catedrático de Economía de la Universidad Autónoma de Madrid y está especializado en desarrollo económico. Sus principales líneas de investigación son: organización espacial de los sistemas productivos, economía de la innovación y política de desarrollo territorial.

${ }^{9}$ CEPAL - Comisión Económica para América Latina y del Caribe, en el área del desarrollo económico, tiene como objetivo la promoción de un crecimiento económico equitativo de largo plazo y la generación y asignación eficiente de recursos financieros para apoyar el desarrollo y la igualdad en los países de América Latina y el Caribe. GTZ Deutsche Gesellschaft Für Technishche Zusammenarbeis - Agencia Alemana de Cooperación Técnica, actualmente GIZ.
} 
Otros trabajos ayudan a establecer enfoques DEL, que maduran o delimitan su alcance frente al deber ser de estos modelos; entre ellos tenemos al profesor Mario D. Tello (2006), quien define DEL para los países en desarrollo y lo diferencia del concepto de descentralización. Carvajal (2009) presenta cuestionamientos sobre modelos alternativos de desarrollo, colocándolos en la discusión del postdesarrollo. Mientras que el modelo alternativo de Mario Rosales y Rafael Urriola “aborda la problemática del desarrollo económico local y su relación con la cohesión social” (Rosales \& Urriola, 2012).

\section{Desarrollo Endógeno}

En un sentido más metódico, el elemento endógeno en los procesos de desarrollo, se incorpora como un mecanismo para fomentar las capacidades internas de una localidad desde adentro. A lo cual, Sergio Boisier (2004) resalta su propósito indicando que el desarrollo endógeno sirve:

Para generar en un territorio dado las condiciones de entorno que le permiten a los seres humanos potenciarse a sí mismos para llegar a ser verdaderas personas humanas, porque, hay que entenderlo de una vez, el desarrollo no lo hace nadie sino las personas en su individualidad y en su sociabilidad. Ni el Estado, ni el capital, ni el sector privado, ni el público, pueden producir el desarrollo de las personas; sólo pueden crear las condiciones de entorno (Boisier, 2004).

Otra consideración, no menos importante al planteamiento endógeno lo presenta Casanova indicando sobre esta perspectiva que

Además, lo social se integra con lo económico. La distribución de la renta y de la riqueza, y el crecimiento económico, no son dos procesos que surgen y toman forma de manera paralela, sino que adquieren una dinámica común debido al hecho de que los actores públicos y privados toman decisiones de inversión orientadas a resolver los problemas locales, los de las empresas y los de la sociedad. Lo local es un espacio en el que las iniciativas de los diversos sectores de la sociedad organizada se hacen realidad (Casanova, 2004). 
En consecuencia, el elemento endógeno ocupa un espacio significativo en el propósito práctico para la implementación DEL.

\section{Institucionalidad}

Desde la teoría y en los ejercicios prácticos DEL, se le asigna un papel importante a la comunidad como un eje fundamental para construcción de procesos de desarrollo; pero también es necesario identificar el rol del actor institucional como pieza articuladora y garante de la misma construcción social y económica; incluyendo la planeación como ejercicio articulado para el diseño de política pública (conjunto de estrategias y acciones que formulan los gobiernos para influir sobre la economía) requerida para cada comunidad. Los representantes de esta corriente institucionalista, “dan primacía al estudio de los problemas de organización y poder del sistema económico, sosteniendo que la economía es más que el mercado" (Taveras, 2012). En este mismo sentido, Sen hace referencia a la institucionalidad desde una perspectiva general, indicando que "su función es generar capacidades humanas y promover el desarrollo" (Sen, 2000). Al respecto, los principales pioneros que en oposición de las teorías clásicas, defendieron la necesidad de integrar a la economía otras áreas de estudio para alinear la visión económica con el interés de lo público y lo social (Mourao, 2007).

En este entendido "las instituciones son reglas formales o informales, que estructuran la interacción social, los incentivos y restricciones que dan forma a la interacción humana" (Prats, 2007). Mientras que las instituciones son reglas de juego, las organizaciones son los jugadores. Su interacción genera el cambio institucional (Prats, 2007). De manera consistente, "el desarrollo depende del funcionamiento del conjunto de la matriz institucional, compuesta por instituciones y organizaciones que cambian a distintas velocidades. La coordinación entre actores e instituciones que operan en los distintos niveles es esencial para el desarrollo" (Prats, 2007). 
Teniendo en cuenta que el enfoque institucional aborda tanto decisiones públicas como económicas, donde afecta los individuos y trasciende al interés general, la política pública, se convierte en un componente de atención advertido para los propósitos DEL, y llamando la atención de líderes y representantes políticos y sociales para hacer útil y práctico este enfoque; ayudando a la discusión del cómo hacer la política pública, que afecta las bases de la organización institucional.

Con base en las anteriores concepciones, señalar la importancia de la dimensión institucional, económica y social, ayuda a interpretar de qué trata el desarrollo económico local para una comunidad, y cómo los modelos de intervención basados en este enfoque DEL, se constituye en una estrategia opcional y no menos válida para diseñar e impulsar procesos de desarrollo local en comunidades caracterizadas por su baja población con limitados ingresos (características propias de los municipios ${ }^{10}$ de categoría sexta ${ }^{11}$ en Colombia), que además se caracterizan por no adecuadas condiciones productivas, sociales, económicas y políticas, limitando los deseados procesos integrales de desarrollo socioeconómicos e institucionales en estas comunidades.

\section{Dimensiones del Desarrollo Local}

En el contexto DEL, las posibilidades de desarrollo social y económico para las comunidades pequeñas como las existentes en Colombia, está relacionada con el estado de avance de las dimensiones a intervenir. Para ello, Vázquez Barquero (1988), distingue varias dimensiones:

\footnotetext{
${ }^{10}$ El municipio es la entidad territorial fundamental de la división político administrativa del Estado, con autonomía política, fiscal y administrativa dentro de los límites que lo señalen la Constitución y la ley y cuya finalidad es el bienestar general y el mejoramiento de la calidad de vida de la población en su respectivo territorio. Ley 136 de 1994.

${ }^{11}$ Definidos por la Ley 617 de 2000 (modificado por Ley 1551 de 2012), como aquellos en los cuales su población sea igual o inferior a 10.000 habitantes y que sus ingresos corrientes de libre destinación anuales no sea superior a $15.000 \mathrm{smmlv}$; importancia económica grado siete (se entiende por importancia económica el peso relativo que representa el Producto Interno Bruto de cada uno de los municipios dentro de su departamento).
} 
Económica, en la cual, los empresarios locales usan su capacidad para organizar los factores productivos locales con niveles de productividad suficientes para ser competitivos en los mercados; Formación de recursos humanos, en la que los actores educativos y de capacitación conciertan con los emprendedores locales la adecuación de la oferta de conocimientos a los requerimientos de innovación de los sistemas productivos locales; Socio-cultural e institucional, en la que los valores e instituciones locales permiten impulsar o respaldar el propio proceso de desarrollo; Políticoadministrativa, en la que la gestión local y regional facilitan la concertación público-privada a nivel territorial y la creación de «entornos innovadores» favorables al desarrollo productivo y empresarial; Ambiental, que incluye la atención a las características específicas del medio natural local, a fin de asegurar un desarrollo sustentable ambientalmente (Vásquez Barquero, 1988).

A partir de esta clasificación, se integran por metodología para el desarrollo del trabajo, a tres dimensiones como lo son, la institucional, la económica y la social.

Desde el enfoque de la endogeneidad Sergio Boisier (2001), presenta el desarrollo local a partir de cuatro dimensiones, que se transponen entre sí y que son:

Dimensión o plan político: a decir del autor debe entenderse como la capacidad de diseñar y ejecutar políticas de desarrollo, así como la capacidad de negociar por parte de los actores del desarrollo local; Dimensión económica: la cual se manifiesta a partir de la generación de inversión y las reinversiones de parte del capital excedente, con la finalidad de diversificar la economía local a partir de proyectos de inversión o planes de negocios que propicien un desarrollo sostenible a largo plazo. Dimensión científica-tecnológica: al respecto, el autor lo refiere como la capacidad de un territorio organizado para generar sus propios procesos de innovación y desarrollo tecnológico, a partir de los cuales se generen modificaciones cualitativas que incrementen la competitividad de los sistemas productivos locales; Dimensión cultural: como un elemento capaz de generar una identidad socio-territorial (Boisier, 2001). 
De lo anterior se precisa que las similitudes para identificar las dimensiones del desarrollo local, corresponden de cómo la interacción de los agentes o actores internos con los externos definen y priorizan el modelo de desarrollo local a implementar; cada uno de los actores en la materia son relevantes y necesarios para comprender las prioridades de las dimensiones que determinen avances al desarrollo económico local; al respecto Alburquerque (2002), presenta una clasificación de actores en tres grupos:

Las instituciones locales y las redes institucionales a las que se articulan (nacionales e internacionales); La sociedad civil, es decir la fuerza de trabajo a movilizar en el proceso de desarrollo y el resto de la población (como beneficiaria directa de dicho proceso). Las empresas, tanto locales como las que por medio del fomento de las inversiones, eventualmente, puedan instalarse en el territorio (Alburquerque, 2002).

Coffey y Polese (1985) definen tres dimensiones específicas para el desarrollo económico local:

Una económica, caracterizada por un sistema de producción que permite a los empresarios locales usar, eficientemente, los factores productivos, generar economías de escala y aumentar la productividad a niveles que permiten mejorar la competitividad en los mercados; otra sociocultural, en que el sistema de relaciones económicas y sociales, las instituciones locales y los valores sirven de base al proceso de desarrollo; y otra, política y administrativa, en que las iniciativas locales crean un entorno local favorable a la producción e impulsan el desarrollo sostenible (Coffey \& Polese, 1985).

Las anteriores percepciones son necesarias para identificar la manera de trascender de la visión del desarrollo local desde un enfoque integral, a la visión del desarrollo económico local, que aunque el énfasis es la dimensión productiva, esta debe trascender a las otras dimensiones, y a los agentes o actores con incidencia en las dimensiones señaladas. 
Finalmente con base en las descripciones anteriores sobre las dimensiones del desarrollo local, y para los propósitos del trabajo, la definición DEL presentada por el profesor Mario D. Tello (2006; 2008), en la que expone al desarrollo económico local como

Un proceso de la dinámica económica, social y política de una área geográfica específica -dentro las fronteras de una economía (país o nación)- resultante del comportamiento, acciones e interacciones de los agentes (económicos, políticos y sociales) que residen en el área geográfica y que tiene la finalidad de incrementar sostenida y sosteniblemente el nivel (más allá de los niveles mínimos necesarios de consumo) y la calidad de vida de los habitantes dicha área geográfica usando plena y eficientemente sus recursos humanos y no humanos (Tello, 2006).

Se toma como referente principal para sintetizar el enfoque de trabajo de las dimensiones, identificando con ello los determinantes del desarrollo económico local en un municipio categorizado de menor desarrollo o de nivel seis en Colombia. 


\section{Caracterización de las Dimensiones del Desarrollo en el Municipio de Nariño,}

\section{Cundinamarca}

En el presente capítulo se identifica el estado actual de las dimensiones del desarrollo para un municipio tipificado en categoría sexta ${ }^{12}$, que corresponden al 87,6\% del total de municipios en Colombia $(1.101)^{13}$, entre ellos el municipio de Nariño, Cundinamarca, que tipifica a este tipo de municipios, los cuales tienen una población igual o menor a 10.000 habitantes y con ingresos corrientes de libre destinación anuales no superiores a quince mil (15.000) salarios mínimos legales mensuales ${ }^{14}$ (se prioriza la categoría por el nivel de ingresos).

\section{Generalidades}

Nariño, Cundinamarca es uno de los municipios más pequeños del departamento ${ }^{15}$, ocupando el sexto lugar con tan solo el 0,23\% de territorio entre los 116 municipios. Pertenece a la provincia de Alto Magdalena, que tiene como principal cabecera de provincia a Girardot, municipio que está ubicado a $23 \mathrm{Km}$, por tal razón ejerce amplia influencia con marcada dependencia económica en el municipio de Nariño, teniendo en cuenta que la capital del país, se encuentra a 149 Km (Alcaldía Municipal de Nariño, Cundinamarca, 2012).

La población está definida como mestiza, sin que haya grupos étnicos segmentados como indígenas o afrocolombianos. Según Planeación Departamental se estima que en el 2014 residen en el municipio $2.189^{16}$ personas que corresponde al 0,08 \% de la población total del departamento;

\footnotetext{
${ }^{12}$ Con base en lo dispuesto en la Ley 136 de 1994, reformada parcialmente por la Ley 617 de 2000 mediante sus artículos $1^{\circ}$ y $2^{\circ}$, se determina la obligatoriedad de los Alcaldes y Gobernadores de los Municipios, Distritos y Departamentos, de realizar el proceso de Auto categorización basados en la información reportada para tal fin por el DANE y la Contraloría General de la República.

${ }^{13}$ Información de la Contraloría General de la República Resolución 578 al 28 de noviembre de 2014.

${ }^{14}$ Ley 136 de 1994, por la cual se dictan normas tendientes a modernizar la organización y el funcionamiento de los municipios, y en su artículo 6 estableció la categorización de los distritos y municipios. Esta ley fue modificada parcialmente por la ley 617 de 2000, la cual cambió el texto del artículo que establecía las categorías de los municipios. ${ }^{15}$ Los datos o cifras registradas para el departamento de Cundinamarca no incluyen datos de Bogotá.

${ }^{16}$ De acuerdo con las proyecciones del DANE, para el 2014 en Colombia hay 443 municipios con población inferior a 10.000 habitantes y el municipio de Nariño Cundinamarca ocupa el lugar 40 con menor población en el país.
} 
de ellos hay un leve porcentaje mayor de mujeres sobre los hombres comparados con la proporción a nivel departamental (ver Gráfica 1).

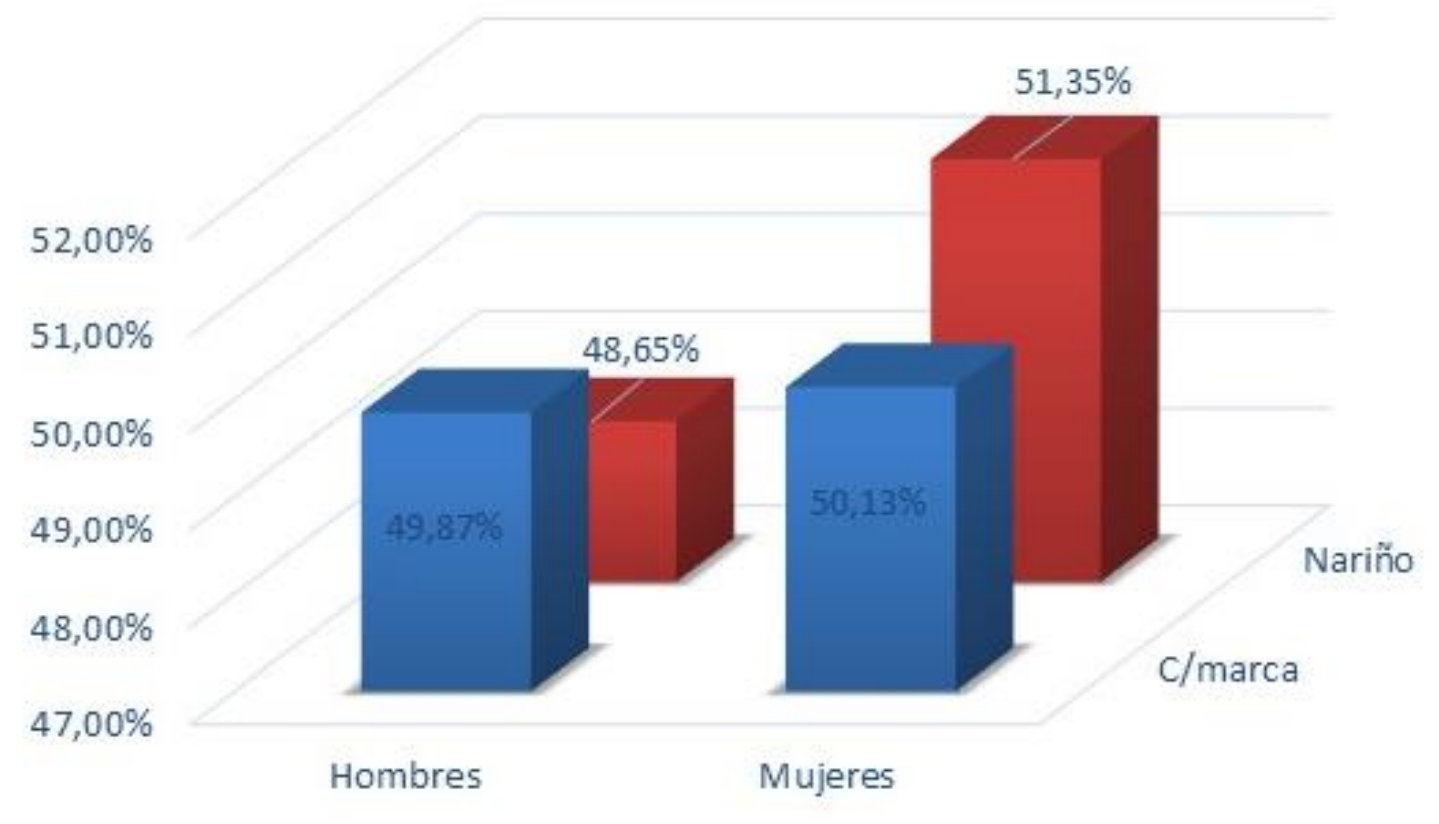

Gráfica 1. Población por genero Proyección a 2014. Fuente: Elaboración propia con base en datos del DANE.

Aunque la diferencia de porcentaje de mujeres respecto a los hombres en el municipio es mínima, la participación de las mujeres en las actividades comunitarias y sociales del mismo municipio registra una diferencia muy significativa, aspecto reflejado en el levantamiento de información, siendo las mujeres las que participaron con mayor interés en el diligenciamiento de la encuesta de percepción. Esto implica un liderazgo preponderante en las mujeres, a quienes se les ha delegado la responsabilidad de asumir procesos de desarrollo local, como ellas mismas los han manifestado, especialmente en los aspectos (dimensiones) sociales y no menos importantes en los económicos e institucionales; a pesar de ello, el municipio no ha contado con una mujer alcalde.

En cuanto a los indicadores de calidad de vida municipal, se identifica un amplio rezago con el promedio departamental, inclusive con el promedio nacional. A continuación se presenta la 
Tabla 1 con el consolidado comparativo del Índice de Pobreza Multidimensional (IPM) ${ }^{17}$, y seguido a este, se presenta la Gráfica donde se compara el NBI - Necesidades Básicas Insatisfechas al 2005 y que corresponde al porcentaje de personas vs hogares sobre la población total vs total de hogares que tiene al menos una necesidad básica insatisfecha (NBI). En Colombia, se tienen en cuenta las siguientes NBI: viviendas con hacinamiento crítico, con condiciones físicas impropias para el alojamiento humano, servicios inadecuados, alta dependencia económica o niños en edad escolar que no asisten a la escuela.

Como se observa en la Tabla 1 y Gráfica 2, el estado actual del NBI para el municipio señala marcadas diferencias en la necesidades no satisfechas, que ratifican el estado de rezago que se presentan en los municipios de categoría sexta, ya que estos comparten similares características medidos en el nivel de ingresos municipal, valor limitado para implementar los procesos de desarrollo local, necesarios para cerrar las brechas de desigualdad y satisfacción de necesidades, para alcanzar mejores niveles de calidad de vida en dichos municipios.

Tabla 1.

Indicadores de calidad de vida

\footnotetext{
${ }^{17}$ El índice IPM fue desarrollado por el Oxford Poverty \& Human Development Initiative (OPHI), es un indicador que refleja el grado de privación de las personas en un conjunto de dimensiones. La medida permite determinar la naturaleza de la privación (de acuerdo con las dimensiones seleccionadas) y la intensidad y profundidad de la misma (ver Anexo A).
} 


\begin{tabular}{|l|c|c|c|}
\hline \multicolumn{1}{|c|}{ INDICADOR } & Colombia & C/Marca & Municipio \\
\hline Índice de Pobreza Multidimensional Promedio (\%) Cálculo DNP censo DANE 2005 & 49,6 & 41,6 & 68,2 \\
\hline Índice de Pobreza Multidimensional Urbana (\%) Cálculo DNP censo DANE & 39,1 & 31,0 & 64,3 \\
\hline Índice de Pobreza Multidimensional Rural (\%) Cálculo DNP censo DANE 2005 & 80,7 & 60,5 & 75,5 \\
\hline Índice de Condiciones de Vida - ICV (puntaje) Censo DANE 2005 & 79,45 & 75,02 & 65,0 \\
\hline$\%$ de Personas con Necesidades Básicas Insatisfechas Censo DANE (2005) & 27,8 & 21,3 & 43,9 \\
\hline$\%$ de personas con Necesidades Basicas Insatisfechas Cabecera Censo DANE (2005) & 19,7 & 15,4 & 41,9 \\
\hline$\%$ de personas con Necesidades Basicas Insatisfechas Resto Censo DANE (2005) & 53,5 & 32,2 & 47,8 \\
\hline$\%$ de Personas en Miseria Censo DANE (2005) & 10,64 & 5,20 & 13,9 \\
\hline
\end{tabular}

Fuente: Secretaria de Planeación de Cundinamarca - Visor Estadístico 2015 (consultado 9/08/15).

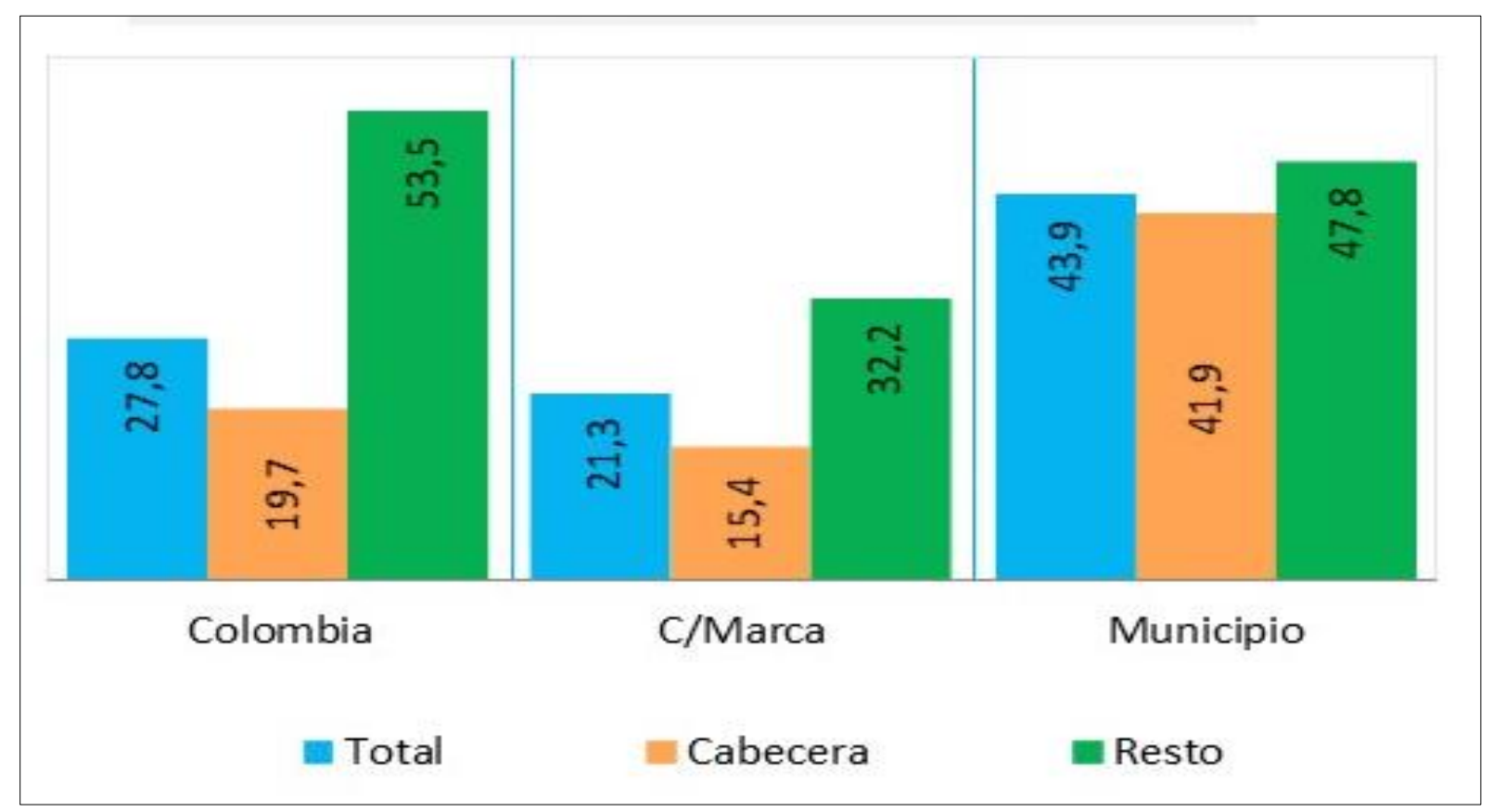

Gráfica 2. Porcentaje población con NBI 2005. Fuente: Secretaria de Planeación de

Cundinamarca - Visor Estadístico 2015 (consultado 9/08/15).

Con base en las descripciones teóricas sobre los elementos fundamentales de cada variable, y el apoyo estadístico de la información secundaria disponible, se hace una asociación de cada elemento o variable con las percepciones emitidas por los representantes de cada sector social, 
económico e institucional, para caracterizar el estado de cada dimensión del desarrollo, como a continuación se describen:

\section{Dimensión Social}

Los aspectos de mayor significancia para una comunidad en la Dimensión Social y que son objeto de estudio, corresponde a la salud, la educación, vivienda, servicios públicos domiciliarios de nivel prioritario (relacionados con servicios de acueducto, energía, alcantarillado y recolección de basuras); en esta misma Dimensión se encuentra servicios comunitarios para el fomento de la cultura de atención de población joven, tercera edad y niños; además se incluyen las relaciones de convivencia a partir del respeto por los derechos humanos, y en general el estado de seguridad del municipio.

A continuación se presenta el estado actual de cada uno de los aspectos en los que se encuentra la Dimensión Social que son referente de la investigación:

Salud. El municipio de Nariño cuenta con un Puesto de salud (Puesto de Salud Nariño IPS pública), que está administrado por el Hospital de Girardot. Actualmente presta los servicios de consulta externa y urgencias en las ramas de Odontología, Enfermería, Droguería, Toma de muestras de laboratorio y presta el servicio de ambulancia los fines de semana y festivos.

Los servicios son tan limitados que están a cargo de un médico, una enfermera un odontólogo y un auxiliar de odontología; lo que implica casi una total dependencia con los servicios en el municipio de Girardot; razón que obliga a atención de citas externas en ese municipio.

Lo más preocupante es la falta de cubertura de los servicios de salud a la totalidad de la población, como se observa en la Gráfica 3, solamente existe un $82 \%$ de cobertura entre los regímenes subsidiado (77\%) y contributivo (5\%), aunque tal cobertura sea un poco superior a 
Cundinamarca, que solo llega al $77 \%$ (contributivo 40,5\% y subsidiado $36 \%$ ), el resultado presenta alto nivel de riesgo asociado a la eficiencia en la prestación del servicio, considerando que tres cuartas partes del total de la población es atendido con el régimen subsidiado y con atención en el municipio vecino (Girardot).

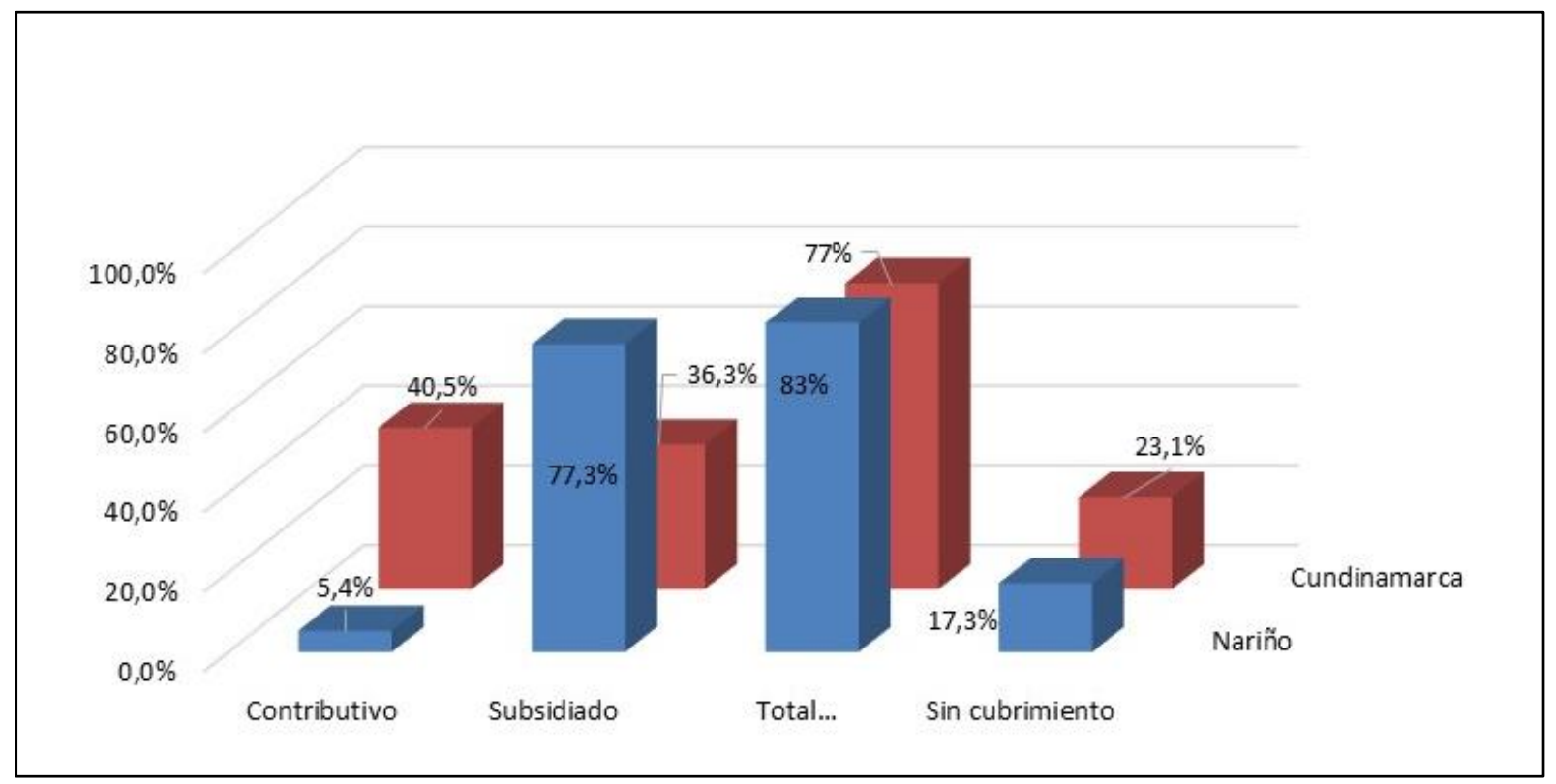

Gráfica 3. Aseguramiento de salud (Población a 2012). Fuente: Elaboración propia con base en datos de la Secretaria de Planeación de Cundinamarca.

Las causas principales de la mortalidad en el Municipio según informe del centro de salud, al año 2014, son por enfermedades crónicas como las coronarias, diabetes e infartos, igualmente se informa que la mortalidad por accidentes es casi nula al igual que por armas de fuego o armas blancas. A pesar de ello, los encuestados manifiestan en un $43 \%$ alta inconformidad por la salud en el municipio, pero hay un $9 \%$ que percibe el servicio de manera excelente.

Educación. El municipio de Nariño cuenta en la actualidad con la institución Educativa Antonio Nariño, modalidad académica jornada diurna disgregada en siete (7) centros, seis de nivel primaria y uno de secundaria (Colegio Antonio Nariño del casco urbano). En general toda la infraestructura educativa se encuentra en buen estado. 
Hay un amplio rezago en la tasa de analfabetismo (DANE, 2005) con un 12,9\%, la cual está muy por encima del nivel departamental que llegó al 6,20 \% y del promedio nacional (8,40 $\%)$.

La tasa de Cobertura de educación es de 86,27 \% para el año 2012, y de 87,75 \% para el 2013; la tasa de deserción corresponde a 1,9 \% y 2,2 \% respectivamente, niveles que están por debajo del promedio departamental que alcanzan al 2,94 \% y 3,17 \% respectivamente. Sin embargo, el número de matrículas netas en todos los niveles para el año 2011 fue de 524, pero con una leve reducción del 5,65\% para el 2012 (496 matrículas), indicando que en los últimos años el porcentaje de crecimiento población no alcanza a cubrir los descensos en el número de matrículas en el municipio, que puede estar asociado a la migración a municipios aledaños.

La causa principal de deserción manifestada por los encuestados, es el cambio de residencia por el cambio de sitio de trabajo de los padres que en su mayoría son cuidanderos de fincas los cuales por su condición de trabajo no cuentan con la estabilidad o con un sitio de residencia permanente.

La Institución Educativa de Nariño reporta que al 2013 el promedio de estudiantes por docente fue de 20,7, obteniendo mejor promedio que el mismo departamento de Cundinamarca con un total de 24 estudiantes.

El municipio de Nariño no cuenta con infraestructura universitaria, sin embargo hay convenios con universidades e institutos ubicados en el Municipio de Girardot, donde se otorgan subsidios y se aporta el transporte de los estudiantes a los diferentes sitios; en el momento hay convenios con la Universidad Minuto de Dios y El Instituto FUNDES.

En esta variable de educación, hay una muy buena valoración o percepción favorable que llega al $70 \%$; sin embargo el $26 \%$ no considera adecuado el servicio, obedeciendo a varias razones 
como docentes sin actualización, falta de tecnología en las aulas y falta de oportunidades para el acceso de jóvenes a instituciones de educación superior, pese que hay oferta en oficios por parte del Servicio Nacional de Aprendizaje - SENA ${ }^{18}$

Vivienda. Es indudable que la población más vulnerable o pobre en nuestro país determina en gran parte su bienestar a partir de la obtención vivienda propia; infortunadamente, en el municipio se presenta una creciente explosión de construcción que no va orientada a la población local sino a una flotante, ya que el territorio es atractivo para la realización de proyectos de vivienda recreativa de tipo condominio, los cuales generan una cifra importante en los recaudos municipales, pero no da respuesta al déficit de vivienda que se presentan en los habitantes locales.

De acuerdo con los datos registrados en el SISBÉN a 2014, en total urbano y rural, hay 446 viviendas que corresponde a 658 hogares y 2.189 personas; implicando que hay un promedio de 4,9 personas por vivienda (el promedio de Cundinamarca es de 5,1). Del total de hogares, el 20,4 \% está pagando arrendamiento, casi un $0,9 \%$ está pagando su vivienda, y el 48,9 \% cuenta con vivienda propia; pero hay un 29,8 que registra condiciones diferentes pero no en propiedad; lo anterior indica que casi el $50 \%$ de los hogares en Nariño no cuentan con una vivienda propia, lo que puede generar inestabilidad para el arraigo de las familias y desarrollo de proyectos de vida en el municipio. Esta situación de incertidumbre la manifiestan un $35 \%$ de los encuestados, los cuales indican que no se sienten satisfechos con las condiciones de acceso a vivienda propia y adecuada, llegando a considerar la posible migración a otros municipios.

Servicios públicos domiciliarios. A pesar las limitantes económicas del municipio, la ubicación territorial le ha permitido el acceso a la oferta de servicios público a la mayoría de la

${ }^{18}$ El Servicio Nacional de Aprendizaje, SENA, es un establecimiento público del orden nacional con personería jurídica, patrimonio propio e independiente y autonomía administrativa. Adscrito al Ministerio del Trabajo de Colombia. 
población nariñense, especialmente en la zona urbana. Los dos servicios más importantes como es el servicio de agua y energía registran una cobertura superior al $90 \%$; sin embargo hay algunos rezagos de cubrimiento de oferta para lo totalidad de la población; como se evidencia en la Gráfica 4, al 2014 no hay un cubrimiento del $100 \%$ en ninguno de los servicios públicos esenciales; por lo cual el $26 \%$ de los encuestados se encuentran insatisfechos con dichos servicios, y los demás (74 \%) han manifestado que el servicio es bueno o muy bueno y el $9 \%$ está totalmente satisfecho con los servicios domiciliarios existentes en el municipio.

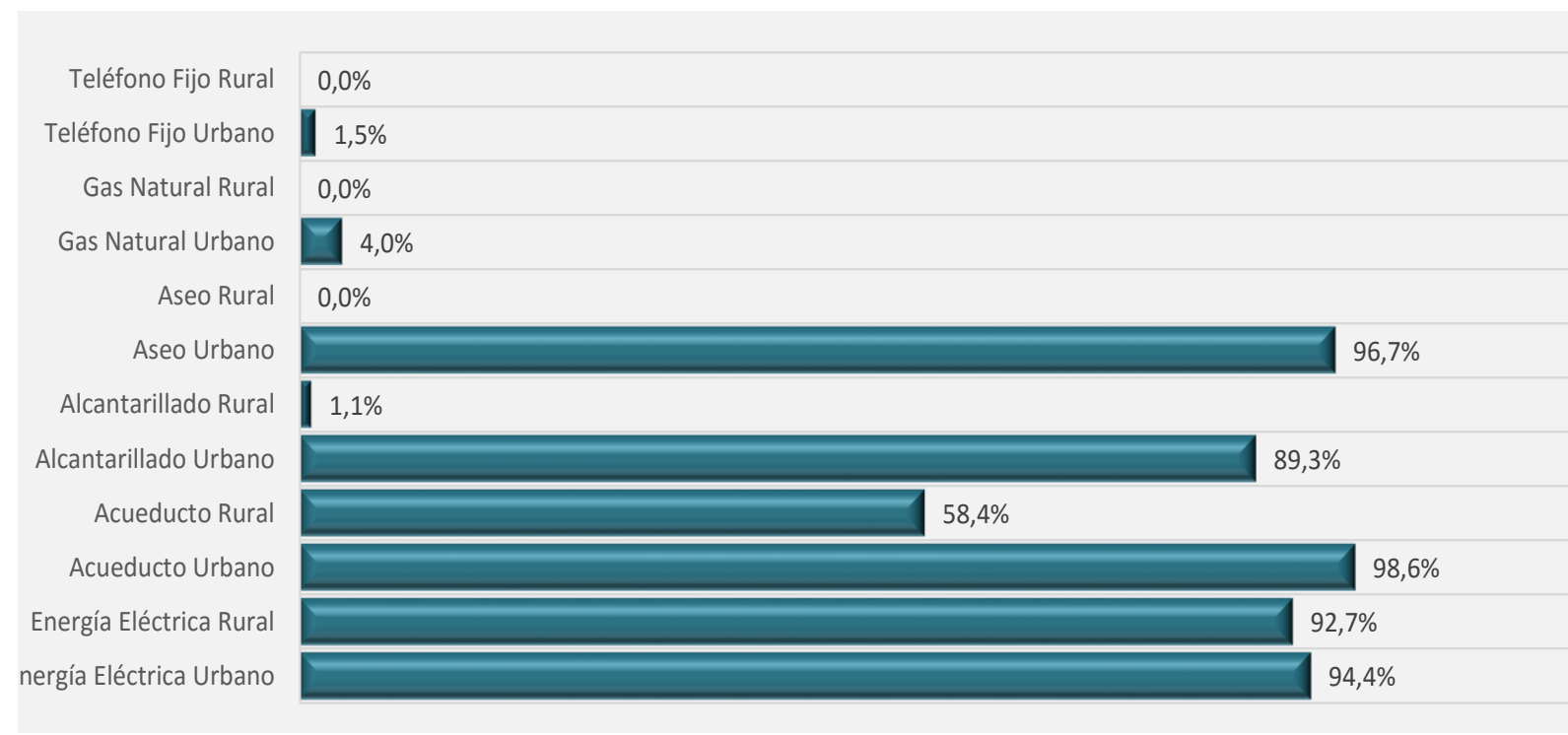

Gráfica 4. Porcentaje de cobertura de servicios públicos (según Sisbén). Fuente: Elaboración propia con base en datos de la Secretaria de Planeación de Cundinamarca.

Servicios comunitarios. En los servicios comunitarios se agrupan en aquellos que se brindan por grupo poblacional y que son importantes para complementar la calidad de vida en sociedad como son la atención a la tercera edad, el cuidado de la niñez, el reconocimiento de la juventud y el fomento a la cultura.

Infortunadamente, no se registran de manera específica datos a nivel departamental o municipal que indiquen cómo es el nivel de atención o prestación de estos servicios, a excepción 
de los datos de vacunación en niños menores a cinco años, en la cual aparece un cubrimiento del $87 \%$, siendo significativamente superior al registrado en el departamento que sólo llega al $78 \%$. Los demás servicios a jóvenes y adultos que registra el municipio están únicamente asociados a los programas nutricionales a través de asistencia alimentaria en restaurantes comunitarios.

Al consultar por estos servicios, los encuestados tienen una percepción favorable en la atención de niños que llega al $87 \%$, asociado a temas de vacunación, alimentación en restaurante escolar y hogares comunitarios. En cuanto a la atención en jóvenes y tercera edad, dos terceras partes $(65 \%)$ coinciden en ambos aspectos que son buenos, pero asociado únicamente a los servicios de programas alimentarios.

En cuanto al fomento de la cultura, sólo una quinta parte $(21 \%)$ de los encuestados manifiestan que hay acciones buenas, que se asocia a la promoción de eventos recreativos de tipo deportivo, pero no hay actividades relacionadas con la danza, música, teatro, artes plásticas, fotografía, video, caricatura, literatura, entre otras.

Seguridad y convivencia. El municipio de Nariño, es uno de las localidades con menores índices de violencia en el departamento de Cundinamarca, y no ha sido afectado significativamente por los hechos del conflicto armado que vive el país desde hace cinco décadas. Por lo que se puede considerar como un territorio sin problemas de inseguridad. Sin embargo, la tasa de muertes violentas (incluye accidentes, homicidios, suicidios, transito, otras no determinadas) es casi la más alta del departamento. Pese que sólo en el 2012 se presentaron 7 muertes ( 5 homicidios y 2 indeterminadas), estas corresponden a 323,62 casos si se tomara por cada cien mil habitantes, que comparado con los casos del departamento equivaldría a sólo 60,1 casos y para Colombia correspondería a 61,1 . 
Aunque estadísticamente no favorecen las cifras de violencia al municipio, si se puede asegurar, al menos por la percepción de los encuestados, que en un $70 \%$ las condiciones de seguridad y convivencia son adecuadas.

A pesar de la seguridad, las relaciones de convivencia asociado al respecto por los derechos humanos, no se obtiene el mismo resultado favorable, dado que sólo el $48 \%$ de los encuestados consideran que es buena la convivencia en el municipio, aunque el registro de la autoridad municipal solamente reporte 5 casos de violencia intrafamiliar (infantil 2, pareja 1 y otros familiares 2), y casos de violencia interpersonal 19 al 2012.

En resumen, el resultado para esta dimensión social por parte de los encuestados es favorable, quienes consideran en un $65 \%$ que la calidad en la prestación de servicios para el desarrollo social del municipio son buenos, y muy buenos un $13 \%$; es decir, que sólo el $22 \%$ de los entrevistados descalifican la calidad de los servicios sociales que en general reciben los habitantes del municipio de Nariño. Sin embargo, se ha conformado un Consejo Consultivo Municipal promovido por la Gobernación de Cundinamarca y que está conformado por mujeres líderes del municipio para representar los asuntos de salud, educación, cultura, grupos de discapacitados, tercera edad, jóvenes, amas de casa y comercio; quienes actúan como interlocutores entre en la gobernación, el municipio y la sociedad civil.

\section{Dimensión Económica}

La segunda dimensión de trabajo corresponde a la económica, en los que se identifican aspectos que contribuyen al desarrollo productivo y de oportunidades económicas para el municipio; entre ellas, se destacan el estado de la infraestructura, las relaciones asociativas existentes, las oportunidades de nuevos negocios y el incentivo a las inversiones; el fomento y sostenibilidad del empleo y la calidad de los ingresos; la organización del comercio y la oferta turística para atraer 
consumidores al municipio; y finalmente la capacidad para brindar calidad y diversidad en la oferta productiva.

La descripción y análisis de las anteriores variables, son el referente principal y de interés para entender el estado actual o de avance de la dimensión económica, lo cual refleja la situación del municipio frente a la necesidad de emprender acciones para promover desarrollo económico local.

Infraestructura. El sistema vial urbano según la Oficina de Planeación Municipal de la Alcaldía de Nariño, en general es una malla vial urbana de buenas condiciones, con 4.982,4 ml de los cuales el $59 \%$ se encuentran pavimentados. La vía regional que une el casco urbano de Nariño con Girardot aunque es competencia de la gobernación de Cundinamarca, son 23 kilómetros de pavimento en buen estado.

Las vías de acceso rural se encuentran en estado aceptable con tramos en pavimento rígido, sistema de huellas y destapado liso con mantenimiento (nivelación y limpieza) periódico; se destacan las vías de Nariño-Buscavida-Sabaneta, por ella se desplazan más del $65 \%$ del total de la población rural y que cuenta con una longitud de 19 km y antigua salida a Girardot conocida como los Mangos de la vereda Oriente.

Por condiciones de la topografía donde se ubica el municipio, hay facilidad para el transporte entre las veredas y el casco urbano, y lo que ello implica la movilidad de la producción rural a los centros poblados de mayor importancia en la región.

En cuanto a las comunicaciones, a pesar del avance en el servicio de telefonía celular, existe un limitado servicio, actualmente solo funciona un operador con señal calidad aceptable y los demás operadores con muchas deficiencias, no se presta el servicio de telefonía local (central telefónica), por lo tanto tampoco el Fax. Se cuenta con una oficina de correo certificado. 
Los medios de comunicación que se utilizan en el municipio también son bastante precarios, no hay un medio escrito o radial, el único operador de televisión por cable es Directv, que por costos la demanda es limitada. En la señal abierta funcionan los canales nacionales.

Bajo este escenario, entre los encuestados hay un $30 \%$ de insatisfacción, por un lado al mal estado de las vías y la falta de medios de comunicación adecuados para el desarrollo económico del municipio; pero también hacen referencia a la necesidad de contar con centros de acopio de productos agrícolas y plantas de procesamiento.

Por el contrario, y producto de la buena movilidad entre veredas y centros poblados más importantes que afectan al municipio, hay un $65 \%$ de los encuestados que consideran buena la infraestructura del municipio.

Apoyo a la asociatividad empresarial. Actualmente el Municipio sólo cuenta con dos organizaciones, una conformada por productores de maíz -ASOMAIZ- y otra conformado por un grupo de mujeres emprendedoras que se denominan Asociación de Mujeres Emprendedoras de Nariño -AMEN-, en su mayoría son productoras de la zona rural y amas de casa del área urbana. Pero no hay una base sólida de agrupaciones de empresarios o asociaciones productivas legalmente constituidas que se encuentra registradas en el municipio.

ASOMAIZ es la organización referente de productores que a pesar de la antigüedad en la conformación, no está consolidada y falta mayor consenso para fortalecerse como organización. Por otro lado, la asociación AMEN no cuenta con activos ni patrimonio para el desarrollo de actividades productivas formales, la administración municipal les ha brindado recursos de capital semilla para el emprendimiento de unidades productivas a nivel individual dentro de la misma asociación. En conclusión, más allá de estos casos, no hay un grupo consolidado en pro de actividades productivas con estructuras claras y fuertes para la asociatividad. 
A pesar de la falta de grupos asociativos en campo productivo, las opiniones de apoyo para este tipo de organizaciones están divididas a partir de la encuesta. Hay un $48 \%$ que manifiestan un deficiente (malo o regular) apoyo a las organizaciones, donde no hay compromisos claros y permanentes desde el nivel local y regional para fortalecer las organizaciones de productores; pero hay otro $48 \%$ que consideran si hay manifestaciones de apoyo para mejorar las condiciones de los productores bajo el sistema asociativo, percepción que está directamente relacionada con la participación de las mujeres que conforman la asociación AMEN y que fueron parte de la encuesta, que a su vez manifiestan simpatía con la administración local.

Promoción e inventivo a los negocios y las inversiones. La identificación de oportunidades para emprender nuevos negocios o hacer inversiones en el municipio, está directamente relacionado con las acciones promovidas por la administración local para impulsar escenarios productivos y comerciales que lleven a la consolidación de procesos empresariales en el municipio.

Antes de conocer las percepciones frente escenarios de promoción de negocios e inversiones, es importante ilustrar la composición de la estructura productiva y económica del municipio (Alcaldía Municipal de Nariño, Cundinamarca, 2012):

Principales actividades económicas. Las principales actividades económicas son la siembra del maíz Yucatán obteniendo un maíz con excelente trillado para la fabricación de arepas, por esta razón se entregó en comodato la trilladora Municipal a la empresa de DON MAIZ, donde su distribución es Nacional e internacional. Un $70 \%$ de los agricultores son arrendatarios, pero los dueños sólo arriendan para cultivos semestrales, y el resto no tiene documentación de la tenencia de las tierras donde trabajan. 
La tecnología implementada en estos cultivos es mínima por el factor Económico. Actualmente se siembra aproximadamente unas 500 hectáreas de Maíz Yucatán con 280 agricultores. Donde su rendimiento promedio es de 1.2 a 1.6 Toneladas por hectáreas si hay buen tiempo. La mayoría de la cosecha se vende a tres proveedores ubicados en la Ciudad de Girardot. La organización del cultivo se hace a nivel del núcleo familiar, dado que la obra de mano es escaza y costosa especialmente en la época de siembra, recolecta, etc.

Otros cultivos como la papaya, la ahuyama, el tomate, la patilla, el melón y el plátano cachaco no han prosperado por la mala manipulación de los herbicidas e insecticidas, sumados al mal Clima se desarrollaron plagas que desterraron los cultivos. Sin embargo, otros productos como la yuca, el sorgo, el algodón, el limón y el mango, aunque tienen un porcentaje de menor participación han sido una buena alternativa para la comercializan, ya que las cosechas varían entre los meses de junio-julio y diciembre, considerando que son cultivos anuales.

Por otra parte, los mejores suelos en las partes planas que son las de la rivera del rio Magdalena actualmente en un $75 \%$ se está utilizando en explotación ganadera de ceba intensiva, con tendencia al crecimiento de hectáreas para esta actividad, a pesar que existe una limitada alimentación debido a los pocos recursos que se tiene para soportar las largas épocas de verano.

La explotación ovina es más de tras patio, donde esta especie se alimenta de los desechos de la alimentación de los humanos y pastorean en las calles y carreteras. En la explotación porcina se ha mejorado la tecnología, pero la única área que da una rentabilidad es la cría, considerando que los costos de la alimentación son concentrados industriales, condicionando la rentabilidad en el producto final. Las explotaciones avícolas son más rentables, pero solo en el manejo de las gallinas y pollos criollos. Ya que los encubados no dan rentabilidad por los altos costos en los 
concentrados. La pesca tampoco tiene buena actividad, ya que el grado de contaminación del Rio Magdalena, ha deteriorado las famosas subiendas de pescado que antes existían.

Los sistemas de producción forestal, no existe. La flora y la fauna que aún se sostiene es gracias a que las áreas donde se encuentran hay pequeñas fuentes hídricas de aguas azufradas.

Con el anterior escenario, la estructura actual de la economía de Nariño está condicionada a dos líneas de producción, el maíz y la ceba intensiva de bovinos, aunque las dos están concentrados en un par de empresarios, la primera genera mayor alternativa de empleo y producción propia; en la segunda, hay desplazamiento de mano de obra y es más costosa su operación.

Bajo esta situación, la administración local enfrenta grandes retos para aumentar y diversificar las alternativas que motiven la entrada de capitales pequeños o grandes para impulsar el desarrollo económico del municipio. Al respecto, la percepción que presentan los habitantes en el tema económico, a partir de los líderes y representantes de sectores entrevistados, es poco clara, considerando que la opinión frente a las oportunidades de hacer negocios es favorable con un 70 $\%$ (61\% opinión buena y $9 \%$ excelente), y para incentivar inversiones es favorable en un $57 \%$ (44\% buena y $13 \%$ excelente); mientras que la opinión desfavorable es del $26 \%$ y $35 \%$ respectivamente; las diferencias corresponden a opiniones que no saben del tema. Lo indica que la mayoría de los entrevistados perciben con muy buenas posibilidades una mejora en la economía local, a partir de las oportunidades existentes en el municipio para hacer negocios, y porque hay incentivos para la inversión.

Calidad de la producción y diversidad de oferta. A partir del anterior punto, donde se describen las principales actividades económicas del municipio, se identifica la percepción que tienen los representantes del municipio acerca de cómo es la calidad y diversidad de la oferta 
productiva, considerando que de esto se derivan oportunidades para emprender y promover acciones directas de desarrollo económico local.

En este aspecto se percibe que hay amplias posibilidades para nuevos y mejores procesos productivos, entendido desde la opinión de los entrevistados, al considerar en un $48 \%$ que hay buena calidad en la producción local; y del mismo modo, para un $35 \%$ la diversidad de oferta productiva es buena. Lo anterior concluye, que hay un importante sector que piensan en la necesidad de mejorar la calidad del producto (39\%) y en diversificar la oferta productiva (52\%).

Finalmente, algunas de las personas encuestadas manifiestan no saber del tema (13\% para ambos casos, calidad y diversidad), pero señalan que el municipio si debe buscar oportunidades de más empleo con nuevas opciones y mayor capacidad de producción.

Empleo e ingresos. Los datos más recientes sobre el nivel desempleo corresponden al departamento, que según el DANE para junio de 2015 es del 8,4\% (Colombia 9,1\%). Y la información más actualizada para el municipio de Nariño, está con corte a 2011 que suministró la red UNIDOS ${ }^{19}$, registrando un desempleo del $50 \%$ y de informalidad en $58 \%$, y comparado con la tasa de desempleo para Cundinamarca para ese periodo correspondió al 9,9 \% y de subempleo 40,6 \% según datos del DANE.

Lo anterior implica que teniendo una tendencia de disminución en el desempleo para Cundinamarca, probablemente esta tendencia también se registre para el municipio de Nariño; pero es evidente la gran brecha de por lo menos 30 puntos de diferencia, marcando un deterioro significativo entre el promedio de los demás municipios del departamento con el de Nariño. Sin embargo, por ser un municipio de vocación rural, los registros no dan cuenta de las formas

\footnotetext{
${ }^{19}$ La Red UNIDOS actualmente es estrategia de ANSPE - La Agencia Nacional para la Superación de la Pobreza Extrema es la entidad encargada de la estrategia nacional de promoción social para la población más pobre y vulnerable, a partir del alineamiento de los instrumentos de focalización de las instituciones públicas, la optimización de la inversión social privada y el impulso de la innovación social.
} 
informales de vinculación a los puestos de trabajo, dado que se destacan las formas de vinculación por jornal, a destajo, por horas, por corte, por obra, etc. Sin que hay un adecuado control de la formalización laboral. De este modo, la calidad de los ingresos también se ven afectados, por el costo de oportunidad de estar o no trabajando; consecuencias directas por la falta de la demanda de mano de obra.

Bajo este escenario, los resultados de la encuesta en estos aspectos ratifican que hay percepción más desfavorable en la calidad de los ingresos, pero no tanto en las oportunidades de empleo. Para el $52 \%$ las alternativas de empleo son muy malas y para el resto son buenas; para este caso el optimismo está en las oportunidades para desarrollar nuevos negocios que posibilitan la vinculación de mano de obra. En cuanto a la calidad de los ingresos, el $65 \%$ manifiesta que son malos o regulares; por ende, los jóvenes buscan alternativas en las ciudades vecinas o directamente emigran a la capital del país buscando oportunidades laborales, quedando en el municipio mano de obra de población adulta mayor o de tercera edad; mientras que el 35 \% piensa que son buenos, pero la cultura del ciudadano nariñense es el consumo de bebidas alcohólicas que afectan el ahorro o la optimización de los ingresos percibidos en el trabajo.

Organización del comercio. La forma de comercialización de los insumos producidos en el municipio se realiza en parte por intermedio de una trilladora ubicada en el casco urbano municipal y por otro lado mediante el transporte de los productos al municipio de Girardot, donde son vendidos a trilladoras. Además, el municipio no cuenta con un mercado conformado o permanente por tal razón gran parte de los insumos y alimentos que demanda la población son traídos o conseguidos en el municipio de Girardot que es el abastecedor de muchos de los productos del consumo y utilización del municipio. 
Lo concerniente al comercio informal o ventas ambulantes, no afecta significativamente a el municipio, dado que desde la Alcaldía de han promovido espacios para controlar este tipo de ventas y no generar desbordamiento de oferta comercial sin la debida organización. Este tratamiento del comercio, registra opiniones favorables del $83 \%$, situación que es evidente al no encontrar en las calles del municipio vendedores ambulantes y por el contrario se cuentan con espacios organizados y definidos para diversas actividades comerciales. El $17 \%$ considera que la organización del comercio es malo y regular, porque no se da la oportunidad de ampliar en número de beneficiarios de los punto de venta (casetas ubicadas en el parque central), los cuales manifiestan están asignados a los amigos políticos de la administración.

Recursos turísticos. Según la Información tomada del Plan de Desarrollo Municipal de Nariño 2012-2015, el Municipio ocupa un lugar privilegiado por la cercanía con el rio Magdalena para el turismo fluvial con recorridos por el rio y deportes acuáticos. La majestuosidad del rio Magdalena, la riqueza histórica y antropológica se convierte en una gran oportunidad para el desarrollo del turismo como una alternativa que contribuirá al desarrollo socioeconómico municipal. Igualmente, las condiciones topográficas del municipio son muy apetecidas por los turistas que practican deportes extremos cono el montañismo, motocross y carreras de aventura; además el municipio cuenta con un corredor ecológico ambiental que comunica con el municipio de Girardot y el cual inicia con una piscina natural de agua azufrada.

La dinámica turística municipal está centrada en los eventos tradicionales, ferias y fiestas en el mes de agosto, las visitas de los familiares de fin de año y fechas comerciales (día del padre, la madre, etc.). Épocas en que su único hotel y sus restaurantes tienen vendida su capacidad de servicio. 
A pesar de las posibilidades y oportunidades con las que estratégicamente cuenta el territorio donde se unidad el municipio de Nariño, el $78 \%$ de los encuestados manifiestan que no hay una adecuada oferta turística, por lo menos el sentir común de los entrevistados, es la falta de infraestructura adecuada para hacer atractivo el municipio, y no hay un liderazgo privado o público para trabajar en el tema. Pero un $22 \%$ de encuestados consideran como buena la oferta turística, considerando que es adecuada o suficiente para los pocos lugares atractivos existentes, siendo innecesario incrementar la infraestructura que hoy se oferta.

Lo anterior implica una ambigüedad; por un lado, las opiniones desfavorables consideran que hay alternativas para desarrollar el sector y por ende la oferta es mala; y por otro lado, las opiniones favorables que la oferta de servicios para el turista es suficiente, porque no hay muchos atractivos para motivar la llegada de turistas. El resultado de las opiniones, son una falta de coordinación, planeación de los representantes del municipio para focalizar objetivos frente a su desarrollo.

El resultado general de percepción para la Dimensión Económica, alcanza un optimismo moderado ante la situación presentada, teniendo en cuenta que un $61 \%$ de los encuestados califican como bueno de los factores analizados le aportan al desarrollo económico del municipio. Mientras que un 39 \% consideran que ellos no están contribuyendo para mejorar económicamente la situación del municipio.

\section{Dimensión Institucional}

De acuerdo con la descripción realizada en el título de las dimensiones del desarrollo local, la clasificación de lo institucional desde la perspectiva de varios autores, corresponde a los agentes que impulsan y articulan acciones entre lo público y lo privado para el diseño y ejecución de políticas para el desarrollo local. 
Con esta referencia, y con las mismas características propias de la localidad en estudio; en la cual, institucionalmente el desarrollo del municipio gira en torno al desempeño de la administración local de turno, es necesario identificar - aunque sea desde la generalidad - cómo la comunidad percibe la gestión administrativa, política y económica del actual gobierno municipal. Pero conscientes que la tarea de las instituciones no es exclusiva de la administración pública, también es importante la identificación de otros actores locales, regionales y nacionales, incluso entes de cooperación internacional que acompañen procesos de desarrollo en la localidad directamente o a través de operadores.

El marco institucional es un aspecto fundamental de entendimiento y respaldo frente a los procesos de desarrollo local y económico local; por tanto, la suma de actores públicos y privados debe ser una condición para que la sociedad civil, como principal benefactor de los resultados económicos y sociales, los integre más allá de las ideologías o intereses particulares, para construir entendimientos comunes. Esto es necesario considerarlo en los procesos de desarrollo local y específicamente en el desarrollo económico local, al encontrar en los encuestados matices en las respuestas al conocer la percepción relacionada con la administración municipal.

La Dimensión Institucional es la más sensible para identificar percepciones, porque implica en el entendido del entrevistado, asumir posición, que puede estar relacionado con los afectos o no hacia la autoridad administrativa municipal de turno (para Colombia, alcaldes). Partiendo con esta premisa, el presente trabajo no busca calificar o cuestionar la gestión de la administración, pero si conocer el estado de avance en los procesos de gestión y relación con la comunidad y los actores locales, como un escenario necesario para promover desarrollo económico local.

Al respecto, se consultó sobre la gestión institucional desde la administración local, la relación con los productores, las comunidades vulnerables y las organizaciones comunitarias, 
específicamente las Juntas de Acción Comunal - JAC ${ }^{20}$; también aspectos relacionados con la prestación de los servicios y el manejo de la economía para separarlo de la gestión en general; finalmente como aspecto importante para considerar en los procesos de gestión, es necesario conocer el liderazgo existente desde la alcaldía en el contexto regional.

Como parte de lo institucional, las organizaciones no gubernamentales son importantes en el desarrollo social y económico; por tanto, la identificación de estos actores corresponde a un insumo necesario en los procesos de desarrollo económico local.

Antes de conocer las percepciones en los aspectos seleccionados y descritos para la Dimensión Institucional, se presenta el inventario institucional del municipio:

La administración funciona en un predio de propiedad del municipio el cual comparte con la estación de policía, la sede de la Alcaldía Municipal mencionada cuenta con oficinas para cada dependencia adecuada y dotada para las diferentes actividades y prestación de los servicios.

La estructura administrativa ${ }^{21}$ es básica y ajustada al presupuesto del municipio, conformada por: despacho de la Alcaldía, oficina de planeación y control interno, secretaria general, Tesorería, Oficina de la UMATA ${ }^{22}$, oficina de servicios públicos, oficina de deportes, almacén, inspección de policía, oficina del Sisbén y la comisaria de familia.

La organización comunitaria está constituida por seis Juntas de Acción Comunal en el Municipio, cinco veredales y una del casco urbano. También existen dos Juntas de vivienda: Junta de Vivienda Comunitaria Divino Niño, y Junta de Vivienda Comunitaria San Cayetano. Además

\footnotetext{
${ }^{20}$ La Junta de Acción Comunal es un organismo de primer grado y corresponde a una organización cívica, social y comunitaria de gestión social, sin ánimo de lucro, de naturaleza solidaria, con personería jurídica y patrimonio propio, integrada voluntariamente por los residentes de un lugar que aúnan esfuerzos y recursos para procurar un desarrollo integral, sostenible y sustentable con fundamento en el ejercicio de la democracia participativa. Ley 743 de 2002, Reglamentada por el Decreto Nacional 2350 de 2003.

${ }^{21}$ Secretaria General del municipio de Nariño.

${ }^{22}$ Unidad Municipal de Asistencia Técnica Agropecuaria (UMATA), cuya función es la de prestar asistencia técnica agropecuaria directa y gratuita a los pequeños productores. Ley 101 de 1993.
} 
existen unos espacios establecidos por la Ley, como: Consejo territorial de Planeación, Junta Municipal de educación, Consejo Municipal Ambiental, Comité local de Prevención de desastres, Consejo Municipal de política social, y Consejo Municipal de cultura.

De acuerdo con la Secretaria de Planeación de Cundinamarca, lo reportado en el FUT Formato único territorial el municipio recibió en el 2014 ingresos totales por valor de 9.590 millones de pesos, lo cual significó un aumento respecto al año anterior de $135 \%$ (Gráfica 5) producto principalmente de otros ingresos no tributarios transferidos por la nación.

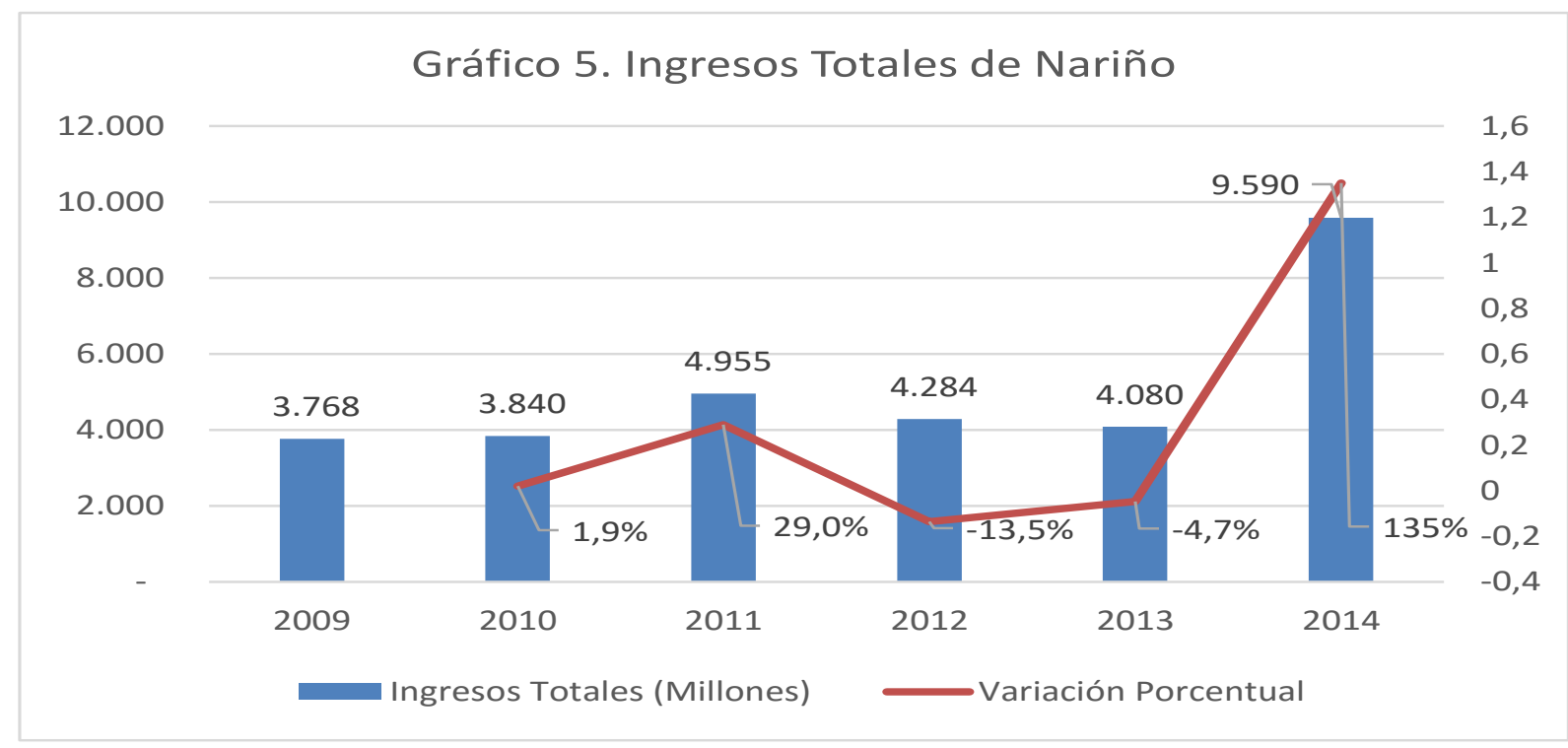

Gráfica 5. Ingresos totales de Nariño, Cundinamarca. Fuente: Elaboración propia con base en datos de la Secretaria de Planeación de Cundinamarca.

Hasta el 2013 el municipio estaba ubicado por ingresos totales anuales, entre los últimos veinte municipios, para el 2014 ascendió a mitad de la tabla, ubicándose entre los primeros 55 de los 116 municipios del departamento. Esta información ayuda a dimensionar el tamaño de los ingresos del municipio teniendo en cuenta que el número uno de ingresos totales es el municipio de Soacha con 416 mil millones de pesos, pero a su vez sólo diez municipios al 2014 superan los ingresos de los 100 mil millones de pesos. 
Una información importante para conocer el manejo de los recursos en el municipio, proviene del Departamento Nacional de Planeación con el informe de desempeño fiscal, la cual señala la posición que tiene cada municipio para el manejo de los recursos públicos medido a través de la autofinanciación de los gastos de funcionamiento, respaldo del servicio de la deuda, la dependencia de las transferencias de la Nación y las Regalías, generación de recursos propios, magnitud de la inversión y la capacidad de ahorro; el último informe disponible corresponde a los años 2011 y 2012, ubicando al municipio de Nariño en la posición 360 y 781 respectivamente a nivel nacional, y a nivel departamental en las posiciones 59 y 102 respectivamente entre los 116 municipios del departamento.

Claramente se identifica un deterioro en el manejo de las finanzas públicas, sin embargo no es concluyente por falta de información en los dos últimos años 2013 y 2014.

Finalmente a continuación se presentan los resultados de las percepciones en las variables seleccionadas para ubicar el estado de la Dimensión Institucional. Empezando por la gestión institucional, hay un resultado favorable con un $83 \%$ de calificación como bueno $74 \%$ y excelente $9 \%$; tan solo el $13 \%$ desaprueba y el $4 \%$ no sabe o preferiblemente decidió no opinar en este punto. Este resultado marcó una tenencia en las demás variables como se observa a continuación.

La relación con los diferentes actores medida a través del apoyo a los productores, la protección a los más vulnerables, y la atención a las JAC, tienen una percepción similar los encuestados considerando que la opinión es favorable en la mayoría de ellos. El apoyo a los productores es considerado bueno, muy buenos y excelente el $70 \%$; la protección a la población más vulnerable (indicador significativo para comunidades pequeñas), llega a una aprobación del $78 \%$ y la relación con las JAC es del $61 \%$, aunque este resultado presenta matices políticos, no todos los entrevistados hacen parte de la línea política del Alcalde y no pertenecen a JAC, el 
resultado lo determinó la importancia que tiene la JAC para la comunidad desde el ámbito social y comunitario.

Otro aspecto importante para identificar el campo institucional, es la misma prestación general de los servicios desde la administración municipal, entendiendo que la comunidad expresa cómo se siente al solicitar servicios o ayudas directamente a la Alcaldía, es una relación de servicio al cliente al momento de hace la solicitud, la oportunidad de respuesta y la satisfacción por el servicio. En este campo se obtuvo un resultado favorable para la administración, pero requiriendo mejorar en este aspecto, considerando que hay un $39 \%$ de opiniones que lo desaprueban, indicando que la prestación de los servicios por parte de la Alcaldía son malos y regulares. EL 61 $\%$ consideran que es bueno (57\%) y excelente $4 \%$. Los resultados de este aspecto dependen en gran parte de la experiencia personal, lo cual trae el recuerdo de las situaciones vividas de manera particular, obviando el interés general.

En el mismo sentido, el aspecto económico personal influye en la opinión sobre el manejo de la economía, aunque esta depende en muchos aspectos del manejo de variables del orden nacional, la medición en este aspecto está relacionado con la promoción y fomento por la inversión privada, la generación de nuevos negocios, el desempeño fiscal y la inversión social, todo en su conjunto desde la perspectiva local. En este aspecto el resultado es positivo con un $61 \%$ de opiniones que consideran bueno (52\%) y excelente (9\%) el manejo de la economía. Los resultados concuerdan o tienen el mismo sentido de las respuestas relacionadas con las preguntas en la Dimensión Económica sobre oportunidades de negocios (70 \%) e incentivo de la inversión (57 \%), y con la respuesta de la prestación de los servicios (61 \%), significando que la administración municipal goza por parte de los encuestados de buena credibilidad. 
Un aspecto importante para determinar las oportunidades de desarrollo promovido desde un escenario regional, es a partir de la capacidad de liderazgo que la administración local presenta en ámbito provincial o regional. En este sentido, los encuestados ven con buena percepción (65 \%) el papel de la Alcaldía o el conjunto de la administración municipal para enfrentar los temas regionales; pero el $18 \%$ considera que la participación de la administración en el contexto regional ha sido inadvertido, a ello se le suma que el $17 \%$ prefiere no opinar, al entender que no ha sido relevante y poco conocidos los resultados, por ende indican - no saber.

Por ultimo e infortunadamente el municipio no cuenta con organizaciones no gubernamentales de orden local, regional y mucho menos de cooperación internacional que adelanten actividades de desarrollo social o productivo, o por lo menos no son identificadas por las misma administración municipal (funcionarios encuestados), ni por la comunidad. Al preguntar si se conoce organizaciones no gubernamentales de diferente orden que realice trabajo en el municipio, el $87 \%$ manifestó que no conocían, y el $13 \%$ indicaron que sí, pero en trabajos ya concluidos con población desplazada, discapacitada y mujeres de la tercera edad; pero no tienen conocimiento directo de los resultados finales, que al parecer fueron positivos.

En términos generales, el $70 \%$ de los encuestados califican muy favorablemente el desempeño de la administración municipal para contribuir en la institucionalidad del municipio, aunque los datos técnicos evidencien otro tipo de resultados; sin embargo, se trata de conocer la percepción de la comunidad, quienes establecen el ambiente para adelantar potenciales procesos de desarrollo económico local en cada localidad. 


\section{Índice de Confianza Municipal a partir de las Percepciones del Desarrollo Local y}

\section{Económico Local}

\section{Proceso de Elaboración del Índice de Confianza}

En el presente trabajo se llama Índice de Confianza Municipal-ICM-, a la medida ponderada que valora el estado general de las dimensiones del desarrollo social, económico e institucional a partir de las percepciones que tienen los pobladores de su comunidad (municipio). Por tanto, el resultado del índice, es un valor cualitativo ${ }^{23}$ que establece (de forma intuitiva para el lector), el nivel de confianza que existe en los pobladores de una comunidad, frente al estado general (conformidad o satisfacción) de desarrollo y bienestar en el municipio.

A continuación se presenta el proceso de elaboración para hallar el índice, advirtiendo que es una propuesta para la construcción de una herramienta original que identifique el nivel de confianza que perciben las comunidades frente a los avances del desarrollo local; además, con la información parcial elaborada durante el proceso de diseño, es útil para estimar o evaluar elementos de incidencia que definen la oportunidad o conveniencia de implementar procesos de desarrollo económico local.

En el primer paso se identifican y se definen las variables, agrupándolas en cada una de las dimensiones de desarrollo de acuerdo con el interés de estudio, pero particularmente orientado a tomar elementos del desarrollo económico local.

La información estadística disponible para los municipios categoría seis en Colombia, no es completa y no todas las variables cuentan con datos actualizados. Por ende, es un aspecto que incide y limita la descripción y caracterización del contexto en el municipio, derivando que en el análisis se otorgue un mayor peso en la percepción de los encuestados, logrando a partir de ellos

\footnotetext{
${ }^{23}$ La escala cualitativa (ordinal) definida para el índice de confianza Municipal: Malo-1, Regular-2, Bueno-3, Muy Bueno-4, y Excelente-5. (de menor a mayor con, entre menos deseable y lo más deseable).
} 
una identificación de factores que inciden en la promoción del desarrollo económico local en este tipo de municipios.

El segundo paso es hacer levantamiento de información a través de encuesta (Anexos B, C y D) con el grupo identificado de líderes o representantes de cada sector. El propósito de la encuesta es "identificar en los actores locales del municipio de Nariño, Cundinamarca las percepciones sobre la situación del desarrollo local, para el diseño de un índice de confianza municipal como insumo en la identificación de determinantes socioeconómicos e institucionales que inciden en la promoción del desarrollo económico local”; para ello, la selección del grupo o determinación de la muestra, se puede hacer con la técnica o método que mejor aplique a la población del municipio o localidad objeto de trabajo.

En el presente trabajo, la falta de disposición a participar de los líderes y representantes de sectores, para el levantamiento de información a través de sesiones grupales, implicó el uso de una técnica de muestreo no probabilística conocida como bola de nieve, llegando primero a los líderes con mayor disposición, y a través de ellos, uno a uno a los demás representantes de cada sector, hasta completar un número significativo de encuestados.

Ahora bien, por qué utilizar un instrumento como la encuesta?, por tratarse de una herramienta de observación y de opinión, facilita la cuantificación y comparación de la información pre-diseñada intencionalmente con preguntas principalmente cerradas, esto ayuda a direccionar el propósito del trabajo frente a las percepciones de cada variable y dimensión de desarrollo seleccionadas, lo cual ayuda a identificar las necesidades y posibles acciones que conduzcan a la implementación adecuada de acciones en desarrollo económico local.

En consecuencia la encuesta es una herramienta que proporciona insumos como resultado de la información recopilada entre los actores o agentes encuestados, comparándose los resultados 
entre sí, y midiendo el peso de las opiniones registradas. Por tanto, el instrumento es útil para para averiguar el grado de conocimiento y satisfacción de los encuestados frente al tema consultado.

En este sentido, es importante reconocer que el levantamiento de información sólo es práctico y efectivo si se realiza directamente desde el conocimiento local objeto del trabajo; es decir, con los actores conocedores de sus propias dinámicas, intereses y capacidades que viven sus propias apuestas de cambio; por tanto, las respuestas se originan desde la espontaneidad y la experiencia. Es así que la información a registrar debe provenir en mayor proporción de las personas nativas de la comunidad en estudio, o de residentes antiguos con arraigo y pertenencia por el desarrollo local. Aunque mayoría de estos actores no manejen con destreza técnica los datos, si tienen la solvencia para hacer que la información derivada de la experiencia se emplee con amplio rigor para tomar decisiones, provocando cambios que afectan sus propios escenarios de intervención.

Como respaldo a la información recopilada, se incluyen en el proceso de análisis los datos provenientes de las fuentes secundarias que están relacionadas directamente con el tema específico de investigación; del mismo modo, y no menos importante - la información recopilada a partir de la observación, es un elemento que valida y confronta los resultados en los escenarios definidos por los encuestados.

El tercer paso, corresponde a la tabulación de los resultados de la encuesta, la cual describe una valoración cualitativa del estado actual de cada variable, con selección única entre valores ordinales definidos con: malo-1, regular-2, bueno-3, muy bueno-4 y excelente-5; y entre las variables de cada dimensión se valora el orden de importancia o jerarquización para hacer una ponderación a través de la herramienta técnica (preferiblemente estadística) para calcular el índice de confianza municipal (o índice de percepción municipal). 
Finalmente, el cuarto paso es el cálculo del índice de confianza. Para hallarlo, se empleó el programa estadístico SPSS “Statistical Package for the Social Sciences”24

\section{Cálculo para Hallar el Índice de Confianza}

El Índice de Confianza Municipal sobre el Desarrollo Local es el resumen de la evaluación de varios aspectos, trabajados a través de un índice sintético, denominado así por la combinación de índices individuales, a los cuales nos referimos como índices componentes (Cabrer, de Castro, \& Pavía, 2001; citado por Mondéjar-Jiménez \& Vargas-Vargas, 2008).

El cálculo del ICM se desarrolla en cuatro pasos que incluyen, el análisis de la consistencia del intrumento, cálculo de ponderadores, cálculo de índice para llegar finalmente al cálculo del índice general (ver Gráfica 6):

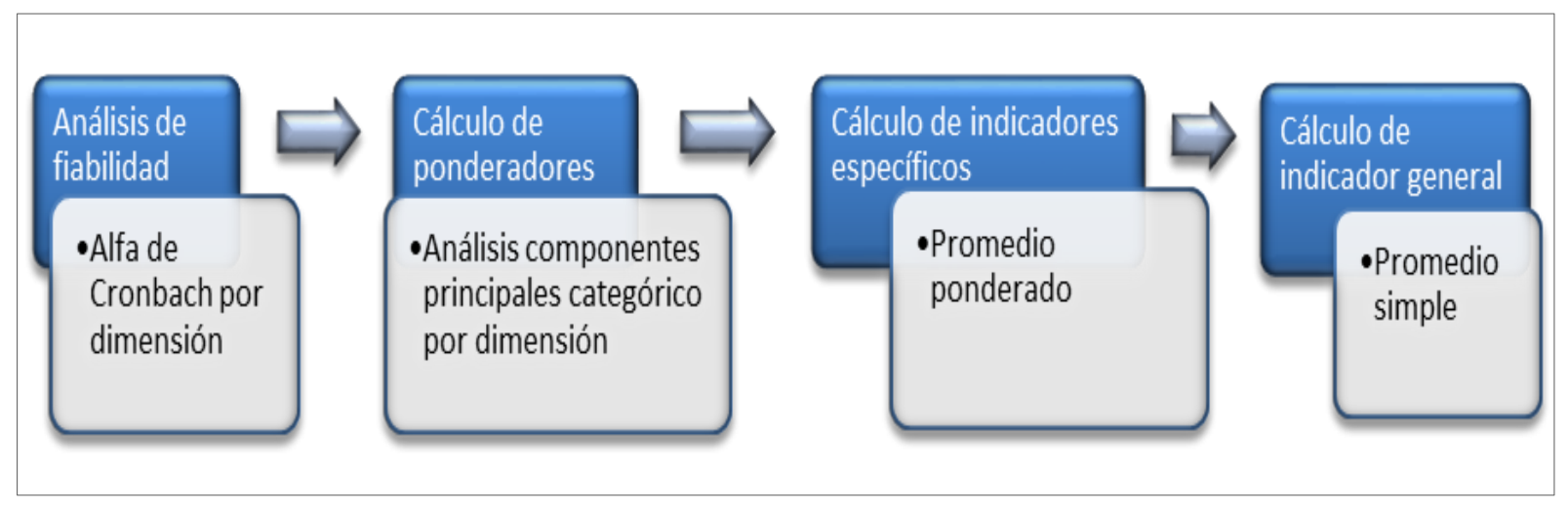

Figura 1. Pasos para calcular el índice. Fuente: Elaboración propia.

Análisis de fiabilidad de las escalas. En psicología e investigación social, la fiabilidad es una propiedad psicométrica, que evalúa el grado de consistencia y estabilidad de las puntuaciones obtenidas tras la aplicación de un instrumento (Cronbach, 1951).

\footnotetext{
${ }^{24}$ Actualmente el nombre completo es IBM SPSS (ya no es acrónimo de nada)
} 
El primer paso, previo al cálculo de parámetros estadísticos, consiste en evaluar la fiabilidad del instrumento, determinar el grado en que los elementos del cuestionario se relacionan entre sí. Este procedimiento se hace para cada una de las dimensiones, para los ítems medidos bajo la misma escala.

Información sobre la Dimensión Social. Esta dimensión está compuesta de 11 ítems, el Alpha de Cronbach calculado es de 0.851 con lo cual se afirma la fiabilidad en esta dimensión (Tabla 2, Anexo E).

Tabla 2 .

Cálculo de fiabiliadad variables Dimensión Social

\begin{tabular}{|l|c|}
\hline \multicolumn{1}{|c|}{ Variables de la Dimensión Social } & $\begin{array}{c}\text { Alfa de Cronbach si se } \\
\text { elimina el elemento }\end{array}$ \\
\hline Salud &, 842 \\
Educación &, 830 \\
Vivienda &, 839 \\
Servicios domiciliarios &, 826 \\
Atención a la Juventud &, 834 \\
Protección a la niñez &, 833 \\
Protección a la tercera edad &, 853 \\
Respeto a derechos humanos &, 846 \\
Seguridad &, 837 \\
Fomento de la cultura &, 848 \\
GENERAL &, 832 \\
\hline
\end{tabular}

Fuente: Cálculo propio del autor.

Información sobre la Dimensión Económica. Se confirma la fiabilidad de la dimensión Económica evaluada en 11 ítems con un Alpha de Cronbach de 0.820 (Tabla 3, Anexo F). 
Tabla 3.

Cálculo de fiabiliadad variables Dimensión Económica

\begin{tabular}{|l|c|}
\hline \multicolumn{1}{|c|}{ Variables de la Dimensión Económica } & $\begin{array}{c}\text { Alfa de Cronbach si se } \\
\text { elimina el elemento }\end{array}$ \\
\hline Oportunidad a los negocios &, 799 \\
Incentivo a la Inversión &, 793 \\
Alternativas de Empleo &, 815 \\
Niveles de Ingresos &, 825 \\
Organización del Comercio &, 830 \\
Oferta turística &, 798 \\
Calidad de la producción &, 775 \\
Diversidad de la oferta Pcc &, 785 \\
Estado de la Infraestructura &, 798 \\
Apoyo a la asociatividad &, 818 \\
GENERAL &, 807 \\
\hline
\end{tabular}

Fuente: Cálculo propio del autor.

Información sobre la Dimensión Institucional. Se confirma la fiabilidad de la dimensión Institucional evaluada en 10 ítems con un Alpha de Cronbach de 0.923 (Tabla 4, Anexo G). 
Tabla 4.

Cálculo de fiabiliadad variables Dimensión Institucional

\begin{tabular}{|l|c|}
\hline \multicolumn{1}{|c|}{ Variables de la Dimensión Institucional } & $\begin{array}{c}\text { Alfa de Cronbach si se } \\
\text { elimina el elemento }\end{array}$ \\
\hline Gestión institucional &, 917 \\
Apoyo a los productores &, 906 \\
Protección a los vulnerables &, 911 \\
Liderazgo regional &, 910 \\
Prestación de los servicios &, 909 \\
Manejo de la economía &, 904 \\
Relación con las JAC &, 907 \\
GENERAL &, 912 \\
ONG's de orden local: &, 932 \\
ONG's de orden regional, nacional o internacionales &, 934 \\
\hline
\end{tabular}

Fuente: Cálculo propia

Las demás preguntas de la encuesta relacionadas con el desarrollo local, desarrollo económico local y la promoción DEL, no son pertinentes por la falta de variabilidad en las respuestas sin ningún aspecto diferenciador (el capítulo 2 presenta el análisis de estos resultados, y son insumo para el capítulo 4), por ende se ignora en el cálculo del análisis para hallar el índice.

Cálculo de ponderadores. Una vez evaluada la consistencia de los índices, se procede a calcular los ponderadores. Las variables utilizadas en la medición son de tipo nominal y ordinal, razón por la cual el procedimiento multivariado más adecuado para realizar el cálculo de los ponderadores es el Análisis de Componentes principales Categórico (CATPCA, del inglés Categorical Principal Components Analysis).

El CATPCA cuantifica simultáneamente las variables categóricas a la vez que reduce la dimensionalidad de los datos. El objetivo de los análisis de componentes principales es la reducción de un conjunto original de variables en un conjunto más pequeño de componentes no correlacionados que representen la mayor parte de la información encontrada en las variables 
originales. La técnica es más útil cuando un extenso número de variables impide una interpretación eficaz de las relaciones entre los objetos (sujetos y unidades). Al reducir la dimensionalidad, se interpreta un pequeño número de componentes en lugar de un extenso número de variables (IBM, 2013).

El procedimiento para el cálculo de los ponderadores es el siguiente: (1) en cada dimensión, se evalúa la varianza explicada (mediante los valores propios) con esta información se escoge el número óptimo de factores; (2) se reescala la varianza de tal manera que su suma de $100 \%$, el valor en cada caso es el ponderador utilizado para el factor; (3) se evalúa las saturaciones de las variables en cada factor, cada variable es asignada al factor que tiene la saturación más alta; y, (4) se reescala las saturaciones de las variables en cada factor de tal manera que sume $100 \%$, ese valor es el peso de la variable dentro del factor.

Conceptualmente, el Índice de Confianza está construido a partir de tres dimensiones, con base a esta estructura se calculan los factores y los ponderadores correspondientes.

Los pesos de cada uno de los ítems que componen los ítems son los siguientes:

Información sobre la Dimensión Social. El CATPCA indica que esta dimensión se puede organizar en tres factores (Figura 2, Anexo H), organizados y ponderados como lo indica el siguiente esquema: 


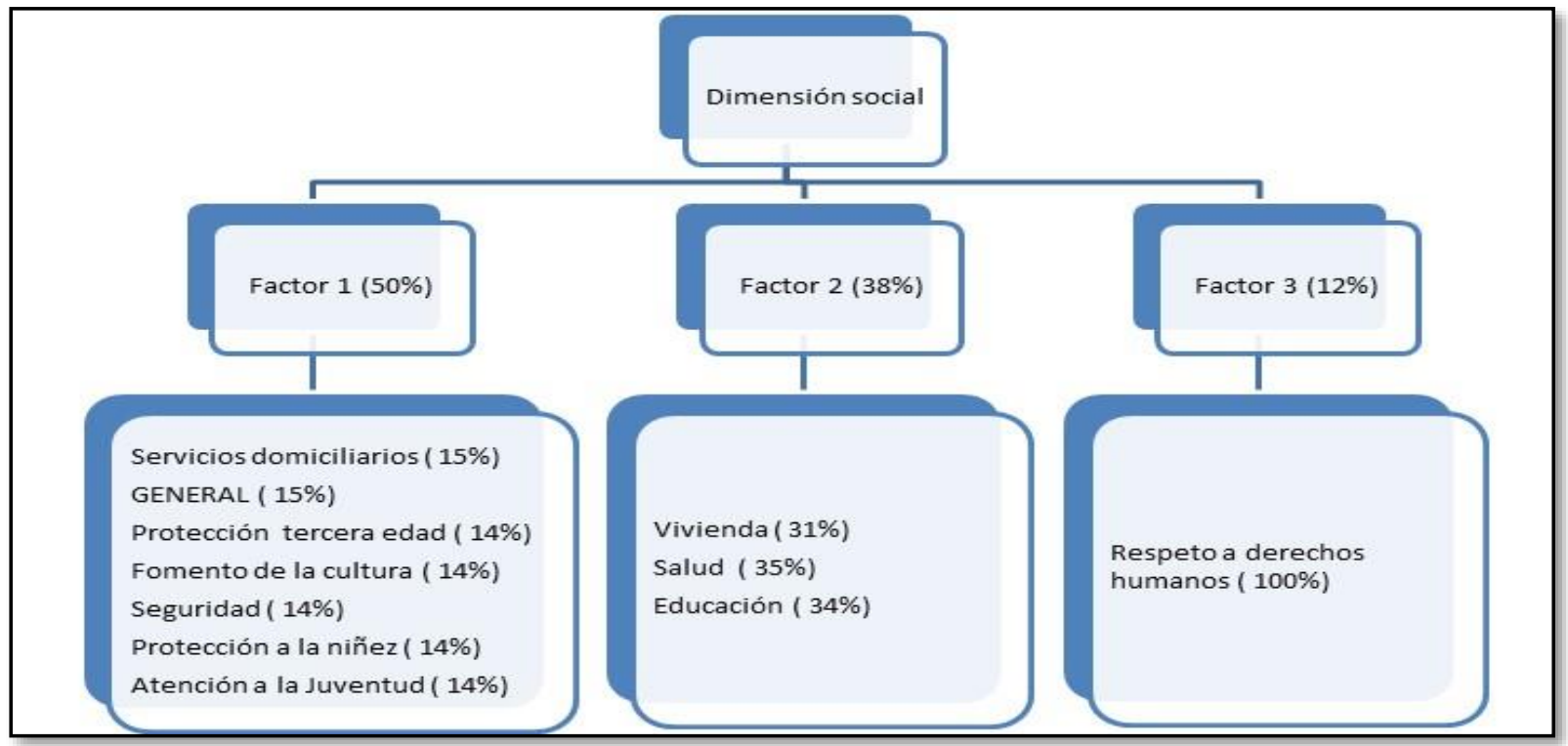

Figura 2. Esquema de cálculo de ponderados Dimensión Social. Fuente: Elaboración propia.

Información sobre la Dimensión Económica. El CATPCA indica que esta dimensión se puede organizar en cuatro factores (Figura 2, Anexo I), organizados y ponderados como lo indica el siguiente esquema:

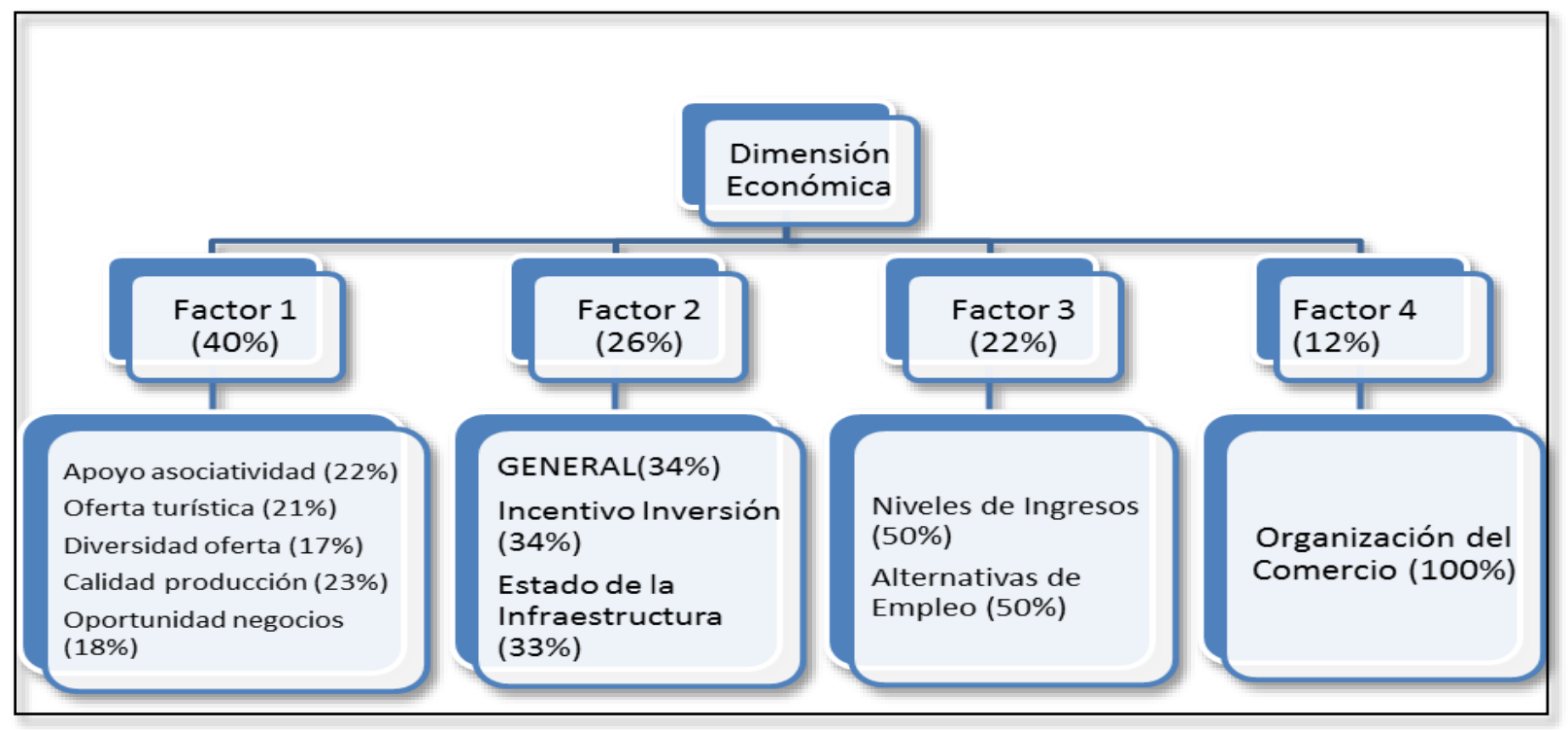

Figura 3. Esquema de cálculo de ponderados Dimensión Económica. Fuente: Elaboración propia. 
Información sobre la Dimensión Institucional. El CATPCA indica que esta dimensión se puede organizar en dos factores (Figura 4, Anexo J), organizados y ponderados como lo indica el siguiente esquema:

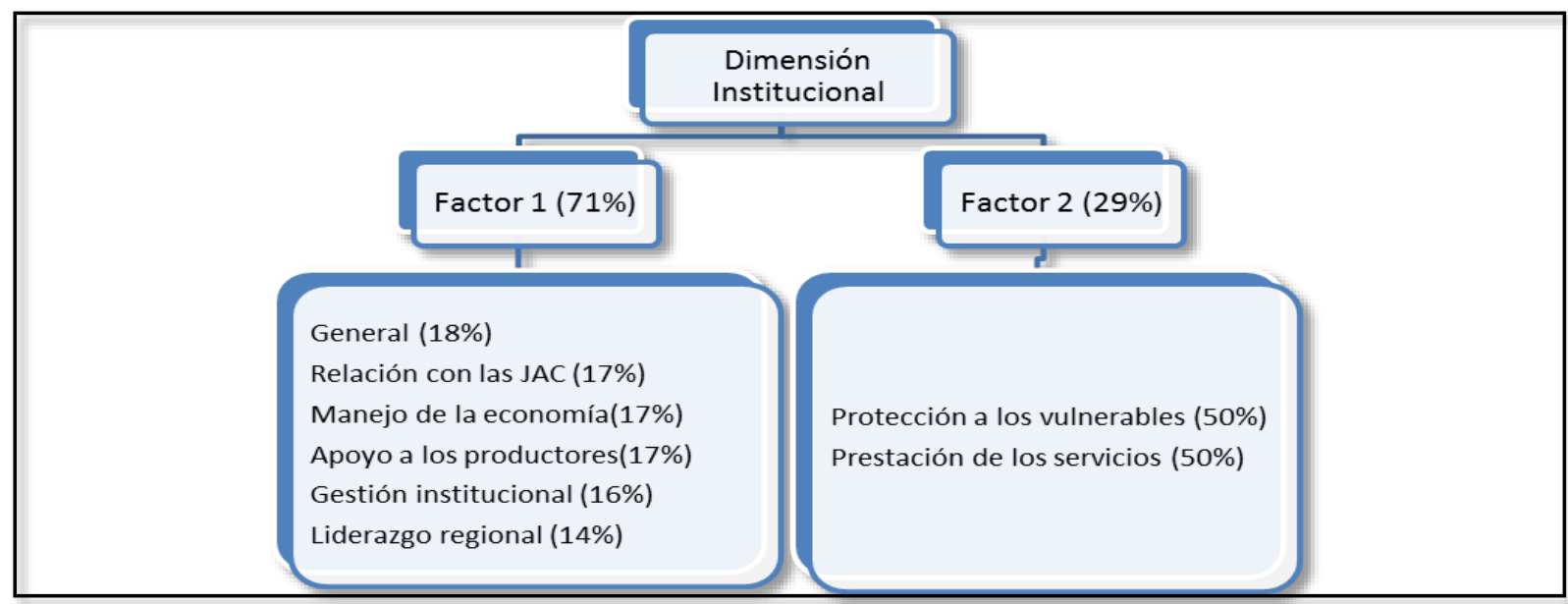

Figura 4. Esquema de cálculo de ponderados Dimensión Institucional. Fuente: Elaboración propia.

El CATPCA además indica que las preguntas que indagan sobre el conocimiento de ONG's no aportan variabilidad, pues sus resultados son constantes, razón por la cual se excluyen del análisis.

Cálculo de indicadores específicos. El cálculo de los factores consiste en evaluar el promedio ponderado de las variables dentro de cada factor haciendo uso de los ponderadores calculados en el paso anterior.

Cada uno de los índices oscila entre 1 y 10, siendo uno (1) un índice indeseable y diez (10) muy deseable, con intermedios de favorable y desfavorable, debido a que se encuentra en condiciones óptimas para implementar proyectos de desarrollo local. A continuación se visualiza la nueva escala de valores: 


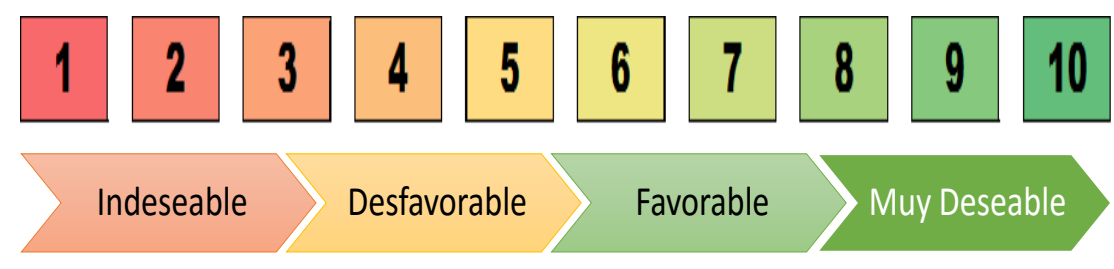

Para ilustrar el cálculo de los factores y del índice de los índices de cada dimensión se describe el procedimiento para calcular el índice de la dimensión social, los demás se hacen análogamente:

Los ponderadores de cada uno de los ítems que componen el factor son los siguientes:

Tabla 5.

Cálculo del ponderado de variables en la Dimensión Social

\begin{tabular}{|c|c|c|c|c|c|}
\hline Factor & $\begin{array}{l}\text { Peso del } \\
\text { factor }\end{array}$ & Cod & Item & $\begin{array}{l}\text { Peso del } \\
\text { Item en el } \\
\text { factor }\end{array}$ & $\begin{array}{l}\text { Peso en la } \\
\text { dimensión }\end{array}$ \\
\hline \multirow{7}{*}{ F1 } & \multirow{7}{*}{$50 \%$} & P1_4 & Servicios domiciliarios & $15 \%$ & $7,3 \%$ \\
\hline & & P1_11 & GENERAL & $15 \%$ & $7,6 \%$ \\
\hline & & P1_7 & Protección a la tercera edad & $14 \%$ & $7,0 \%$ \\
\hline & & P1_10 & Fomento de la cultura & $14 \%$ & $6,8 \%$ \\
\hline & & P1_9 & Seguridad & $14 \%$ & $7,1 \%$ \\
\hline & & P1_6 & Protección a la niñez & $14 \%$ & $7,1 \%$ \\
\hline & & P1_5 & Atención a la Juventud & $14 \%$ & $7,1 \%$ \\
\hline \multirow{3}{*}{$\mathrm{F} 2$} & \multirow{3}{*}{$38 \%$} & P1_3 & Vivienda & $31 \%$ & $11,9 \%$ \\
\hline & & P1_1 & Salud & $35 \%$ & $13,1 \%$ \\
\hline & & P1_2 & Educación & $34 \%$ & $13,0 \%$ \\
\hline F3 & $12 \%$ & P1_8 & Respeto a derechos humanos & $100 \%$ & $12,0 \%$ \\
\hline
\end{tabular}

Fuente: Cálculo propio

Para cada uno de los encuestados se calcula la calificación en cada factor:

$$
\begin{aligned}
& \begin{aligned}
F 1=\left(7.3 \% * P 1_{4}\right)+\left(7.6 \% * P 1_{11}\right)+\left(7.0 \% * P 1_{7}\right)+\left(6.8 \% * P 1_{10}\right) \\
+\left(7.1 \% * P 1_{9}\right)+\left(7.1 \% * P 1_{6}\right)+\left(7.1 \% * P 1_{5}\right)
\end{aligned} \\
& F 2=\left(11.9 \% * P 1_{3}\right)+\left(13.1 \% * P 1_{1}\right)+\left(13.0 \% * P 1_{2}\right) \\
& F 3=\left(12 \% * P 1_{8}\right)
\end{aligned}
$$

Se calcula el índice haciendo uso de los factores calculados en el paso anterior:

$$
\text { I.D.Social }=(50 \% * F 1)+(38 \% * F 2)+(12 \% * F 3)
$$


En el Anexo K se encuentra los resultados de los índices las tres dimensiones: social, económica e institucional, para las cuales se utilizaron los pesos en cada dimensión calculados en la sección anterior (los cálculos se realizaron en SPSS ver sintaxis en Anexo D) y que se ilustran a continuación:

Tabla 6.

Cálculo del ponderado de variables en la Dimensión Económica

\begin{tabular}{|c|c|c|c|c|}
\hline Factor & $\begin{array}{l}\text { Peso del } \\
\text { factor }\end{array}$ & Item & $\begin{array}{l}\text { Peso del } \\
\text { Item en el } \\
\text { factor }\end{array}$ & $\begin{array}{l}\text { Peso en la } \\
\text { dimensión }\end{array}$ \\
\hline \multirow{5}{*}{$\mathrm{F} 1$} & \multirow{5}{*}{$40 \%$} & Apoyo a la asociatividad & $22 \%$ & $8,7 \%$ \\
\hline & & Oferta turística & $21 \%$ & $8,2 \%$ \\
\hline & & Diversidad de la oferta Pcc & $17 \%$ & $6,7 \%$ \\
\hline & & Calidad de la producción & $23 \%$ & $9,3 \%$ \\
\hline & & Oportunidad a los negocios & $18 \%$ & $7,1 \%$ \\
\hline \multirow{3}{*}{$\mathrm{F} 2$} & \multirow{3}{*}{$26 \%$} & GENERAL & $34 \%$ & $8,8 \%$ \\
\hline & & Incentivo a la Inversión & $34 \%$ & $8,7 \%$ \\
\hline & & Estado de la Infraestructura & $33 \%$ & $8,5 \%$ \\
\hline \multirow{2}{*}{ F3 } & \multirow{2}{*}{$22 \%$} & Niveles de Ingresos & $50 \%$ & $11,0 \%$ \\
\hline & & Alternativas de Empleo & $50 \%$ & $11,0 \%$ \\
\hline F4 & $12 \%$ & Organización del Comercio & $100 \%$ & $12,0 \%$ \\
\hline
\end{tabular}

Fuente: Cálculo propio 
Tabla 6.

Cálculo del ponderado de variables en la Dimensión Institucional

\begin{tabular}{|c|c|c|c|c|}
\hline Factor & $\begin{array}{l}\text { Peso del } \\
\text { factor }\end{array}$ & Item & $\begin{array}{l}\text { Peso del } \\
\text { Item en el } \\
\text { factor }\end{array}$ & $\begin{array}{l}\text { Peso en la } \\
\text { dimensión }\end{array}$ \\
\hline \multirow{6}{*}{$\mathrm{F} 1$} & \multirow{6}{*}{$71 \%$} & GENERAL & $18 \%$ & $12,7 \%$ \\
\hline & & Relación con las JAC & $17 \%$ & $12,4 \%$ \\
\hline & & Manejo de la economía & $17 \%$ & $12,3 \%$ \\
\hline & & Apoyo a los productores & $17 \%$ & $12,2 \%$ \\
\hline & & Gestión institucional & $16 \%$ & $11,3 \%$ \\
\hline & & Liderazgo regional & $14 \%$ & $10,2 \%$ \\
\hline \multirow{2}{*}{$\mathrm{F} 2$} & \multirow{2}{*}{$29 \%$} & Protección a los vulnerables & $50 \%$ & $14,4 \%$ \\
\hline & & Prestación de los servicios & $50 \%$ & $14,6 \%$ \\
\hline
\end{tabular}

Fuente: Cálculo propio

Cálculo de índice general. Los anteriores cálculos permiten evaluar el desempeño general en cada una de las dimensiones, además se calcula un índice general que resulta de promediar los tres índice calculados anteriormente:

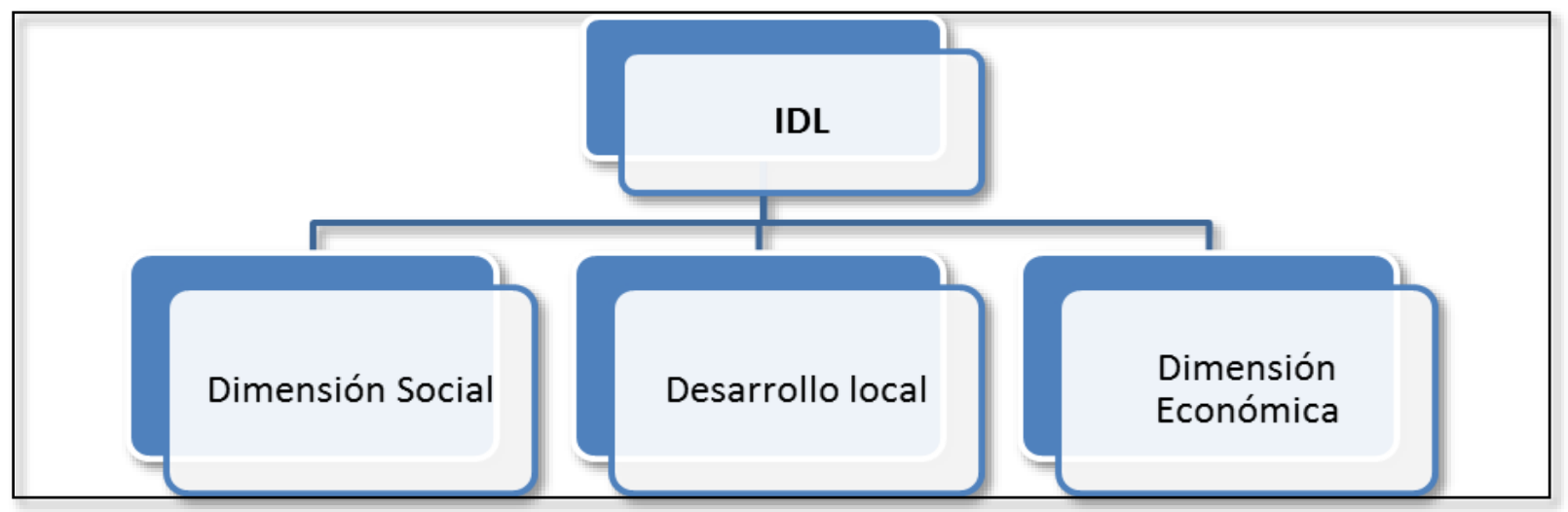

Figura 5. Esquema para el cálculo del Índice de Confianza. Fuente: Elaboración propia.

$$
\boldsymbol{I C M}=(\text { I.D.Social })+(\text { I.D. Local })+(\text { I.D.Económica })
$$

\section{Índice de Confianza Municipal}

Se obtienen las siguientes medidas resumen de los índices calculados: 
Tabla 8.

Cálculo del ponderado de índice general

\begin{tabular}{|c|c|c|c|c|}
\hline Dimensiones & $\mathrm{N}$ & Mínimo & Máximo & Media \\
\hline Índice desarrollo social & 23 & 3,13 & 8,33 & 5,6206 \\
\hline Índice económico & 23 & 3 & 7,71 & 5,1102 \\
\hline Índice desarrollo institucional & 23 & 2,05 & 10 & 5,6132 \\
\hline \multicolumn{2}{|c|}{ Índice General } & 3,24 & 8,35 & 5,763 \\
\hline
\end{tabular}

Fuente: Cálculo propio

En términos generales, todos los índices arrogan resultados intermedios o buenos, con un promedio en el índice de confianza de 5,7630, indicando que la percepción general de los encuestados es medianamente deseable (denominación del nuevo criterio). Dicho de otra forma, que en una escala de 1 a 10, la situación de desarrollo local (combinación de variables y dimensiones), es aceptable (buena en escala original) para el municipio de Nariño, Cundinamarca, en la opinión del promedio de los encuestados, personas que ostentan la representación de los diferentes sectores que inciden en el desarrollo del municipio.

Si nuevamente se re-escala a los valores originales para asociarlos y ubicarlos bajo el resultado cualitativo de percepción (escala inicial de valores), se tiene como resultado final, que el índice hallado, está ubicado en la tercera valoración (bueno), indicando que la percepción de confianza es "bueno" para el consolidado total.
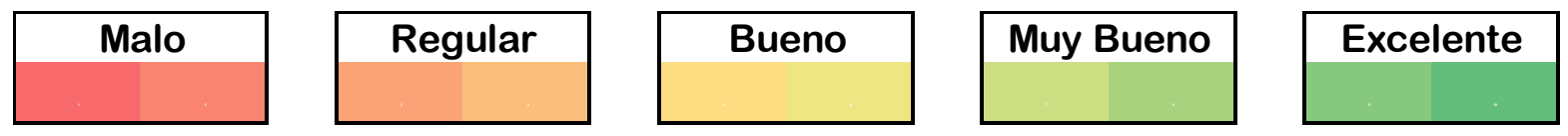
Ajustado a lo anterior, el resultado final $(5,76)$ indica que el Índice de Confianza Municipal hallado, instintivamente infiere que la percepción que tienen los pobladores sobre el estado del desarrollo local para el municipio de Nariño - Cundinamarca es bueno (valoración media).

Por tratarse de una percepción, la medida que arroja el Índice de Confianza Municipal no establece el significado que puede representar para cada habitante del municipio, el valor resultante; es decir, para el caso de Nariño - Cundinamarca el resultado de "Bueno" puede tener muchos significados, entendiendo que para diferentes habitantes, el estado de desarrollo local, puede oscilar entre conforme, adecuado o insuficiente; o en otra perspectiva con posibilidad de comparación, este resultado puede oscilar entre, el desarrollo local del municipio está mejorando, es igual o está empeorando.

Lo que sí es posible interpretar, es que el resultado de "bueno" obtenido para el promedio de las dimensiones del desarrollo social, económico e institucional deben mejorar o seguir avanzando, dado que al compararlo con las últimas cifras oficiales del DANE al 2005 (citados en el capítulo 1), el índice de pobreza multidimensional (IPM) calculado era del $68 \%$, y el porcentaje de población con necesidades básicas insatisfechas (NBI) del 43,9\%; situación que posiblemente haya mejorado en los últimos 10 años.

Para el desarrollo del siguiente capítulo, se toma como insumo el resultado del índice (ICM) y de cada dimensión, para relacionar (confrontar) con el desempeño ${ }^{25}$ de cada variable alcanzado en la encuesta; el resultado del análisis ayuda a la identificación de prioridades de intervención como factor para estimar determinantes que conduzcan a una posible implementación de procesos de desarrollo económico local. Dicho de otra manera, hay menor posibilidad de intervenir, cuando el estado de percepción se encuentra en el estado menos deseable, o viceversa.

\footnotetext{
${ }^{25}$ El desempeño de cada variable es el resultado obtenido en la encuesta; para ello, se toma el valor promedio (porcentaje) consolidado del promedio simple en porcentaje.
} 


\section{Determinantes Socioeconómicos e Institucionales para el Desarrollo Económico Local}

\section{Bases Teóricas de los Determinantes del Desarrollo Local}

El presente capítulo propone la identificación de los principales determinantes que faciliten condiciones para la implementación de procesos de desarrollo económico local, asociados a un municipio pequeño (categoría sexta en Colombia) caracterizado por la dependencia económica e institucional para generar procesos autónomos de desarrollo local.

Aunque existen importantes teorías, trabajos y antecedentes que aproximan la identificación de los determinantes que limitan o fortalecen a un territorio para alcanzar un mejor desarrollo local; sin embargo, estos no son suficientes para asegurar la mejor fórmula que garantice acertados procesos de intervención, o de lo contrario ya se tendrían superados los problemas de bajo desarrollo en la comunidades más vulnerables, independiente de las características del territorio en términos de tamaño de población y nivel de ingresos (aspectos de tipificación municipal).

Para hacer el planteamiento en la identificación de los determinantes objeto del presente trabajo, se parte del aspecto teórico (señalados en el primer capítulo de este documento), los cuales son necesarios para sustentar los insumos propuestos y desarrollados como propuesta técnica (definición de un índice de percepción), este último como referente para construcción de una alternativa metodológica, para establecer condiciones previas de intervención bajo el enfoque del desarrollo económico local.

Como elementos teóricos de referencia sobre el accionar y alcance del desarrollo económico local -que a criterio propio- resumen de forma muy práctica los aspectos fundamentales para la política del desarrollo local son; por un lado Francisco Alburquerque con la presentación de los elementos básicos necesarios para la implementación de iniciativas de desarrollo económico 
local, apoyado en principio por la definición de J. A. Ábalos (2000), quien indica que "una iniciativa de desarrollo económico local no es únicamente un proyecto exitoso en un territorio. Se requiere una concertación institucionalizada de los actores públicos y privados locales más relevantes con una estrategia de desarrollo común" (Alburquerque, 2004), para Alburquerque los ocho elementos básicos o pilares fundamentales corresponden en su orden a:

Movilización y participación de actores locales; actitud proactiva del gobierno local; la existencia de equipos de liderazgo local; la cooperación público-privada; elaboración de una estrategia territorial de desarrollo; fomento de microempresas y pyme y capacitación de recursos humanos; coordinación de programas e instrumentos de fomento; y por último, institucionalidad para el desarrollo económico local (Alburquerque, 2004).

Estos elementos registran un factor común relacionado con la adopción y articulación de iniciativas locales, involucrando a los agentes gestores y promotores del desarrollo, la suma de esto, propicia por sí mismo un escenario coordinado de movilidad social, económica e institucional, que en teoría son los insumos para abordar las problemáticas por lo menos del entorno local.

Por otro lado Vásquez Barquero (2000), identifica seis fortalezas y seis limitaciones de la política de desarrollo económico local Por el lado de las fortalezas describe: "los procesos de ajuste productivo; mejoramiento de la productividad y competitividad; gestión del empleo y las innovaciones; utilización del potencial de desarrollo territorial; impulso al control local del desarrollo; y dinamización de los procesos de descentralización” (Vásquez Barquero, 2000); aspectos que están directamente relacionados con la dimensión económica, que impulsa intereses en los actores (independiente de lo equitativos que sean), pero fundamentales para incentivar procesos de acumulación de beneficios individuales y/o colectivos. Y por el lado de las limitaciones señala: 
(...) la inexistencia de un marco legal adecuado; autonomía reducida de la acción local; insuficiencia de recursos humanos adecuados para la gestión local; falta de masa crítica en las unidades territoriales (institucionalidad); coordinación insuficiente entre los actores; y reparto del poder entre los niveles administrativos (Vásquez Barquero, 2000); aspectos que hacen mayor énfasis a la falta de capacidad de gestión que incide en la dimensión institucional.

\section{Determinantes Endógenos para el Desarrollo Económico Local}

Con la identificación de los elementos básicos o prioritarios fundamentales para la implementación de iniciativas de desarrollo local, se deriva el primer elemento determinante, el cual es fue percibido y señalado durante el levantamiento de información por líderes y representantes de sectores sociales, económico e institucional en el municipio de trabajo; quienes señalan que la movilidad o visibilidad de las iniciativas que se generan en los agentes locales, es limitada y carece de plena autonomía, asumiéndose lineamientos nacionales o regionales, que condicionan la propuesta local; de tal manera que, un primer determinante es la promoción de iniciativas entre los $\underline{\text { agentes, }}$ entendida como las acciones que impulsan los pobladores dentro del marco legal, con la apropiación de los recursos físicos y el reconocimiento de las ventajas comparativas del territorio, logrando la definición y el diseño de planes, programas y proyectos que apunten a resolver las necesidades locales.

Para hacer efectiva la promoción de iniciativas, es necesario la identificación de los actores locales, con el compromiso articulador de las iniciativas con propósitos comunes; por tanto, un segundo determinante es la participación coordinada de los agentes sociales, económicos e inclusive políticos, y con ellos sus representantes, que son el soporte de cohesión de los determinantes que hacen posibles los procesos de desarrollo económico local, movilizando los procesos de gestión e implementación de las iniciativas locales de desarrollo. Por ende, los elementos básicos a que referencia Alburquerque (2004), toman fuerza desde la perspectiva del 
individuo, identificando en él y en ellos (agentes) el común denominador para promover y articular una adecuada o conveniente política de desarrollo local.

Teóricamente, este determinante lo plantea de manera indirecta el profesor Mario D. Tello (2006) quien identifica agentes (en el enfoque institucional, que está liderado por individuos), quienes inciden en los procesos de desarrollo local, como son:

(...) las empresas capitalistas y los entes que las representan; unidades productivas no capitalistas y entes que las representan; capital social y los entes que lo representan; los diversos estamentos del Estado (gobiernos central, regional y local) y los entes que los representan; las universidades y centros de investigación (privados y estatales) y los entes que los representan; el resto de instituciones, agentes y entes no incorporados en los agentes anteriores (Tello, 2006).

Estos agentes presentan el mismo común denominador de los elementos básicos identificados por Alburquerque, centrando el recurso humano como el principal actor integrador. En consecuencia hace sentido, ubicar la perspectiva de los líderes y representantes como el insumo principal del trabajo para establecer los determinantes que hagan posible la implementación de acciones de desarrollo económico local en el contexto propio de cada municipio.

Ahora bien, separando al sujeto del componente institucional, se identifica la importancia del rol del individuo con él mismo y su comunidad frente a las dimensiones del desarrollo, para ello, la definición que cita Carlos Zorro $^{26}$ en el documento El desarrollo: perspectivas y dimensiones. Aportes interdisciplinarios (2007) - artículo "Entorno humano y desarrollo económico local", considera que las dimensiones del desarrollo son "las distintas facetas individuales, sociales y de contexto, que permiten aproximarse a su integralidad y, eventualmente, contribuir a orientar su evolución futura” (Zorro Sánchez, 2007). Y con ella los elementos que

\footnotetext{
${ }^{26}$ Profesor del CIDER, Universidad de los Andes
} 
explican esta definición, incorpora, "atributos individuales del ser humano; las relaciones de los seres humanos entre sí y con otros seres; los ámbitos de ejercicio de los atributos y relaciones; y la orientación y los criterios que presiden ese ejercicio" (Zorro Sánchez, 2007). Esta definición y los elementos que la conforman, no difiere del enfoque del trabajo, por el contrario enfatiza en la percepción del individuo para hacer posible su propio desarrollo y de quienes lo rodean. Por tanto, las dimensiones del desarrollo social, económico e institucional están condicionadas esencialmente a la capacidad que tiene los individuos para interactuar socialmente a partir de las motivaciones de interés personal (componente cultural), más allá de los recursos físicos y legales que posea.

De este modo, los procesos de desarrollo local y en especial los que generan el desarrollo económico local, está directamente relacionado con la gestión del interés individual del agente con causa común, siendo el tercer determinante que moviliza positiva o negativamente a una comunidad, con el propósito de alcanzar el denominado Desarrollo Comunitario, citado el profesor Carvajal (2009), como "una acción coordinada y sistemática que, en respuesta a las necesidades o a la demanda social, trata de organizar el progreso global de una comunidad territorial bien delimitada o de una población-objetivo, con la participación de los interesados” (Rezsohazy, citado en Zárate, 2007, citado por Carvajal Burbano, 2009).

Igualmente en el mismo documento enfatiza un elemento que aplica plenamente al determinante "interés individual con causa común” que deriva del sujeto (agente), indicando que:

El Desarrollo Comunitario prioriza como eje fundamental de su quehacer el desarrollo de los sujetos a partir de su participación activa en procesos que, si bien tiene por objeto ofrecer herramientas para satisfacer necesidades, ello no puede ser posible sin la corresponsabilidad de los sujetos en sus propios procesos, partiendo de su dinámica particular y de sus recursos personales 
para potencializar acciones que conduzcan al crecimiento y desarrollo (Zárate, 2007:197-199, citado por Carvajal Burbano, 2009).

En consecuencia como está registrado en el primer capítulo, que el elemento endógeno en los procesos de desarrollo local, es un mecanismo para fomentar las capacidades internas de una localidad desde adentro.

Por tanto cobra mayor sentido, la identificación hasta ahora de los tres determinantes (participación de los agentes, promoción de iniciativas entre los agentes, y gestión del interés individual del agente con causa común), que desde la perspectiva de Sergio Boisier (2004) el desarrollo endógeno sirve

(...) para generar en un territorio dado las condiciones de entorno que le permiten a los seres humanos potenciarse a sí mismos para llegar a ser verdaderas personas humanas, porque, hay que entenderlo de una vez, el desarrollo no lo hace nadie sino las personas en su individualidad y en su sociabilidad. Ni el Estado, ni el capital, ni el sector privado, ni el público, pueden producir el desarrollo de las personas; sólo pueden crear las condiciones de entorno (Boisier, 2004).

En síntesis, como se observa en la Gráfica 6, al asociar los determinantes con las dimensiones de desarrollo definidas en el trabajo, presentan sentido al identificar que el nivel avance o desarrollo de cada dimensión está determinado por el nivel de movilidad de los actores y agentes, entendido por la vinculación a los procesos (participación), decisión en lograr propósitos (gestión), y reconocimiento en las acciones (promoción). 


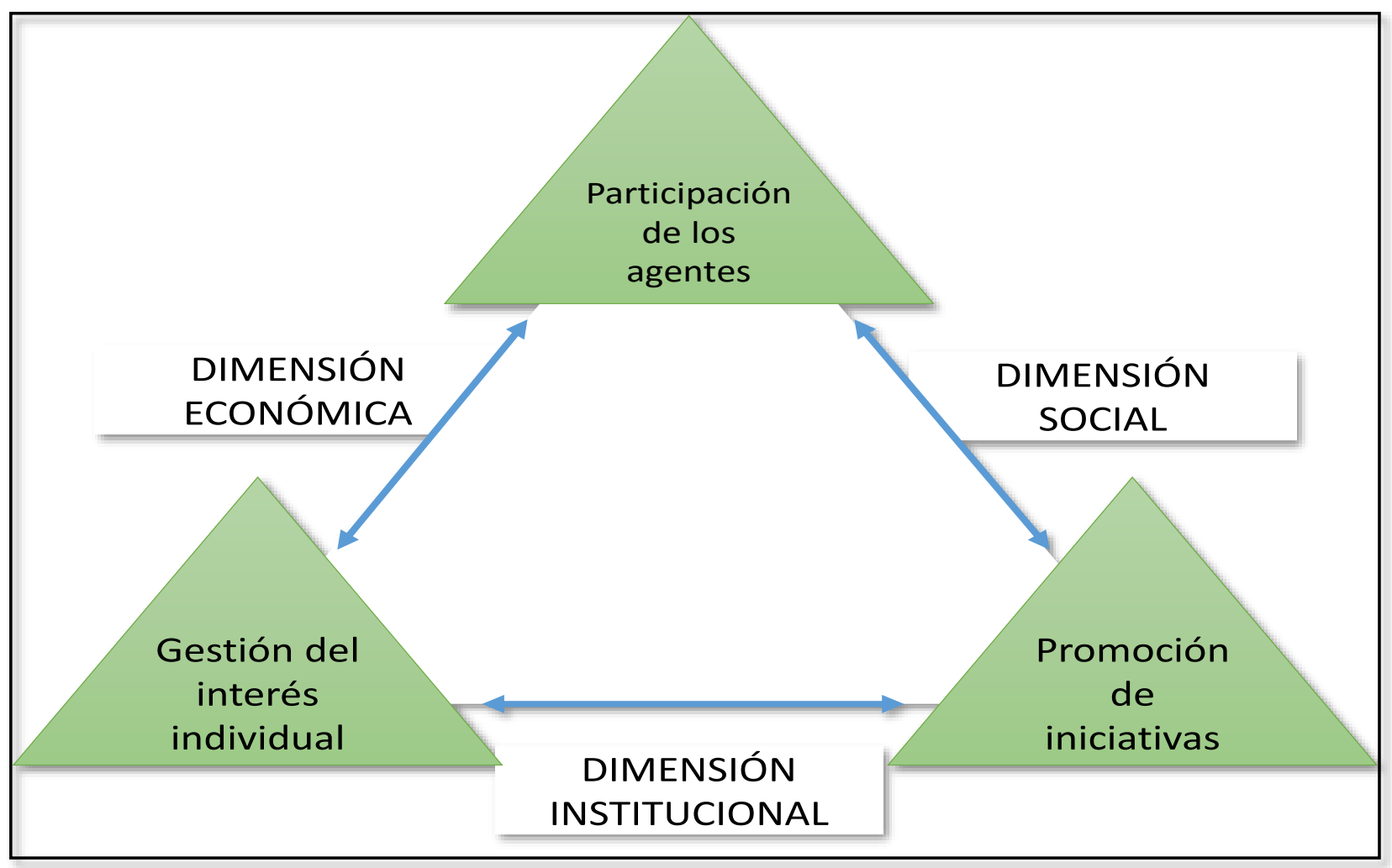

Gráfica 6. Determinantes y dimensiones del desarrollo local. Fuente: Elaboración propia.

\section{Incidencia de Variables en el Desarrollo Económico Local}

Con tres componentes desarrollados hasta ahora, como son, los resultados analizados en la encuesta de percepción (caracterización), presentación de las bases y referencias teóricas para identificar determinantes, y cálculo del índice de confianza; se presentan a continuación los aspectos de incidencia para la oportuna implementación de procesos de desarrollo económico local en el municipio de Nariño, Cundinamarca, basados en las percepciones registradas por los líderes y representantes en cada uno de los sectores sociales, económico e institucionales (dimensiones de desarrollo priorizadas en el presente trabajo).

La propuesta de identificación de las principales variables con incidencia en el desarrollo local para el municipio en estudio, consiste primero tomar el valor de cada una de las variables por 
dimensión como se indica en la Tabla 9, y de forma conjunta se grafican en un plano cartesiano ${ }^{27}$; posteriormente, sobre el plano se demarca el resultado del Índice de Confianza Municipal (Bueno); igualmente se señalan las otras escalas de valoración, para ubicar en qué lugar se concentran los resultados.

Por otro lado, se calcula la participación que tiene cada variable por dimensión, como se muestra en la Tabla 9; de manera práctica, se emplea para evidenciar qué tan importante es la variable para la dimensión, frente a la valoración obtenida (percepción que tienen los encuestados, sobre el estado actual de la variable). Al repetir este ejercicio por grupo de factores, se puede establecer las prioridades de intervención por dimensión, teniendo en cuenta los determinantes propuestos en la sección anterior.

\section{Tabla 9.}

Valoración del desempeño por variable

\footnotetext{
${ }^{27}$ En el plano cartesiano se ubican los valores con el desempeño por variable. En el eje de las abscisas la valoración,
} y en el eje de las ordenadas la escala en porcentaje. 


\begin{tabular}{|c|c|c|c|c|c|c|c|c|c|c|c|}
\hline \multirow[b]{2}{*}{ Desempeño } & \multicolumn{11}{|c|}{ DIMENSIÓN SOCIAL } \\
\hline & Salud & Educación & Vivienda & \begin{tabular}{|c|} 
Servicios \\
domiciliario \\
$\mathrm{s}$
\end{tabular} & $\begin{array}{l}\text { Atención a } \\
\text { la Juventud }\end{array}$ & $\begin{array}{c}\text { Protección a } \\
\text { la niñez }\end{array}$ & $\begin{array}{c}\text { Protección a } \\
\text { la tercera } \\
\text { edad }\end{array}$ & $\begin{array}{l}\text { Respeto a } \\
\text { derechos } \\
\text { humanos }\end{array}$ & Seguridad & $\begin{array}{c}\text { Fomento de } \\
\text { la cultura }\end{array}$ & GENERAL \\
\hline 0 - No sabe & $0 \%$ & $4 \%$ & $0 \%$ & $0 \%$ & $0 \%$ & $0 \%$ & $0 \%$ & $0 \%$ & $0 \%$ & $4 \%$ & $0 \%$ \\
\hline 1 - Malo & $4 \%$ & $0 \%$ & $9 \%$ & $4 \%$ & $4 \%$ & $0 \%$ & $9 \%$ & $4 \%$ & $0 \%$ & $0 \%$ & $0 \%$ \\
\hline 2 - Regular & $39 \%$ & $26 \%$ & $26 \%$ & $22 \%$ & $30 \%$ & $13 \%$ & $26 \%$ & $48 \%$ & $30 \%$ & $74 \%$ & $22 \%$ \\
\hline 3 - Bueno & $43 \%$ & $57 \%$ & $48 \%$ & $57 \%$ & $39 \%$ & $61 \%$ & $57 \%$ & $35 \%$ & $43 \%$ & $9 \%$ & $65 \%$ \\
\hline 4 - Muy Bueno & $4 \%$ & $13 \%$ & $13 \%$ & $13 \%$ & $17 \%$ & $13 \%$ & $0 \%$ & $4 \%$ & $13 \%$ & $4 \%$ & $13 \%$ \\
\hline 5 - Excelente & $9 \%$ & $0 \%$ & $4 \%$ & $4 \%$ & $9 \%$ & $13 \%$ & $9 \%$ & $9 \%$ & $13 \%$ & $9 \%$ & $0 \%$ \\
\hline Total & $100 \%$ & $100 \%$ & $100 \%$ & $100 \%$ & $100 \%$ & $100 \%$ & $100 \%$ & $100 \%$ & $100 \%$ & $100 \%$ & $100 \%$ \\
\hline \multirow[b]{2}{*}{ Desempeño } & \multicolumn{11}{|c|}{ DIMENSIÓN ECONÓMICA } \\
\hline & $\begin{array}{c}\text { Oportunidad } \\
\text { a los } \\
\text { negocios }\end{array}$ & $\begin{array}{l}\text { Incentivo a } \\
\text { la Inversión }\end{array}$ & $\begin{array}{c}\text { Alternativas } \\
\text { de Empleo }\end{array}$ & $\begin{array}{c}\text { Niveles de } \\
\text { Ingresos }\end{array}$ & \begin{tabular}{|c|} 
Organizació \\
$\mathrm{n}$ del \\
Comercio
\end{tabular} & $\begin{array}{l}\text { Oferta } \\
\text { turística }\end{array}$ & $\begin{array}{c}\text { Calidad de } \\
\text { la } \\
\text { producción }\end{array}$ & \begin{tabular}{|c|}
$\begin{array}{c}\text { Diversidad } \\
\text { de la oferta } \\
\text { Pcc }\end{array}$ \\
\end{tabular} & $\begin{array}{c}\text { Estado de la } \\
\text { Infraestructu } \\
\text { ra }\end{array}$ & $\begin{array}{c}\text { Apoyo a la } \\
\text { asociativida } \\
\mathrm{d}\end{array}$ & GENERAL \\
\hline 0 - No sabe & $4 \%$ & $9 \%$ & $0 \%$ & $0 \%$ & $0 \%$ & $0 \%$ & $13 \%$ & $13 \%$ & $4 \%$ & $9 \%$ & $0 \%$ \\
\hline 1 - Malo & $0 \%$ & $4 \%$ & $4 \%$ & $0 \%$ & $0 \%$ & $4 \%$ & $0 \%$ & $4 \%$ & $4 \%$ & $13 \%$ & $4 \%$ \\
\hline 2 - Regular & $26 \%$ & $30 \%$ & $48 \%$ & $65 \%$ & $17 \%$ & $74 \%$ & $39 \%$ & $48 \%$ & $26 \%$ & $35 \%$ & $35 \%$ \\
\hline 3 - Bueno & $52 \%$ & $39 \%$ & $43 \%$ & $30 \%$ & $78 \%$ & $17 \%$ & $26 \%$ & $17 \%$ & $30 \%$ & $35 \%$ & $61 \%$ \\
\hline 4 - Muy Bueno & $9 \%$ & $4 \%$ & $0 \%$ & $4 \%$ & $0 \%$ & $4 \%$ & $17 \%$ & $17 \%$ & $30 \%$ & $4 \%$ & $0 \%$ \\
\hline 5 - Excelente & $9 \%$ & $13 \%$ & $4 \%$ & $0 \%$ & $4 \%$ & $0 \%$ & $4 \%$ & $0 \%$ & $4 \%$ & $4 \%$ & $0 \%$ \\
\hline Total & $100 \%$ & $100 \%$ & $100 \%$ & $100 \%$ & $100 \%$ & $100 \%$ & $100 \%$ & $100 \%$ & $100 \%$ & $100 \%$ & $100 \%$ \\
\hline
\end{tabular}

Tabla 9. (Continuación).

Valoración del desempeño por variable

\begin{tabular}{|l|c|c|c|c|c|c|c|c|}
\hline \multirow{2}{*}{ Desempeño } & \multicolumn{9}{|c|}{ DIMENSí́n INSTITUCIONAL } \\
\cline { 2 - 10 } & $\begin{array}{c}\text { Gestión } \\
\text { institucional }\end{array}$ & $\begin{array}{c}\text { Apoyo a los } \\
\text { productores }\end{array}$ & $\begin{array}{c}\text { Protección a los } \\
\text { vulnerables }\end{array}$ & $\begin{array}{c}\text { Liderazgo } \\
\text { regional }\end{array}$ & $\begin{array}{c}\text { Prestación de } \\
\text { los servicios }\end{array}$ & $\begin{array}{c}\text { Manejo de la } \\
\text { economía }\end{array}$ & $\begin{array}{c}\text { Relación con las } \\
\text { JAC }\end{array}$ & \begin{tabular}{c} 
GENERAL \\
\hline 0 - No sabe
\end{tabular} \\
\hline 1 - Malo & $4 \%$ & $13 \%$ & $0 \%$ & $17 \%$ & $0 \%$ & $9 \%$ & $17 \%$ & $0 \%$ \\
\hline 2 - Regular & $9 \%$ & $13 \%$ & $17 \%$ & $17 \%$ & $17 \%$ & $26 \%$ & $17 \%$ & $30 \%$ \\
\hline 3 - Bueno & $52 \%$ & $48 \%$ & $52 \%$ & $30 \%$ & $35 \%$ & $43 \%$ & $43 \%$ & $52 \%$ \\
\hline 4 - Muy Bueno & $22 \%$ & $9 \%$ & $17 \%$ & $26 \%$ & $22 \%$ & $9 \%$ & $4 \%$ & $13 \%$ \\
\hline 5 - Excelente & $9 \%$ & $13 \%$ & $9 \%$ & $9 \%$ & $4 \%$ & $9 \%$ & $13 \%$ & $4 \%$ \\
\hline Total & $100 \%$ & $100 \%$ & $100 \%$ & $100 \%$ & $100 \%$ & $100 \%$ & $100 \%$ & $100 \%$ \\
\hline
\end{tabular}

Fuente: Cálculo propio

Tabla 10.

Porcentaje de participación de cada variable por dimensión 


\begin{tabular}{|c|c|c|c|}
\hline \multicolumn{4}{|c|}{ DIMENSIÓN SOCIAL } \\
\hline Variable & \multicolumn{2}{|c|}{$\begin{array}{c}\text { Factor } \\
\text { Ponderado }\end{array}$} & $\begin{array}{c}\text { Peso } \\
\text { Variable }\end{array}$ \\
\hline Salud & $35 \%$ & \multirow{3}{*}{$38 \%$} & $13 \%$ \\
\hline Educación & $31 \%$ & & $12 \%$ \\
\hline Vivienda & $34 \%$ & & $13 \%$ \\
\hline Servicios Domicialiarios & $15 \%$ & \multirow{6}{*}{$50 \%$} & $8 \%$ \\
\hline Fomento a la cultura & $14 \%$ & & $7 \%$ \\
\hline Protección Tercera edad & $14 \%$ & & $7 \%$ \\
\hline Protección a la Niñez & $14 \%$ & & $7 \%$ \\
\hline Seguridad & $14 \%$ & & $7 \%$ \\
\hline Atención a la juventud & $14 \%$ & & $7 \%$ \\
\hline $\begin{array}{l}\text { Respecto a los derechos } \\
\text { humanos }\end{array}$ & $100 \%$ & $12 \%$ & $12 \%$ \\
\hline General & \multicolumn{2}{|c|}{$15 \%$} & $8 \%$ \\
\hline
\end{tabular}

\begin{tabular}{|c|c|c|c|c|c|c|c|}
\hline \multicolumn{4}{|c|}{ DIMENSIÓN ECONÓMICA } & \multicolumn{4}{|c|}{ DIMENSIÓN INSTITUCIONAL } \\
\hline Variable & \multicolumn{2}{|c|}{$\begin{array}{c}\text { Factor } \\
\text { Ponderado }\end{array}$} & $\begin{array}{c}\text { Peso } \\
\text { variable }\end{array}$ & Variable & \multicolumn{2}{|c|}{$\begin{array}{c}\text { Factor } \\
\text { Ponderado }\end{array}$} & $\begin{array}{c}\text { Peso } \\
\text { variable }\end{array}$ \\
\hline Apoyo a la asociatividad & $22 \%$ & \multirow{5}{*}{$40 \%$} & $9 \%$ & Relación con las JAC & $17 \%$ & \multirow{5}{*}{$71 \%$} & $12 \%$ \\
\hline Oferta turística & $21 \%$ & & $8 \%$ & Manejo de la economía & $17 \%$ & & $12 \%$ \\
\hline Diversidad de oferta & $17 \%$ & & $7 \%$ & Apoyo a productores & $17 \%$ & & $12 \%$ \\
\hline $\begin{array}{l}\text { Calidad de la } \\
\text { producción }\end{array}$ & $23 \%$ & & $9 \%$ & Gestión Intitucional & $16 \%$ & & $11 \%$ \\
\hline $\begin{array}{l}\text { Oportunidad de } \\
\text { negocios }\end{array}$ & $18 \%$ & & $7 \%$ & Liderazgo regional & $15 \%$ & & $11 \%$ \\
\hline Incentivo a la inversión & $34 \%$ & \multirow[b]{2}{*}{$26 \%$} & $9 \%$ & Protección vulnerables & $50 \%$ & \multirow[b]{2}{*}{$29 \%$} & $15 \%$ \\
\hline $\begin{array}{l}\text { Estado de } \\
\text { infraestructura }\end{array}$ & $33 \%$ & & $9 \%$ & Prestación de servicios & $50 \%$ & & $15 \%$ \\
\hline Nivel de ingresos & $50 \%$ & \multirow{2}{*}{$22 \%$} & $11 \%$ & General & \multicolumn{2}{|c|}{$18 \%$} & $13 \%$ \\
\hline Alternativas de empleo & $50 \%$ & & $11 \%$ & & & & \\
\hline $\begin{array}{l}\text { Organización del } \\
\text { comercio }\end{array}$ & $100 \%$ & $12 \%$ & $12 \%$ & & & & \\
\hline General & \multicolumn{2}{|c|}{$33 \%$} & $9 \%$ & & & & \\
\hline
\end{tabular}

Fuente: Cálculo propio.

El análisis de todas las variables y dimensiones, se efectúa a partir del Índice de Confianza Municipal; por tanto, de acuerdo con la percepción que tienen los pobladores del municipio de Nariño, Cundinamarca, el estado actual de desarrollo local es “bueno”, y por ende, la identificación de variables se realiza con el supuesto de sostener o mejorar las condiciones actuales de cada variable en cuestión. Al respecto, la situación de cada dimensión y las incidencias en el desarrollo es el siguiente:

Dimensión Social. Como se observa en la Gráfica 7, las variables en la dimensión social con desempeño por encima del resultado del índice de confianza "bueno", es decir entre muy bueno o excelente ${ }^{28}$, es muy bajo, con resultados máximo del $17 \%$ y $13 \%$ respectivamente. Únicamente se presenta situación favorable por encima de la media (bueno), son las variables de protección de los niños y de la tercera edad.

\footnotetext{
${ }^{28}$ La escala inicial de valores corresponde a 0-No sabe, 1-Malo, 2-Regular, 3-Bueno, 4-Muy Bueno y 5-Excelente; sin embargo, únicamente por diseño de gráfico los valores asignados por el aplicativo inicia desde 1. Por tanto, los valores de los gráficos corresponde a: 1-No sabe, 2-Malo, 3-Regular, 4-Bueno, 5-Muy Bueno y 6-Excelente.
} 
Por otro lado, el mayor número de variables conservan la tendencia, o por lo menos se aproxima al ICM, quedando en una situación de favorabilidad o de aceptación, quedando concentrado el estado de la dimensión entre regular y buena.

Desde la perspectiva de grupo de factores establecido en el método CATPCA (del inglés Categorical Principal Components Analysis), el grupo de variables con mayor peso para considerar de mayor atención y que requieren medidas para aumentar la percepción del promedio de pobladores, son la salud, la educación y la vivienda; las cuales se ubican con resultados de $83 \%$, $83 \%$ y $74 \%$ respectivamente, si se suman los valores de regular y bueno. Aunque hay otras variables con igual situación, éstas no tienen tanto peso o relación de importancia, por lo cual pertenecen a otro grupo o factor; en consecuencia, es necesario establecer desde los grupos de interés acciones en los temas de salud, educación y vivienda, especialmente el primero por tener un porcentaje superior al $40 \%$ en situación de desfavorable. Es necesario dinamizar la participación de los grupos de personas que trabajan por el sector salud, ya que solamente se identificó un solo comité de la sociedad civil interesado en el tema, considerando que la mayoría de los habitantes reciben servicios de salud desde el municipio vecino Girardot, que cuenta con mejor infraestructura y de atención.

Para esta primera dimensión relacionado con el tema social, es viable la implementación de los determinantes planteados para mejorar el aspecto salud, como son la participación de los actores que afectan el sector salud, la promoción de iniciativas para hacer más eficiente el servicio de salud, y la gestión de intereses que hagan posible conformar grupos de trabajo en beneficio de dicho sector. 


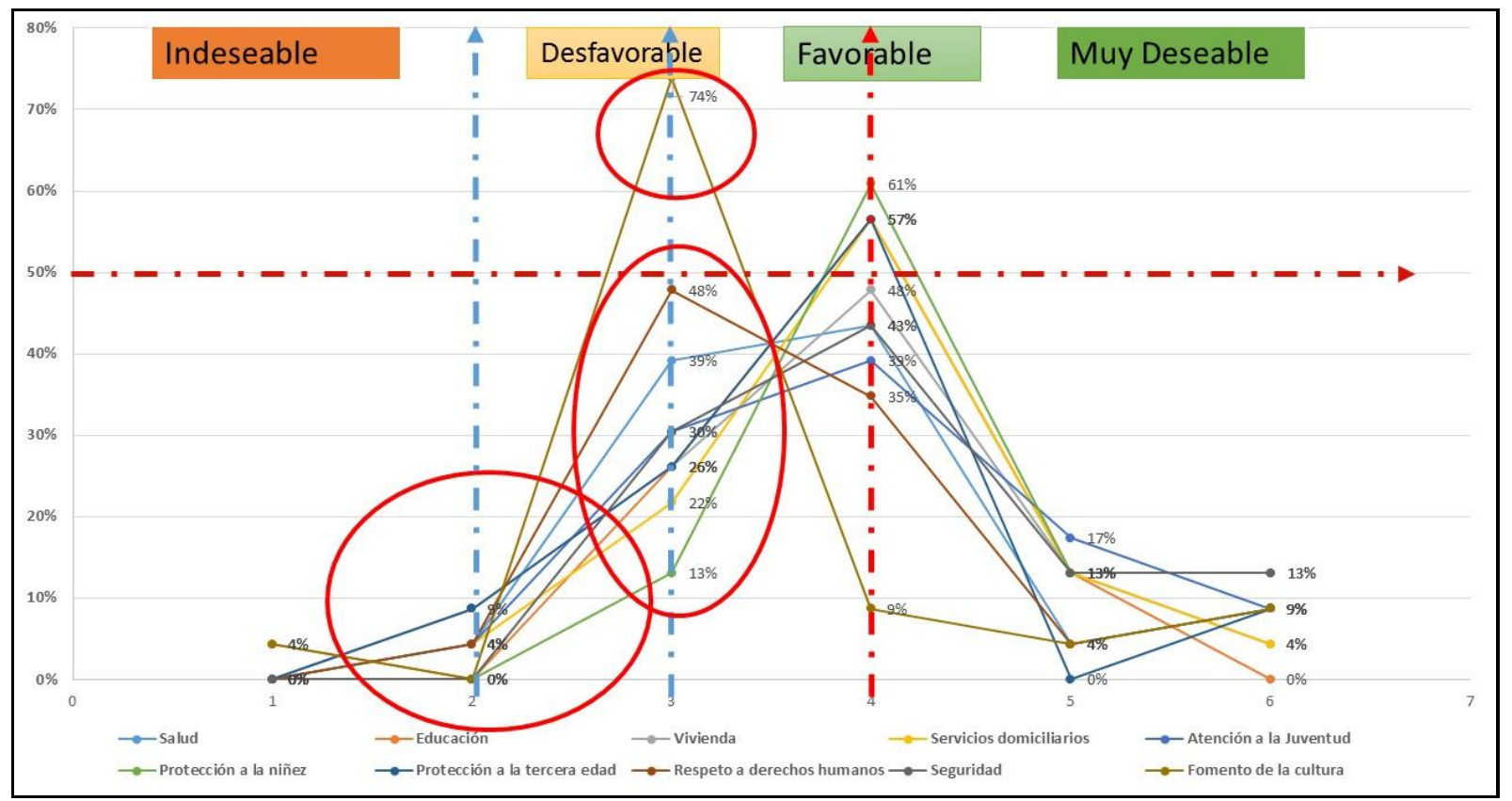

Gráfica 7. Resultados de desempeño de variables Dimensión Social. Fuente: Elaboración propia.

Dimensión Económica. En la dimensión económica las variables que presentan mayor participación son las alternativas de empleo y el nivel de ingresos, con un $11 \%$ cada uno; sin embargo la variable sobre organización de comercio representa el $12 \%$, pero el desempeño de esta variables positiva con un $78 \%$ de favorabilidad, contrario al ingreso y el empleo que se ubican en el $65 \%$ y $52 \%$ (incluyendo el $4 \%$ de valoración como malo) respectivamente en desempeño regular.

En la Gráfica 8 observa como el resultado de "muy deseable" no es muy significativo, que al compararlo con la dimensión social, es más bajo, solamente ubicándose en "muy bueno" la variable de infraestructura con $30 \%$. Lo demás conserva una misma relación de respuestas, concentrándose en el punto medio entre desfavorable y favorable; indicando que la percepción no es muy positiva en esta dimensión, presentando el índice más bajo de las tres dimensiones como se registra en el capítulo anterior (social e institucional 5,6; económico 5,1). 


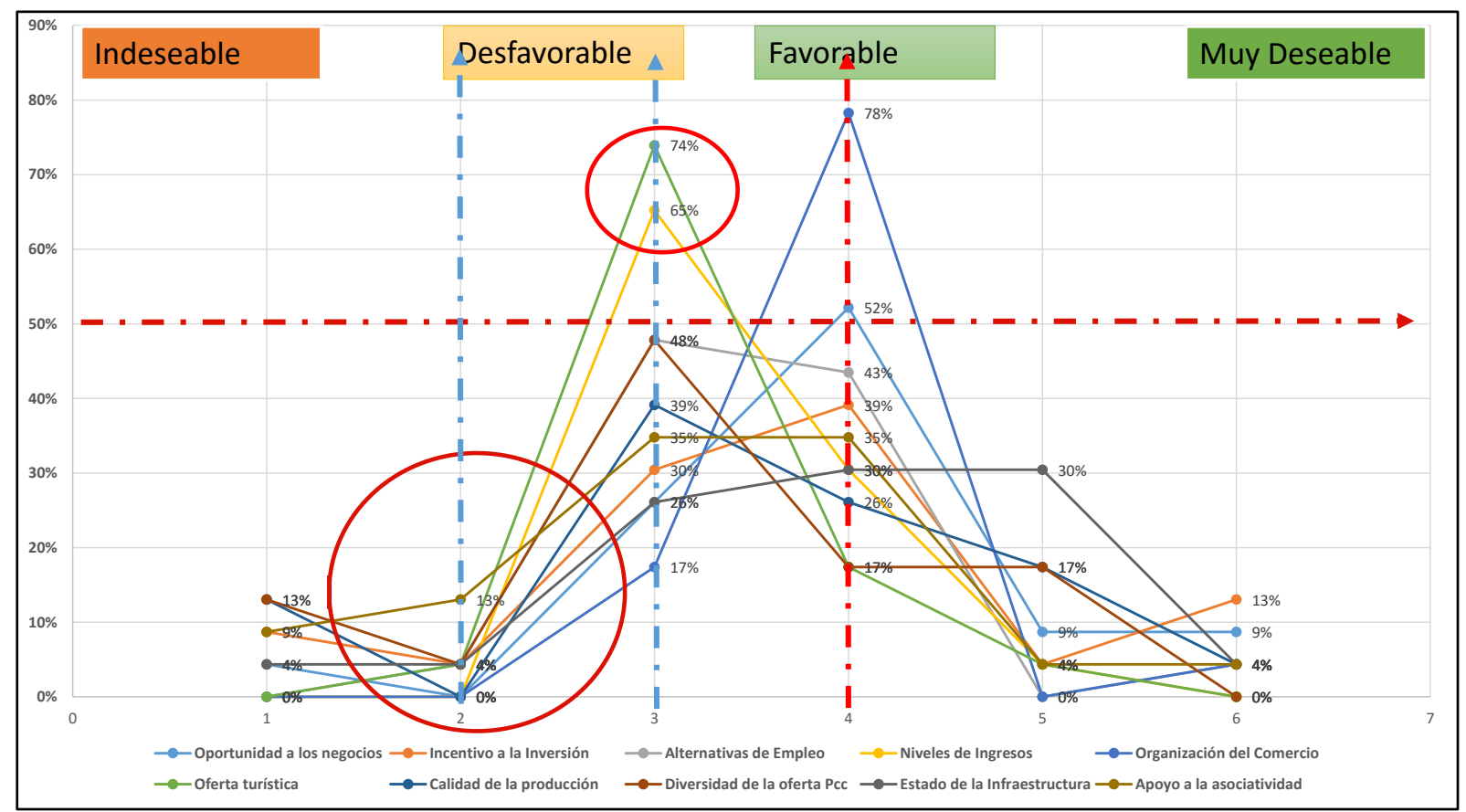

Gráfica 8. Resultados de desempeño de variables Dimensión Económica. Fuente: Elaboración propia.

El resultado de esta dimensión es concordante con el registro presentado en el capítulo de caracterización, donde aparecen cifras de desempleo al 2011 del $50 \%$ y de informalidad en $58 \%$.

En contraste a ello, los encuestados manifiesta que en el municipio si hay alternativas para la inversión y oportunidades para hacer negocios, ubicándose estas variables con un $18 \%$ en el estado muy deseable.

Al escenario anterior, aplica nuevamente los tres determinantes considerando que existen alternativas no exploradas para mejorar las condiciones económicas del municipio pero carece de apoyo por parte de sectores privados y el mismo actor público. Situación evidenciada con la falta de interés para la explotación del sector turismo que es un sector con proyección para el país y las regiones; no hay estructuras organizativas de productores fuertes para competir en otros mercados; y no existe participación de sectores gremiales, gubernamentales o cooperativos que promuevan las iniciativas de tipo productivo, a nivel individual o asociativo. 
Los factores de ubicación, infraestructura, oferta ambiental, no son determinantes para generar desarrollo en el municipio de Nariño, dado que son propios del que hacer y coexistencia de los habitantes; los cuales están presentes como una oportunidad para generar una oferta con ventajas comparativas. El aprovechamiento depende es directamente de la participación de grupos de interés, el apoyo a las iniciativas que se derivan de estos recursos, y del interés por aprovechar las oportunidades claramente existentes en el sector turístico especialmente y sus derivaciones en el campo comercial.

Dimensión Institucional. El estado de desarrollo de la dimensión institucional, a pesar de presentar un nivel de aceptabilidad igual al social y mejor al económico, registra una serie de contrastes en la valoración de desempeño, por ejemplo existe una valoración muy positiva en la gestión institucional, ubicándose entre favorable y muy deseable del $83 \%$, contrario a la relación con las Juntas de Acción Comunas JAC, que desaprueban la gestión con un resultado del 40 \% aproximadamente; pero contrario a ello, el apoyo a los productores es favorable con un $70 \%$.

Por otro lado la gestión con la población más vulnerable del municipio es superior a favorable con un $78 \%$, pero la prestación de los servicios es desaprobada con un $39 \%$. En la Gráfica 14 se observa el registra de dos tendencias, una que ubica la gestión institucional en un estado favorable y muy deseable, pero total mente opuesto, se registra una situación desfavorable y menos deseada. 


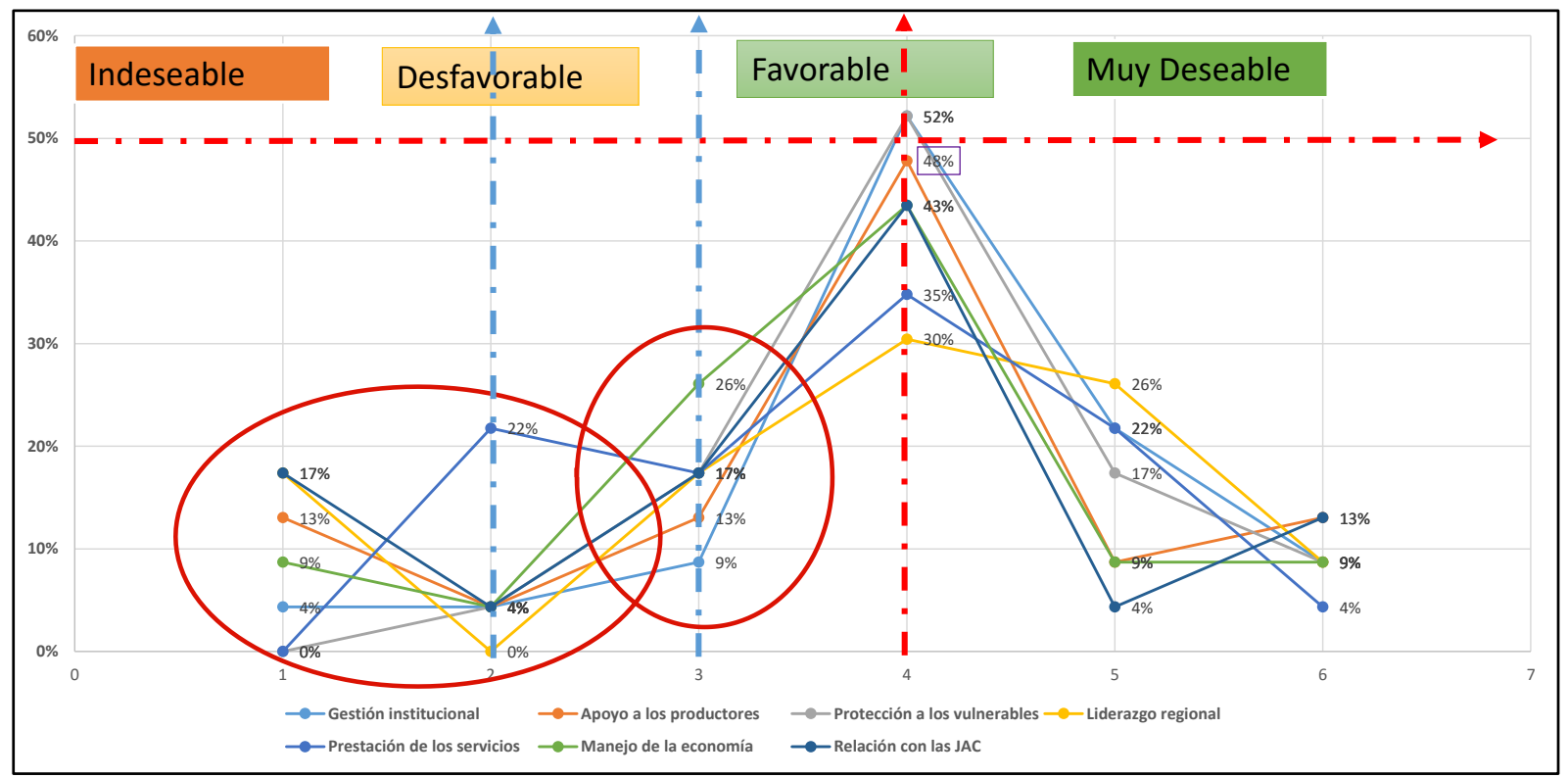

Gráfica 9. Resultados de desempeño de variables Dimensión Institucional. Fuente: Elaboración propia.

En esta dimensión, se presenta el mayor número de respuestas que no responden por desconocimiento del tema o por no dejar opinión en la gestión pública. En este caso las variables con mayor participación son la atención a los vulnerables y la prestación de los servicios; y en menor participación está el liderazgo que se ejerce en la región, que a su vez presenta el mayor número de respuestas de "no sabe"; y también con menor participación, está la gestión institucional. Las restantes variables, como apoyo a los productores y el manejo de la economía, están directamente relacionadas con los aspectos económicos, pero con el enfoque de gestión.

Los determinantes indicados en el trabajo, tienen igual sentido para esta dimensión desde la perspectiva política, ya que es un oficio que no se distancia de las relaciones sociales, económicas y por supuesto de lo institucional; que además son el canal para establecer los escenarios de desarrollo en cada comunidad. Por lo tanto, lo participación de agentes, el apoyo o promoción a las iniciativas de la comunidad, y la gestión de los interés particulares con discurso 
de lo social o colectivo, es vigente y requiere la permanente articulación y gestión con actores externos en temas de política nacional.

Finalmente, se observa en la Gráfica 10 como el desempeño general en cada dimensión se está cerca al índice de percepción o de confianza municipal, logrando un resultado por encima de favorable en el promedio de todas las variables, consolidando de esta manera el cálculo del índice de confianza.

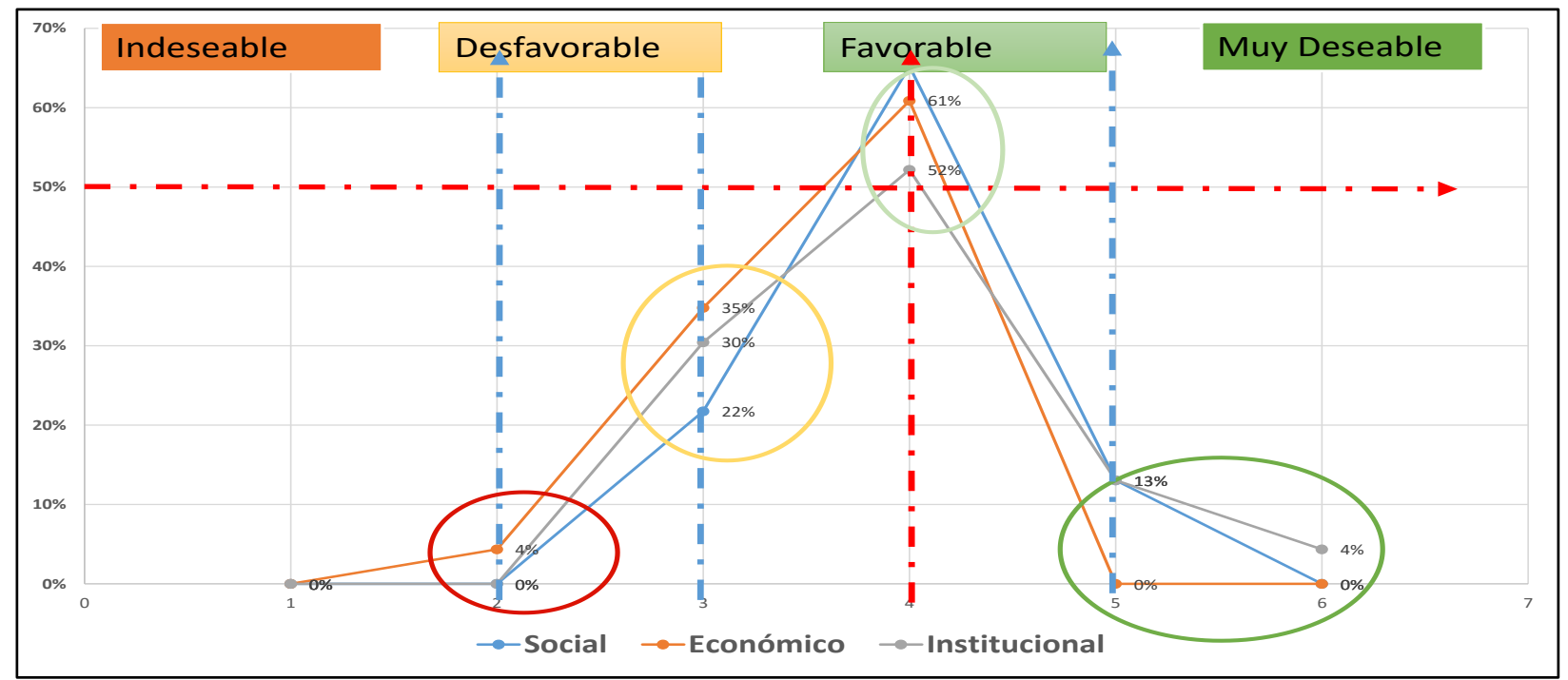

Gráfica 10. Resultados desempeño general por Dimensión. Fuente: Elaboración propia.

\section{Perspectivas que Promueven el Desarrollo Económico Local}

Para desarrollar ésta sección, es importante primero citar para el contexto la hipótesis de Perroux (1983) sobre polos de desarrollo, indicando que:

(...) el crecimiento de una región o área local es determinado por las industrias y firmas de punta u otros actores económicos dominantes en dicha región o área local. Estas industrias, firmas o actores tienen algunas ventajas (tecnológicas, de nivel de riqueza, de influencia política, etc.) que les permiten desarrollarse (Tello, 2006).

Dicho planteamiento afirma que el crecimiento de una región está "determinado" por la industria y otros actores económicos, sin presentar otro tipo de consideraciones o determinantes 
que incidan en el crecimiento; por la cual, si ésta fuese la única condición, las poblaciones (municipios) tipificadas en sexta categoría, estarán condicionadas a crecer, solo si, existe un nivel de desarrollo de industria por procesos internos o por firmas representativas que se ubiquen en la región.

Desarrollar industria en comunidades pequeñas, con vocación tradicional en el sector primario sin valor agregado y bajos niveles de competitividad, con rezago tecnológico y poco aprovechamiento de los recursos naturales, físicos y humanos, requieren de un proceso de preparación y adaptación complejo, costoso y duradero. Razón por la cual emprender procesos de desarrollo económico local, es una alternativa para coordinar y proyectar mejores niveles de desarrollo local, y que no está dado necesariamente en el desarrollo industrial, pero si del aprovechamiento de los recursos, generación de valor, y el aprovechamiento de las ventajas comparativas que ofrece cada región.

El trabajo no pretende detallar la forma y los métodos para implementar procesos de desarrollo económico local, el propósito es señalar o referenciar que los alcances que generan estos procesos; los cuales son exitosos en la medida que haya compromiso en los diferentes agentes. Por tanto, recordando lo señalado en el primer capítulo de este trabajo, donde se menciona a La Organización Internacional del Trabajo - OIT, quien resalta la definición que hace el investigador Andrés Rodríguez-Pose (2002), para el Desarrollo Económico Local, indicando que:

Es un proceso de desarrollo participativo que fomenta los acuerdos de colaboración entre los principales actores públicos y privados de un territorio, posibilitando el diseño y la puesta en práctica de una estrategia de desarrollo común a base de aprovechar los recursos y ventajas competitivas locales en el contexto global, con el objetivo final de crear empleo decente y estimular la actividad económica (Rodríguez-Pose, 2002). 
Definición que se ajusta a los elementos técnicos reseñados a lo largo del presente documento, pero aclarando que hay otras definiciones que guardan criterios similares relacionados con la participación de actores o agentes, intereses comunes y fomento o promoción de las estrategias o iniciativas de los mismos participantes.

Pese al planteamiento teórico del propósito DEL, la implementación de acciones a través de las diferentes metodologías que oferta el mercado (agencias o firmas de consultoría internacional o nacional proveen servicios a gobiernos regionales o locales para la implementación de programas DEL), no siempre son exitosas ya que requieren una serie de elementos que propicien, jalonen y sostengan estos procesos, máxime cuando se requiere hacer redefinición de las formas tradicionales de gestión, coordinación y ejecución de las estrategias de desarrollo presentes en las políticas, programas y proyectos en los contextos municipales con mayor vulnerabilidad social, económica e institucional.

Implementar DEL requiere de elementos generadores de cambio, especialmente de actitud en el sujeto (los pobladores), propiciando con ellos escenarios específicos de DEL a través de la promoción, la gestión y la participación con propósitos comunes claramente definidos; es decir, establecer objetivos y metas en diferentes espacios de tiempo.

La propuesta de Índice de Confianza Municipal -ICM-, es un referente de medición para identificar a través de la percepción de los pobladores (representados por sus líderes) si hay elementos generadores de cambio que hagan posible la implementación de estrategias DEL, considerando que pueden cumplirse condiciones necesarias, pero no suficientes para hacer posible la realización de una estrategia DEL. Por lo tanto, con la aplicación del ICM se recogen insumos para identificar los determinantes necesarios y suficientes para definir potencialmente las probabilidades de ejecución de estrategias DEL. 
Para el caso del municipio de Nariño, Cundinamarca, el Índice de Confianza Municipal es de 5,76 en una escala de 1 a 10, siendo 1 menos deseable y 10 más deseable, que al re-escalarlo a los valores originales de la encuesta (malo, regular, bueno, muy bueno y excelente), indica que la valoración obtenida es de "bueno", inclusive con el mismo resultado desagregado por dimensiones. Bajo este resultado, el índice infiere automáticamente que a partir de las percepciones de los representantes de los sectores, el estado general del desarrollo local es "bueno".

Con este primer escenario (percepción de favorabilidad al estado general de desarrollo local en el municipio), se adhiere al análisis los resultados generales de la segunda parte de la encuesta, relacionado con el conocimiento que tienen los representantes (encuestados) sobre el desarrollo local y el desarrollo económico local (ver Anexo L). Las preguntas relacionadas con este aspecto, no se realizaron con rigor técnico, simplemente la encuesta captaba si conocían del tema con una respuestas de "si" o "no", sin profundizar que tanto era el conocimiento en la temática; sin embargo, con las respuesta se identificó la disposición o receptividad que los encuestados manifiestan sobre el tema. Para el ejercicio, es fundamental conocer el nivel de vinculación a procesos derivados por estrategias de desarrollo local y económico local, independiente si es con entidades locales o externas al municipio.

Los resultados arrojados por la encuesta, relativamente son predecibles por la disposición de los encuestados en estar vinculados a las actividades que se desarrollen para el beneficio del municipio. Además, al involucrar en la pregunta el término “desarrollo”, predispone positivamente al encuestado en responder positivamente.

La Gráfica 11, registra el alto porcentaje de respuestas positivas relacionadas con el conocimiento de qué es desarrollo local en el $78 \%$, promotores de acciones en el tema en un 89 
$\%$, y si han tenido participación en actividad alguna con proyectos de desarrollo local en un $67 \%$. El resultado positivo en este grupo de preguntas sobre el tema en particular, no asegura que las respuestas obedezcan a la realidad, pero si evidencia una alta disposición a conocer sobre el tema, lo cual es positivo para las iniciativas a emprender.

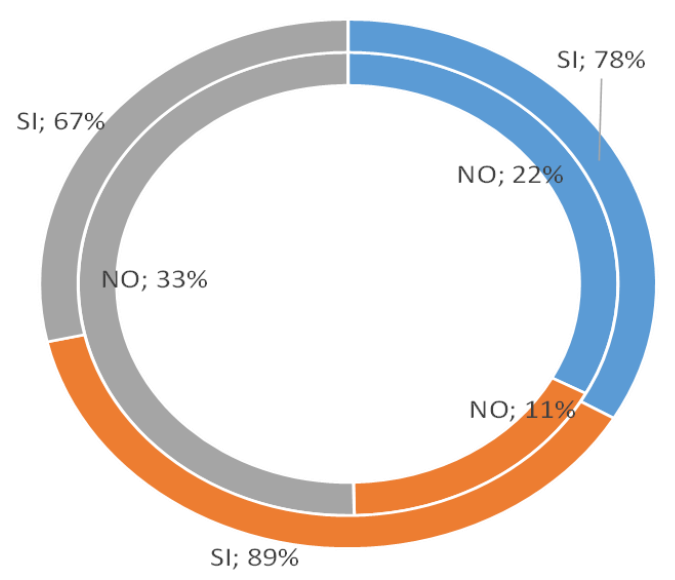

- Conoce qué es Desarrollo Local

- Conoce si persona o entidad alguna ha promovido acciones para el Desarrollo Local

- Ha participado de proyectos o acciones para el Desarrollo Local

Gráfica 11. Conocimiento en los temas de Desarrollo Local. Fuente: Elaboración propia.

Del mismo modo, sobre las preguntas relacionadas con el conocimiento específico en desarrollo económico local, los encuestados manifiestan amplio conocimiento, aunque la participación directa en dichos procesos sea menor que en temas de desarrollo local (ver Gráfica 12). 


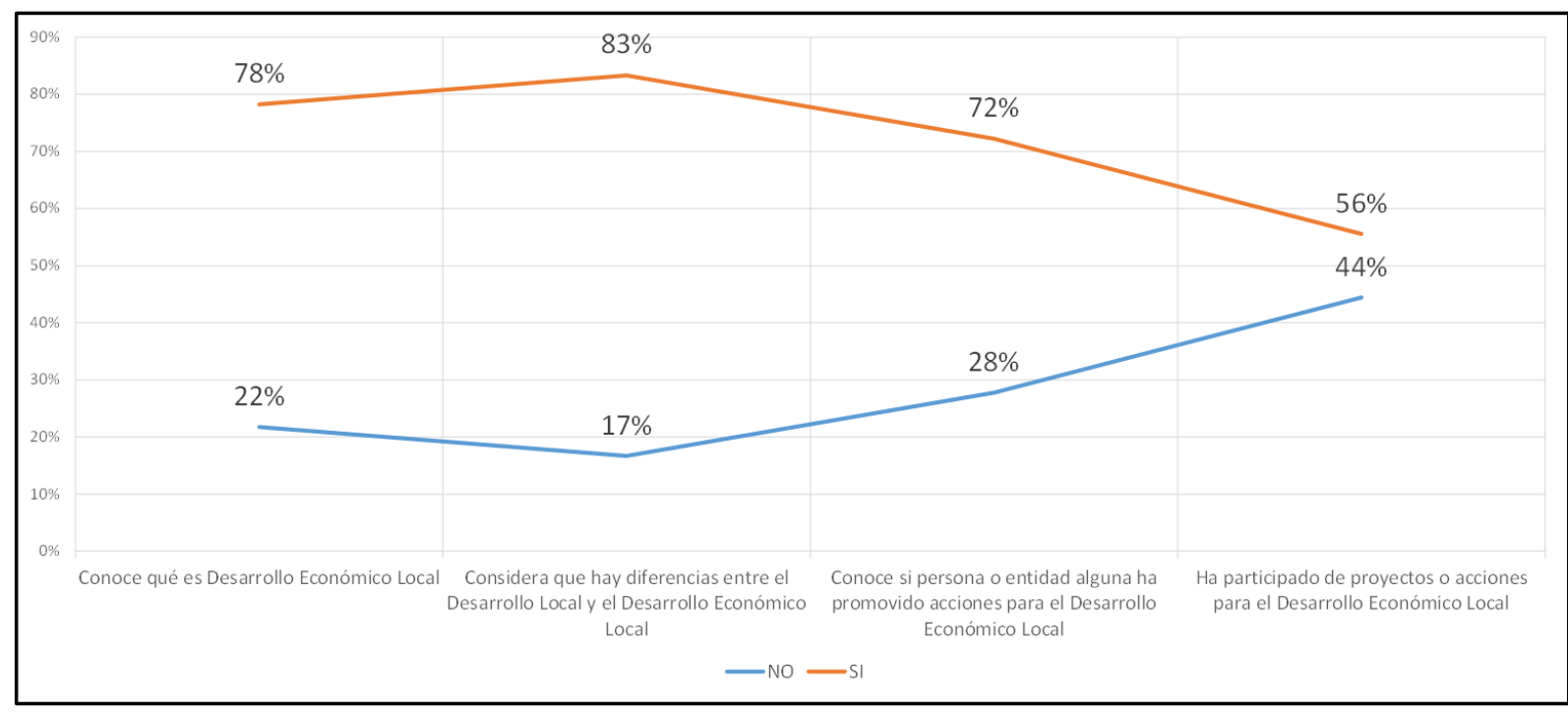

Gráfica 12. Conocimiento en los temas de Desarrollo Económico Local. Fuente: Elaboración propia.

Aunque las respuestas en los dos grupos de preguntas no garantizan veracidad sobre el nivel de conocimiento que tienen los encuestados, éstas si presentan consistencia al evidenciar que los encuestados asocian el desarrollo local con acciones más amplias y transversales en diferentes factores del desarrollo, lo que facilita mayor participación de agentes en actividades para su desarrollo. Y de manera concreta, reconocen que las acciones de desarrollo económico local presentan un enfoque más específico en términos de mejorar espacios para la productividad, el empleo, la generación de ingresos, entre otros.

Por otra parte, a pesar de manifestarse positivamente conocimiento en los dos tipos de desarrollo, la percepción que se tiene frente a los resultados finales en las intervenciones conocidas, tanto en desarrollo local como económico, está repartido, obteniendo un porcentaje favorable (bueno) mayor en desarrollo local (44\%), que en económico (28\%); pero el porcentaje obtenido de muy bueno, en más favorable para el desarrollo económico local (33\%), que en el de local (17\%). La percepción para un resultado excelente es igual para los dos casos (ver Gráfica 
13). La inconsistencia en las respuestas se deriva en el alto porcentaje (33\% DEL y $28 \%$ DL) que se presentó, al manifestarse que no conocen los resultados en este tipo de intervenciones.

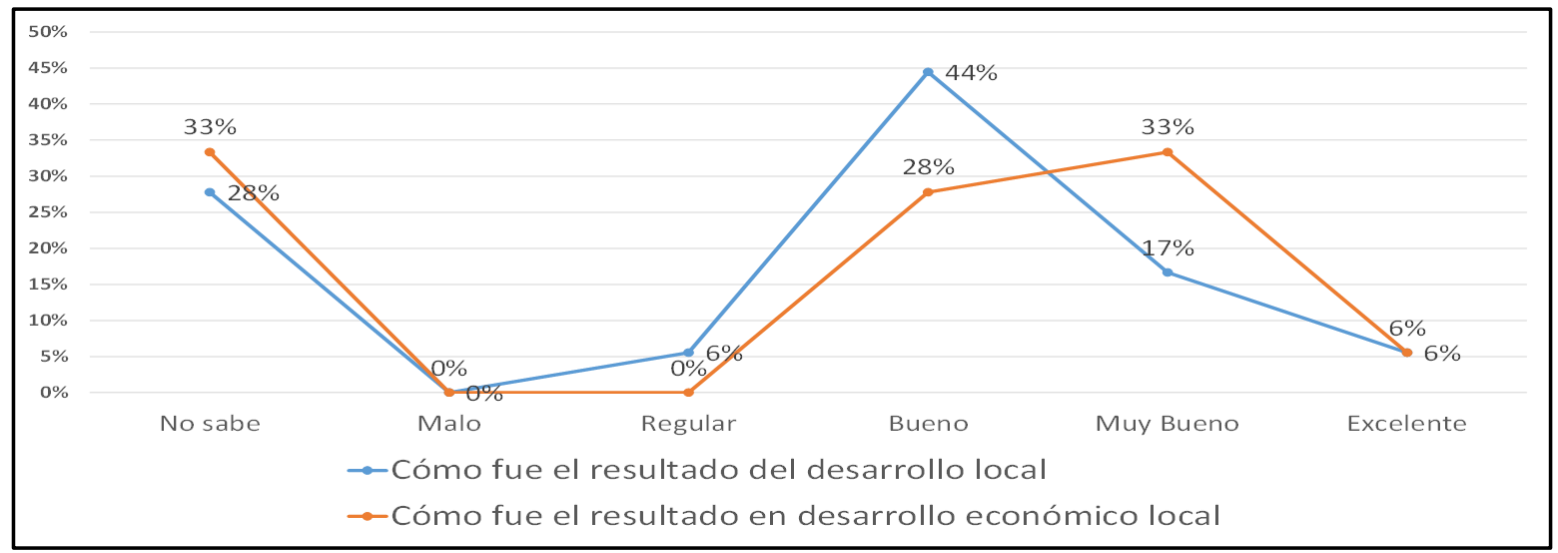

Gráfica 13. Comparación de resultados en Desarrollo Local y Económico. Fuente: Elaboración propia.

Finalmente, el aspecto más importante a resaltar es la amplia disposición para conocer y aplicar estrategias de desarrollo económico local para beneficio del municipio, como se observa en la Gráfica 14.

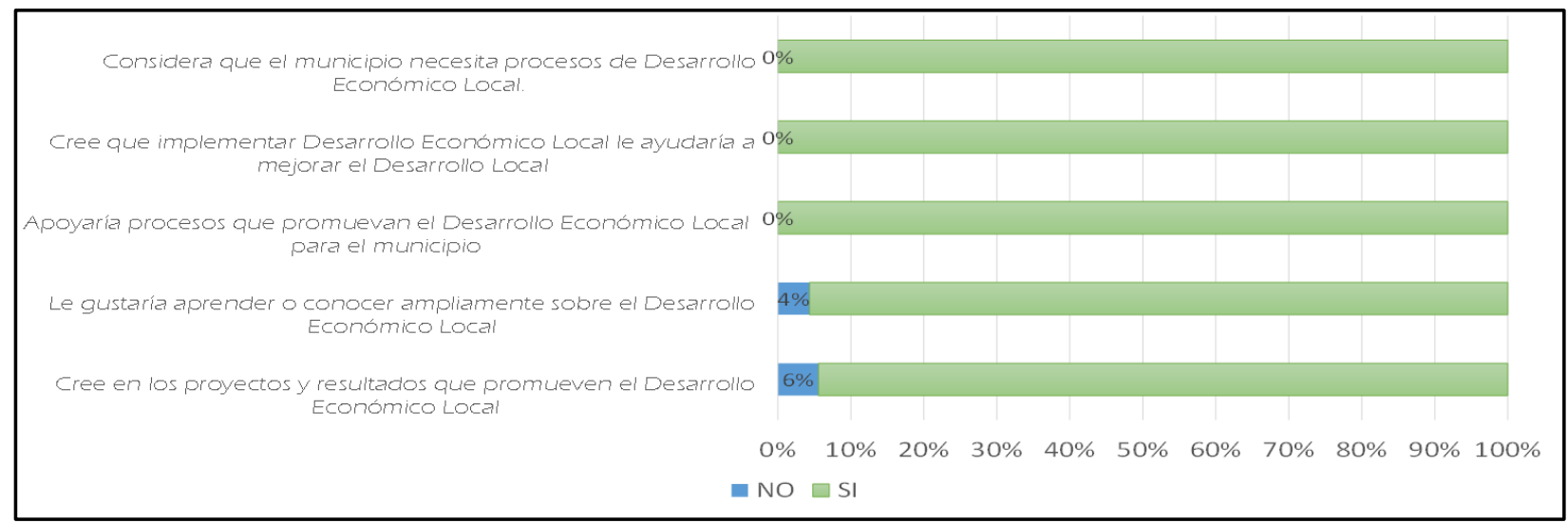

Gráfica 14. Comparación de resultados para la promoción del Desarrollo Local y Económico. Fuente: Elaboración propia. 
Bajo estos dos escenarios, por un lado el Índice de Confianza Municipal con resultado favorable; y por el otro, con la disposición amplia en adelantar procesos de desarrollo económico local en el municipio, se concluye que hay condiciones favorables para recomendar la implementación de iniciativas DEL, teniendo en cuenta que hay elementos que inciden en la priorización de acciones a partir de los resultados obtenidos en variables correspondientes a las dimensiones económica e institucional, como está registrado en las secciones correspondientes del presente capítulo.

Con la anterior conclusión, se debe precisar que no son suficientes las condiciones favorables a nivel interno (condiciones de tipo endógenas) para lograr propósitos de beneficio local con las acciones DEL, es necesario considerar las condiciones exógenas de mercado, para sumar aliados en los términos señalados por Perroux (1983) sobre los polos de desarrollo, para lograr las ventajas que ofrece un externo es aspectos tecnológicos, de inversión, y de incidencia política.

Finalmente como recomendación, es fundamental consolidar las relaciones con las comunidades aledañas (mayores o menores) definiendo propósitos comunes de región. Además, tener presente para una recomendable implementación de estrategias DEL las recomendaciones presentadas por el profesor Vásquez (2000) como son:

La planificación estratégica del desarrollo local; la estrategia de pequeños pasos; compatibilidad de los instrumentos con el sistema institucional; fomento de la capacidad empresarial y la innovación; impulso de las redes de empresas; y los acuerdos para el desarrollo económico local (Vásquez Barquero, 2000). 


\section{Conclusiones}

Teóricamente, el desarrollo económico local debe fortalecerse a partir las convicciones internas de cada territorio, pero desde los primeros planteamientos hace pocas décadas, hasta la actualidad, los países son cada vez más globalizados y competitivos, dejando de ser economías cerradas y proteccionistas, sumándose así a mercados más exigentes; por esa misma razón, se presionan a los centros de producción (territorios, comunidades, productores, etc.) a que también evolucionen con las exigencias del mercado; bajo este nuevo panorama las comunidades tradicionalmente proveedoras de insumos al mundo, deben también evolucionar con los mercados, y las convicciones en materia de producción también deben adaptarse; desde esa perspectiva, el desarrollo económica local debe abordarse con el respeto a las convicciones tradicionales y culturales de cada comunidad, pero con la visión de estar a la medida de los retos que el mundo le exige.

En la actualidad se cuenta con amplia teoría sobre la concepción del deber ser del desarrollo económico local, definida con preceptos y lineamientos medulares para desarrollar estrategias que beneficien el desarrollo local acordes con las necesidades y objetivos de cada municipio. Sin embargo, no existe una formula única y verdadera para afirmar que la concepción no puede ser ajustable a las nuevas realidades de cada región. Por lo tanto, los factores endógenos, sobre el cual se soporta el planteamiento DEL, está obligado a revalidar enfoques para darle entrada a factores externos, pero sin afectación en la autonomía.

Efectuar una planeación ajustado a las necesidades de un territorio (localidad o municipio, etc.) sin contar con cifras o datos actualizados, dificulta el cumplimiento de los propósitos y alcances necesarios para avanzar a mejores escenarios de desarrollo; por tanto, esto hace parte de los círculos viciosos que, en una comunidad no se pueda superar los bajos niveles de desarrollo. 
Situación evidenciada en el capítulo de caracterización, las cifras estadísticas disponibles son obsoletas, dejando el mayor peso a la percepción de los habitantes, como el insumo principal para valorar la condición de avance de las dimensiones del desarrollo. Incluso los agentes externos interesados en ingresar a un territorio pueden frenar decisiones de inversión, por la falta oportuna y actualizada de información que indique el comportamiento de la localidad en cuestión.

El Índice de Confianza Municipal ICM, es una manera de identificar el estado de condiciones para implementar acciones de desarrollo económico local, en cualquier comunidad de baja población o bajos ingresos. Debe entenderse como un referente que indica (evidencia señales particulares a cada municipio) la oportunidad o no, para emprender iniciativas o acciones bajo una estrategia DEL. La cifra hallada con la metodología propuesta (elaboración de encuesta y procesamiento de datos con el programa estadístico SPSS), es un referente que mide el nivel de favorabilidad para asumir retos en condiciones básicas; entendiendo que destinar recursos donde no se generan condiciones mínimas de implementación, es un costo que se puede minimizar, en la medida que se empleen instrumentos que identifiquen los riesgos. En síntesis el ICM, es un instrumento de medición para entender los riesgos que pueden incidir en la aplicación de procesos DEL en determinado municipio (percepción con mayor favorabilidad, es menor el riesgo de implementación). Aunque es un instrumento no validado técnicamente, es una propuesta para seguir construyendo, con el propósito de identificar posibles riesgos en comunidades que no generan condiciones básicas para la implementación de estrategias DEL, evitando así la pérdida significativa de recurso humano, económico y financiero.

Los autores más conocidos en los temas de desarrollo económico local, plantean una serie de determinantes asociados por lo general a condiciones físicas, materiales, financieras, territoriales, económicas, culturales, factores endógenos o exógenos, etc., que conceptualmente y 
en la práctica todos son válidos; Sin embargo, desde el enfoque del sujeto (individuo), es fundamental identificar los intereses particulares, que a su vez se conviertan en intereses colectivos; debe existir además un reconocimiento del individuo que lo motive a incorporarse a ese propósito común; y lo mismo con los demás agentes o actores a nivel institucional, para hacer de una causa individual una causa colectiva.

La identificación oportuna de criterios determinantes para la implementación de estrategias DEL como son, la promoción, gestión y participación, es fundamental para medir el nivel de aceptación e interés en los procesos DEL a emprender. Sin embargo, en los procesos sociales (incluyendo procesos productivos o económicos con población en estado de vulnerabilidad) no siempre se pueden establecer condiciones estándares que determinen los riesgos o las oportunidades para ejecutar las mejores acciones; por lo cual, siempre existirá determinantes necesarios pero no suficientes para asegurar todas las condiciones que inciden en la implementación de procesos DEL.

El resultado final del trabajo no es la construcción y validación de un índice, tampoco es la construcción de una metodología para establecer determinantes; en ambos casos, aunque si se desarrollan a lo largo del trabajo, lo esencial no es la forma o el método que se presenta, lo importante es que el presente trabajo ayude como referente a motivar la generación de iniciativas que permitan el diseño, construcción y validación de herramientas o mecanismos metodológicos adecuados para identificar o establecer previamente a cualquier intervención DEL, cuáles son los determinantes mínimos necesarios para lograr un mejor desarrollo local en cualquier comunidad, con disminución de riesgos y costos, a través de la implementación de estrategias DEL, teniendo en cuenta los escenarios actuales de competitividad, y la apertura de mercados con alcance internacional; pero conservando el respeto a la identidad y la autonomía local. 


\section{Referencias Bibliográficas}

Ábalos, J. A. (2000). El fomento al desarrollo productivo local: orientaciones, actores, estructuras y acciones. La situación en Chile en los noventa. Santiago, Chile: Comisión Económica para América Latina y el Caribe (CEPAL).

Alburquerque, F. (2004). Desarrollo económico local y descentralización en América Latina. Revista de la CEPAL (82).

. (2002). Desarrollo económico territorial. Guía para Gentes. Sevilla: Instituto de Desarrollo Regional Fundación Universitaria.

\& Cortés, P. [comp.] (2001). Desarrollo económico local y descentralización en América Latina: Análisis comparativo. Santiago, Chile: CEPAL/GTZ, Proyecto Regional de Desarrollo Económico Local y Descentralización.

Alcaldía Municipal de Nariño, Cundinamarca. (2012). Plan de desarrollo municipal 2012-2015

"Trabajo, oportunidad y progreso para Nariño". Nariño, Cundinamarca.

Amate F., I. \& Guarnido R., A. (2011). Factores determinantes del desarrollo económico y social. Málaga, España: Universidad de Almería, Serie Analistas económicos de Andalucía, VI Premio Unicaja de investigación económica.

Boisier, S. (2001). Desarrollo (local): ¿De qué estamos hablando? En O. Madoery, \& A. Vásquez Barquero, Transformaciones globales, Instituciones y Políticas de desarrollo local. Rosario: Editorial Homo Sapiens.

. (2004). Desarrollo endógeno: ¿para qué?, ¿para quién? (El Humanismo en una Interpretación Contemporánea del Desarrollo). Santiago, Chile: Universidad Católica. 
Cabrer, B., de Castro, J., \& Pavía, J. M. (2001). Indicadores económicos regionales y su problemática: una visión de síntesis. En B. Cabrer Borrás, Análisis regional. El proyecto Hispalink (págs. 259-277). Madrid, España: Análisis regional. El proyecto Hispalink.

Carvajal Burbano, A. (2011). Desarrollo local: Manual básico para agentes de desarrollo local y otros actores. Málaga, España.

(2009). ¿Modelos alternativos de desarrollo o modelos alternativos al desarrollo? Escuela de Trabajo Social y Desarrollo Humano de la Universidad del Valle.

Casanova, F. (2004). Desarrollo local, tejidos productivos y formación. Abordajes alternativos para la formación y el trabajo de los jóvenes. Montevideo: CINTERFOR.

Coffey, W. J., \& Polese, M. (1985). Local development: conceptual basis and policy implications. Regional Studies (19).

Cole, J. H. (2004). Determinantes del crecimiento económico mundial, 1980-99. Ciencias Económicas (24), 29-48.

Colombia. Unidad de Desarrollo Regional y Urbano del Departamento Nacional de Planeación. (1981). La política de desarrollo regional en Colombia. Eure, (22). Bogotá D.C.: Universidad de los Andes, Facultad de Economía, CEDE. . Congreso de la República. (1991). Constitución Política de Colombia. Bogotá D.C.: Legis. (1994). Ley 136. Bogotá D.C.: Diario Oficial.

Corbo, V. \& Vergara, R. (1992). Los determinantes del crecimiento económico: Introducción. Cuadernos de Economía, XXIX (87), 165-169.

Cronbach, L. J. (1951). Coefficient alpha and the internal structure of test. Psychometrika, XVI (3), 297-334. 
DANE. (2005). Censo general. Perfil Colombia. Bogotá: Departamento Administrativo Nacional de Estadística.

De Mattos, C. A. (1990). La descentralización, ¿una nueva panacea para impulsar el desarrollo local? Cuadernos de Economía, (14), 173-194.

Díaz A., J. C. \& Ascoli A., J. F. (2006). Reflexiones sobre el desarrollo local y regional. Ciudad de Guatemala: Universidad Rafael Landívar, URL-KFW.

Domínguez, M. R. (2013). José Luis Sampedro (1917-2013), pionero de los Estudios del Desarrollo. Revista Iberoamericana de Estudios de Desarrollo, II (1), 119-125.

Domínguez S, M.; et al. (2011). Una revisión crítica para la construcción de indicadores sintéticos. Revista de métodos cuantitativos para la economía y la empresa (11), 41-47.

Felber, C. (2011). Economía del bien común, un modelo de economía con futuro.

Fernández de Castro del C., J. A. (2005). Una nueva concepción del municipio colombiano. Bogotá D.C.: Pontificia Universidad Javeriana, Facultad de Derecho.

Gago, A. (1993). Planificación y Desarrollo Regional. Curso Latinoamericano de Desertificación. La Matanza, Argentina.

Guillén Romo, H. (2007). Francois Perraux: pionero olvidado de la economía del desarrollo. Mundo siglo XXI (11), 11-22.

Heirli, U. (1979). Desarrollo de los mercados locales: una salida para Colombia? [tesis de posgrado] St. Gallen, Suiza: Universidad de St. Gallen.

Herschel, F. J. (1961). Determinantes del desarrollo. Buenos Aires, Argentina: Asociación de Economía Política.

IBM. (2013). IBM SPSS Statistics 22 Core System. Guía del usuario. España: IBM. 
Jaimes I., O. \& Guerrero R., A. (2000). Participaciòn y Desarrollo Local Prioridad Regional de las Universidades. Reflexión Política, II (3). Bucaramanga, Colombia: Universidad Autónoma de Bucaramanga.

Max-Neef, M. A. (1993). Desarrollo a escala humana. Conceptos, aplicaciones y algunas reflexiones. Montevideo: Editorial Nordan-Comunidad.

Mesopartner.com. (s.f.). Participación y acción para la competitividad local. Una metodología para estimular el desarrollo económico en su región: www.mesopartner.com.

Meyer-Stamer, J. (2004). Participación y Acción para la Competitividad Local (PACA): Impulsando iniciativas para el Desarrollo Económico Local. Duisburgo, Alemania.

Mondéjar-Jiménez, J., \& Vargas-Vargas, M. (2008). Indicadores sintéticos: una revisión de los métodos de agregación. Economía, Sociedad y Territorio , VIII (27), 565-585.

Montaño A., M. A.. (2014). Modelo de desarrollo económico local para la diversificación de la estructura Productiva y la Articulación del Tejido Empresarial en Baja California Sur [tesis doctoral]. Tijuana, México: Universidad Autónoma de Baja California.

Mourao, P. R. (2007). El institucionalismo Norteamericano: Orígenes y Presente. Revista de Economía Institucional , IX (16), 315 -325.

Mujica R., P. \& Quiroz, J. (1992). Los determinantes del crecimiento económico: La evidencia empírica y el problema de equivalencia observacional. Cuadernos de Economía, XXIX (27), 307-328.

Muñoz G., O. H. \& Holguín L., M. (2001). El papel de los municipios colombianos en la planeación y gestión del desarrollo local: sus fundamentos teórico-conceptuales. Tendencias, II (2), 115-147. Pasto: Universidad de Nariño, Facultad de Ciencias Económicas y Administrativas. 
Organización Internacional del Trabajo. (2014). Fomento de las economías locales. OIT: Programa de Empresas Sostenibles.

Perroux, F. (1983). A New Concept of Development. UNESCO.

Prats, J. O. (2007). Revisión crítica de los aportes del institucionalismo a la teoría y la práctica del desarrollo. Revista de economía institucional , IX (16), 121-148.

Reyes, G. E. (s.f.). Principales Teorías sobre el Desarrollo Económico y Social.

Rodríguez-Pose, A. (2002). El papel de la OIT en la puesta en práctica de estrategias de desarrollo económico local en un mundo globalizado. Londres: Departamento de Geografía y Medio Ambiente, LSE.

Rojas M., L. M. (2006). Manual para la Gestión Municipal del Desarrollo Económico Local. Lima: OIT, Oficina Sub Regional para los Países Andinos, Proyecto Pres.

Rondinelli, D. A. (1988). Método aplicado de análisis regional: La dimensión espacial de la política de desarrollo. Medellín: Universidad de Antioquia.

Rosales, M., \& Urriola, R. (2012). Hacia un modelo integrado de desarrollo económico local y cohesión social. Barcelona: DRG.

Sampedro, J. L. (2009). Triple nivel, doble estrategia y otro desarrollo. EH, 364-387.

Secretaría de Planeación de Cundinamarca. (2015). Visor Estadístico 2015. Recuperado el 9 de Agosto de 2015, de Página web de la Secretaría de Planeación de Cundinamarca.

Sen, A. (2000). Desarrollo y libertad. Barcelona: Editorial Planeta S.A.

Silva L, I. \& Sandoval, C. (2012). Metodología para la elaboración de estrategias de desarrollo local. Santiago, Chile: Naciones Unidas, CEPAL, Instituto Latinoamericano y del Caribe de Planificación Económica y Social. 
Taveras, R. (3 de Febrero de 2012). Ciclo Económico, Ciclo Político y Gasto Público en la República Dominicana. Obtenido de Monografias.com: http://www.monografias.com/ usuario/perfiles/roma_n_taveras/monografias

Tello, M. D. (2008). Desarrollo Económico Local, Descentralización y Clusters: Teoría, Evidencia y Aplicaciones. Lima, Perú: CENTRUM Católica - Centro de Negocios de la Pontificia Universidad Católica del Perú. (2006). Las teorías del desarrollo económico local y la teoría y práctica del proceso de descentralización en los países en desarrollo. Lima: Departamento de Economía y CENTRUM de la Universidad Católica del Perú.

Vásquez Barquero, A. (2009). Desarrollo local, una estrategia para tiempos de crisis. Apuntes del CENES, XXVIII (47), 117-132.

(2000). Desarrollo Económico Local y Descentralización: aproximación a un marco conceptual. Santiago, Chile: Proyecto CEPAL/GTZ. (1988). Desarrollo local. Una estrategia de creación de empleo. Madrid: Pirámide.

Zorro Sánchez, C. [comp.] (2007). El desarrollo: perspectivas y dimensiones. Aportes interdisciplinarios. Bogotá: Universidad de los Andes, CIDER, Ediciones Unidas: Koninkrijk der Nederlanden, Embajada del Reino de los Países Bajos. 


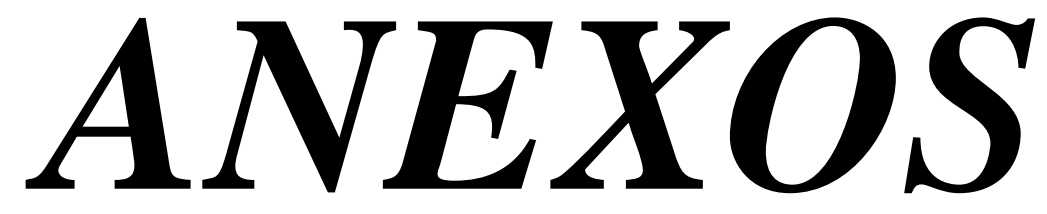




\title{
Anexo A. Índice de Pobreza Multidimensional (IPM-Colombia)
}

\section{7-2008 y meta del PND para 2014*}

\author{
Departamento Nacional de Planeación - DNP \\ Dirección de Desarrollo Social - DDS
}

Subdirección de Promoción Social y Calidad de Vida-SPSCV

Qué es el IPM

El Índice de Pobreza Multidimensional (IPM), desarrollado por el Oxford Poverty \& Human Development Initiative (OPHI), es un indicador que refleja el grado de privación de las personas en un conjunto de dimensiones. La medida permite determinar la naturaleza de la privación (de acuerdo con las dimensiones seleccionadas) y la intensidad de la misma EL IPM es la combinación del porcentaje de personas consideradas pobres, y de la proporción de dimensiones en las cuales los hogares son, en promedio, pobres).

Qué mide el IPM de Colombia

La propuesta de IPM desarrollada por el Departamento Nacional de Planeación para Colombia está conformada 5 dimensiones y 15 variables.

Dimensiones y variables del IPM para Colombia

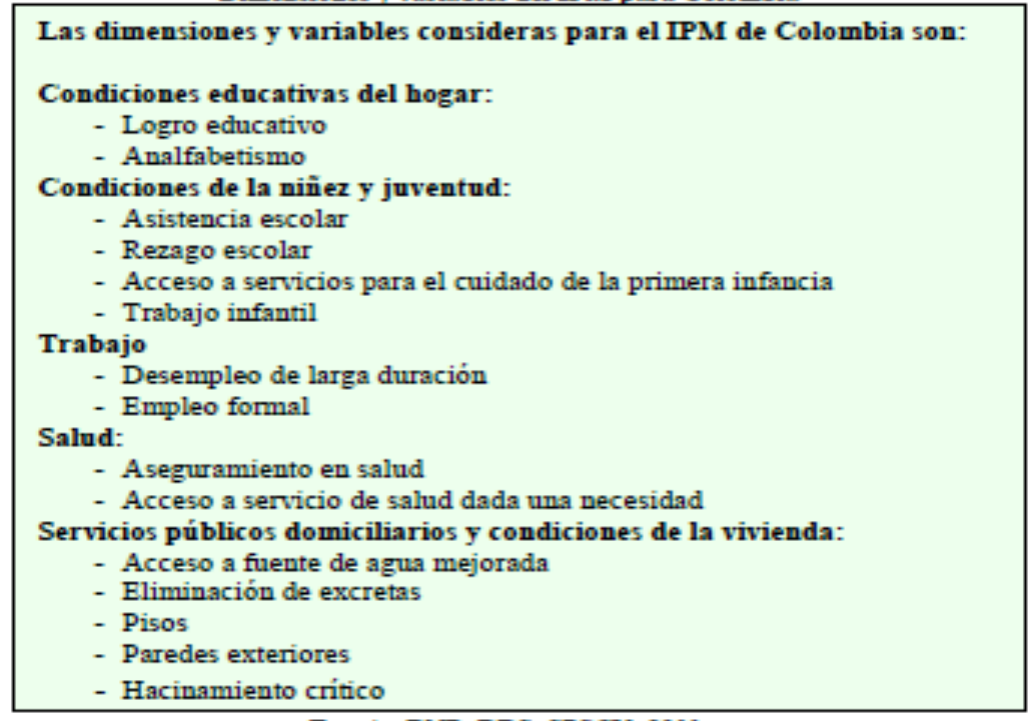

Fuente: DNP. DDS, SPSCV. 2011.

*Departamento Nacional de Planeación. 2011. Bases del Plan Nacional de Desarrollo 2010-2014. Prosperidad para todos. 
De acuerdo con esta medida, se considera que una persona está condición de pobreza si cuenta con privaciones en al menos 5 de las variables seleccionadas (33\% del total de privaciones). La medida permite obtener estimaciones de la incidencia de la pobreza multidimensional para diferentes dominios geográficos. 


\section{Anexo B. Diseño de Encuesta de Percepción sobre las Dimensiones del Desarrollo y el Desarrollo Económico Local}

\section{Presentación: Por qué utilizar como herramienta una encuesta}

La encuesta es una herramienta de observación y de opinión, facilita la cuantificación y comparación de la información pre-diseñada intencionalmente con preguntas principalmente cerradas, esto ayuda a direccionar el propósito del trabajo frente a las percepciones de cada variable y dimensión de desarrollo seleccionadas, lo cual ayuda a identificar las necesidades y posibles acciones que conduzcan a la implementación adecuada de acciones en desarrollo económico local.

En consecuencia es una herramienta que facilita la recopilación de información entre los actores o agentes encuestados, comparándose los resultados entre sí, y midiendo el peso de las opiniones registradas. Por tanto, el instrumento es útil para para averiguar el grado de conocimiento y satisfacción de los encuestados frente al tema consultado.

En este sentido, es importante reconocer que el levantamiento de información sólo es práctico y efectivo si se realiza directamente desde el conocimiento local objeto del trabajo; es decir, con los actores conocedores de sus propias dinámicas, intereses y capacidades que viven sus propias apuestas de cambio; por tanto, las respuestas se originan desde la espontaneidad y la experiencia. Es así que la información a registrar debe provenir en mayor proporción de las personas nativas de la comunidad en estudio, o de residentes antiguos con arraigo y pertenencia por el desarrollo local. Aunque mayoría de estos actores no manejen con destreza técnica los datos, si tienen la solvencia para hacer que la información derivada de la experiencia se emplee con amplio rigor para tomar decisiones, provocando cambios que afectan sus propios escenarios de intervención. 
Como respaldo a la información recopilada, se incluyen en el proceso de análisis los datos provenientes de las fuentes secundarias que están relacionadas directamente con el tema específico de investigación; del mismo modo, y no menos importante - la información recopilada a partir de la observación, es un elemento que valida y confronta los resultados en los escenarios definidos por los encuestados.

\section{Objetivos de la encuesta:}

Objetivo General:

Identificar en los actores locales del municipio de Nariño, Cundinamarca las percepciones sobre la situación del desarrollo local, para el diseño de un índice de confianza municipal como insumo en la identificación de determinantes socioeconómicos e institucionales que inciden en la promoción del desarrollo económico local.

De manera específica el presente instrumento permitirá capturar información primaria con tres propósitos:

1. Identificar desde la perspectiva de la comunidad (actores locales), el estado actual de las dimensiones del desarrollo en el ámbito social, económico e institucional (caracterización)

2. Conocer la percepción que tienen los actores locales sobre el conocimiento y alcance que deriva un proceso de desarrollo económico local.

3. Identificar factores que inciden en la implementación de procesos para el desarrollo económico local.

\section{Estructura del Formulario.}

Los elementos de la estructura de la encuesta presentan las siguientes características:

1. Las preguntas se agruparán en tres grupos principales con presuntas cerradas para cada variable, que se complementan de forma opcional con preguntas abiertas para identificar en 
términos generales las percepciones sobre cada dimensión social, económica e institucional; y un grupo de preguntas sobre el conocimiento de conceptos y acciones en procesos de desarrollo local y económico local.

2. Cada dimensión agrupará elementos propios de cada sector y recogerá los elementos de perspectiva sobre el desarrollo local definidos en el objetivo del trabajo.

3. Las preguntas sobre las dimensiones tendrá las preguntas relacionadas directamente con la temática, definidas con un propósito deliberado, buscando concordancia con los objetivos de la encuesta, y apoyados con respuestas generales de opinión.

4. Las preguntas en términos generales son cerradas, para fácil diligenciamiento y control de las respuestas; con preguntas que abordan conocimiento, opinión e intención de los encuestados sobre el tema específico.

5. Las preguntas sobre las variables de cada dimensión tendrán una sola opción de respuesta en términos cualitativos de menor a mayor (malo-1, regular-2, bueno-3, muy bueno-4 y excelente5). La parte final de cada dimensión, tendrá una pregunta abierta para identificar aspectos relevantes asociados con las fortalezas y oportunidades, como las debilidades y amenazas para el buen desarrollo de la respectiva dimensión.

6. Las preguntas de percepción, sobre conocimiento y posible promoción del desarrollo económico local, se perfilan con la intención deliberada de tener respuestas a partir de los resultados de la primera parte del cuestionario, con el fin de levantar insumos que identifiquen determinantes para la implementación de acciones en desarrollo económico local. 
IV. Estructura de la Encuesta (batería de preguntas)

\begin{tabular}{|c|c|c|c|c|}
\hline Dimensiones & Variables & $\begin{array}{c}\text { Situación } \\
\text { actual }\end{array}$ & $\begin{array}{c}\text { Fortaleza } \\
\text { S }\end{array}$ & $\begin{array}{c}\text { Amenaza } \\
\text { S }\end{array}$ \\
\hline Social & $\begin{array}{l}\text { Salud, educación, vivienda, } \\
\text { servicios domiciliarios, } \\
\text { juventud, niñez, tercera edad, } \\
\text { derechos humanos, seguridad, } \\
\text { cultura. }\end{array}$ & & & \\
\hline Económica & $\begin{array}{l}\text { Negocios, inversión, empleo, } \\
\text { ingresos, comercio, turismo, } \\
\text { producción (calidad y oferta), } \\
\text { Infraestructura, asociatividad. }\end{array}$ & & & \\
\hline Institucional & $\begin{array}{l}\text { Administración municipal, } \\
\text { ONG's locales, regionales e } \\
\text { internacionales. }\end{array}$ & & & \\
\hline Desarrollo local & \multicolumn{4}{|l|}{ Conocimiento, aplicaciones locales } \\
\hline $\begin{array}{l}\text { Desarrollo } \\
\text { económico local }\end{array}$ & \multicolumn{4}{|c|}{ Conocimiento, aplicaciones locales y alternativas de implementación } \\
\hline
\end{tabular}

\section{Grupos focales - Muestreo (técnica bola de nieve)}

Para establecer el grupo de personas objeto de la encuesta, es por medio de la técnica conocida como muestreo de bola de nieve $\mathrm{e}^{29}$, el cual es un método no probabilístico para identificar

\footnotetext{
${ }^{29}$ Tomado de https://explorable.com/es/muestreo-de-bola-de-nieve
} 
a los sujetos potenciales en estudios en donde los sujetos son difíciles de encontrar, o la población de estudio es muy limitada a un subgrupo muy pequeño de la población; esta técnica funciona en cadena, con un primer sujeto identificado o referente de contacto, es más fácil identificar a otras personas que tengan un rasgo de interés similar; para la muestra de interés se acude a personas conocedoras del entorno local y de sus principales líderes, que fácilmente se ubican por el tamaño reducido de la población, con un número total según proyecciones del DANE para el 2015 es de 2.203 personas (cabecera 1.449).

En consecuencia, la identificación del grupo objetivo de la encuesta (actores locales) en cada una de las dimensiones, social, económico e institucional, se hace a partir de la ubicación de los principales líderes, representantes o delegados de los sectores y organizaciones sociales y productivas en funcionamiento; igualmente, los funcionarios de las instituciones gubernamentales, que en los municipios pequeños su participación es predominante y casi dependiente para el desarrollo de acciones en todos los ámbitos de desarrollo municipal. A través de estos, se logrará conformar los grupos, mediante voz a voz, producto de la cercanía y confianza entre las mismas organizaciones.

$\mathrm{Al}$ respecto, los grupos de intervención o focales se agrupan por dimensión de desarrollo a trabajar, como se señala a continuación:

En la dimensión social, la muestra se obtiene a partir de los representantes o delegados de las diferentes instituciones que se identifican en cada área, para el campo educativo como son las 5 escuelas rurales y el colegio urbano, de grupos culturales, funcionarios del único puesto de salud, representantes del sector vivienda que corresponde a dos Junta de Vivienda Comunitaria Divino Niño, y Junta de Vivienda Comunitaria San Cayetano, y por supuesto los que hacen parte de la 
prestación de servicios domiciliarios especialmente de energía, agua y saneamiento básico relacionado con el tratamiento de aguas servidas, la recolección y disposición de residuos sólidos, y algún delegado del Consejo Municipal Ambiental.

Para la dimensión económica, en primera instancia se ha considerado que el registro formal de unidades de negocios en el municipio es reducido, teniendo en cuenta que no hay una institución oficial que haga el registro local, además la tipología propia de este tipo de municipio es que los negocios son informales, que en el mejor de los casos están agrupados en organizaciones productoras a través de asociaciones. En tal sentido, la participación de los representantes es fundamental para el levantamiento de la información que corresponden a los principales negocios de comercio, servicios como turismo y de los pertenecientes a los del sector agropecuario.

En la dimensión institucional, la estructura administrativa de la alcaldía está conformada por una Oficina de planeación y control interno, la Secretaria general, la tesorería, la oficina de la Umata, de servicios públicos, de deportes, del Sisbén, además se incluye la comisaría de familia y la inspección de policía. Por otro lado, tiene representación de las seis Juntas de Acción Comunal, cinco veredales y una del casco urbano; finalmente los representantes de los grupos religiosos, el católico y las tres iglesias cristianas.

Con el personal identificado por dimensión de desarrollo, se constituyen los grupos más representativos del municipio para el levantamiento de información, al respecto se cuenta con una participación por dimensión de no menos a 7 personas por grupo focal (por dimensión), y se procede a la implementación de la metodología para la aplicación del instrumento de encuesta, como se indica a continuación: 


\section{Metodología de la encuesta ${ }^{30}$}

Para el diligenciamiento de la encuesta, se llevarán a cabo las siguientes etapas, a saber:

1. Planeación de la jornada para el levantamiento de información

2. Coordinación y preparación de los eventos de trabajo (definición de los grupos focales y organización logística)

3. Convocatoria de los actores locales, sujetos de entrevista (grupos focales)

4. Reunión de socialización (propósitos y metodología) con grupos focales

5. Micro taller - Actividad de motivación para la generación de confianza en los grupos focales.

6. Desarrollo de entrevista personales y diligenciamiento de encuesta

\section{Cobertura y ámbito de la encuesta}

La encuesta se aplicará en el municipio de Nariño, Cundinamarca, con representación de sectores productivos, sociales e institucionales del área urbana y rural.

\section{Identificación de riesgo}

Por tratarse de un ejercicio voluntario, donde no hay incentivos para motivar la participación de los representantes de los sectores a trabajar, se prevé un bajo nivel de asistencia; para ello, se buscará promover el evento con el apoyo directo de funcionarios de la administración municipal, y que son allegados al personal de apoyo vinculados específicamente para desarrollar el trabajo.

\footnotetext{
${ }^{30}$ La metodología propuesta, corresponde al diseño inicial para el levantamiento de la información; sin embargo, por la falta de interés (sin una contraprestación) por parte de los representantes de cada sector en la participación voluntaria a las reuniones de socialización y micro taller, se cambió el método y se procedió directamente a realizar la entrevista y diligenciamiento de encuesta.
} 
El desarrollo del evento tendrá una duración por grupo máximo de 3 horas, lo cual facilita la participación de los representantes; se hará en un espacio no laboral, y se dispondrá de los recursos logísticos (incluyendo refrigerios y transporte), para la asistencia de los encuestados.

\section{Ventajas y limitantes del instrumento y la muestra seleccionada}

Ventajas:

- $\quad$ Información directa y fiable (principio de buena fe).

- $\quad$ Útil para evaluar cambios y comparar opiniones.

- $\quad$ Permite encuestar a los agentes representativos con incidencia en el cada sector

- $\quad$ Permite trabajar sobre un « modelo reducido» de la población objetivo.

- Permite evidenciar los resultados de políticas desde la perspectiva de un grupo hacia otro grupo de personas.

$\underline{\text { Limitantes: }}$

- $\quad$ Las diferencias entre agentes de diferentes instituciones, puede generar sesgo de opinión afectando la objetividad de la situación actual.

- $\quad$ Los resultados representan una imagen simplificada de la realidad, ya que los encuestados que representan sólo un pequeño subgrupo de toda la población.

- $\quad$ La muestra presume poco representativa, no garantizada en ella una total objetividad de la realidad. 


\section{Anexo C. Formulario de Encuesta}

\section{ENCUESTA DE PERCEPCIÓN SOBRE EL DESARROLLO ECONÓMICO LOCAL}

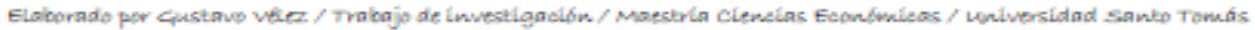

I. REGISTRO dE UBICACIÓN

Paiz: Colombia $\quad$ Departamento: Cundinamaroa
Enouestador (a):
Feoha de Entrevista:
Lugar de entrevista:

11. INFORMACIÓN DEL ENCUESTADO

Nombre Persona Encuestada:

Instituoión, organización o unidad produotiva que representa:

Cargo en la entidad

I de años de vinoulación

Partioipación en otras organizaoiones No __ Si__. Cuall(es)

Otroc cargoc

Nivel Eduoativo:

Oeupación: Independiente___ Hogar___ Empleado_

Ninguno___ Presoolar___ Primaria___ Seoundaria__ Técnica __ Universitaria ___ Poogrado___

Sexo: Femenino____ Macoulino____ Edad____ Nümero de años de residenoia en el munioipio

III. INFORMACIÓN SOBRE LA DIMENSIÓN SOCIAL

1. Cómo oalifioa la oalidad en la prestación de los siguientes servioioc para el desarrollo sooial del munioipio:

1.0 Salud

1.1 Eduoaciön

1.2 Vivienda

1.3 Servicioe domioiliarioe

1.4 Atención a la Juventud

1.5 Protecoión a la niñez

Excelente Muy bueno

Regular

Malo

Excelente __ Muy bueno ___ Bueno

Regular

Malo

Excelente __ Muy bueno ___ Bueno

Excelente __ Muy bueno ___ Bueno

Regular _ Malo

Excelente __ Muy bueno ___ Bueno

Regular __ Malo

Regular _ Malo

1.6 Protecoión a la teroera edad

1.7 Respeto a derechos humanos

1.8 Seguridad

Excelente __ Muy bueno ___ Bueno

Excelente __ Muy bueno ___ Bueno

Excelente __ Muy bueno ___ Bueno

Regular _ Malo

Regular _ Malo

Regular Malo

Malo

No sabe

1.9 Fomento de la cultura

Excelente __ Muy bueno ___ Bueno

Regular

Malo No sabe

2. De aouerdo con la anterior valoraoión, en términos generales oómo oalifica el estado de la dimensión social para el munioipio:

Excelente Mury bueno

Bueno

Regular

Malo

No sabe

3. Cuàl es la prinoipal fortaleza y oportunidad :

4. Cuál es la prinoipal debilidad y amenaza:

IV. INFORMACIÓN SOBRE LA DIMENSIÓN ECONÓMICA

5. Cómo oalifioa el aporte o contribuoiön de los siguientes aspeotos para el benefioio de la eoonomia del munioipio:

5.0 Oportunidad a los negovios

5.1 Inoentivo a la lnversión

5.2 Alternativas de Empleo

5.3 Niveles de Ingresos

Exoelente

Exoelente Bueno

l

5.4 Organización del Comercio

5.5 Oferta turistica

5.6 Calidad de la producción Regular

Exoelente _ Muy buen

Exoelente Muy bueno

Excelente

Mury bueno

Exoelente __ Muy bueno

Exoelente _Muy bueno

Exoelente Muy bueno

- Bueno

Regular Malo

5.7 Diversidad de la oferta Poo Muy bueno

Bueno Regular

Malo No sabe

5.8 Estado de la Infraestruotura

5.9 Apoyo a la asooiatividad

Exoelente _Muy bueno

Bueno

Regular

Malo

No sabe

6. De aouerdo con la anterior

valoración, en tërminos generales oömo

munioipio:

Excelente Mury bueno

Bueno i

8. Cuàl es la prinaipal debilidad y amenaza: 
v. INFORMACIÓN SOBRE LA DIMENSIÓN INSTITUCIONAL

9. Cómo oalifioa a la administraoiön munioipal relacionado con los Siguientes aspectos:

9.1 Gestión instituoional

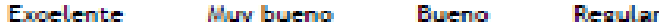

9.2 Apoyo a los produotorez

Exoelente Mury bueno

- Bueno

Regular

Malo __ No zabe

9.3 Protecoioin a loz vulnerables

9.4 Liderazgo regional

Exoelent

Bueno

Regular

Malo No sabe

9.5 Prestaoioin de loz servioios

9.6 Manejo de la economia

Exoelente __ Muy bueno ___ Buen

Regular _ Malo __ No zabe

Exoelente __ Muy bueno ___ Buen

Regular __ Malo __ No sabe

Exoelente _ Muy bueno

Regular __ Malo __ No sabe

lación con las JAC

Muy bueno

Bueno

Regular _ Malo __ No sabe

10. Conoce organizaoiones no gubernamentales - ONG ${ }^{\prime}=$ de orden looal: No

Regular _ Malo No sabe

11. Si la respuesta es pocitiva oómo oalifica la funoión que realiza en el munici Si.

11.1 Gestion instituoional

11.2 Apoyo a los productores

Exoelente Muy bueno Bueno

Regular

Exoelente __ Muy bueno ___ Bueno No sabe

11.3 Proteoción a loe vulnerables

11.4 Liderazgo regional

Mury bueno ___ Bueno

Regular

Malo __ No sabe

11.5 Prestación de loe servicios

11.6 Relaoioin oon laz JAC

Muy bueno

Bueno

Regular __ Malo ___ No sabe

Exoelente __ Muy bueno ___ Buen

Regular _ Malo __ No sabe

11.7 Trabajo oon otras ONG' =

Exoelente Muy bueno____ Bueno

Regular

Malo No sabe

Exoelente

Mury bueno

Bueno Regular

Malo N__ No sabe

12. Conoce organizaoiones no gubernamentales ONG's de orden regional, nacional o internacionalez: No __ Si___

13. Si La respuesta es pocitiva oómo oalifica la funoión que realiza en el municipio relacionado oon los Siguientes aspeotos:

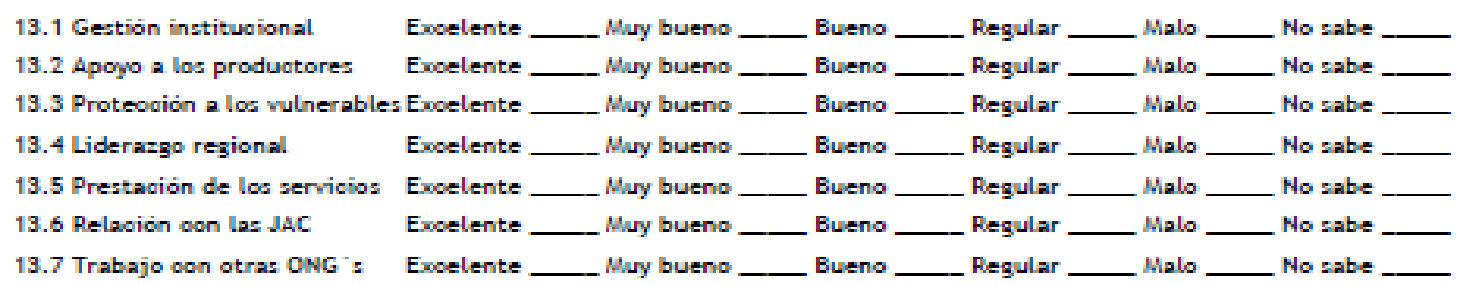

14. En términos generales cómo oalifioa la gestión de las instituoiones tanto públioa como privada (ONG' $z$ ) en el desarrollo del munioipio: Exoelente __ Muy bueno ___ Bueno___ Regular __ Malo __ No sabe ___

15. Cual es la prinoipal fortaleza y oportunidad :

16. Cuäl es la prinoipal debilidad y amenaza:

I

VI. EL DESARROLLO LOCAL

17. Conoce o sabe qué ez el Desarrollo Looal?

18. Conoce si alguna persona o entidad ha promovido o realizado aooiones de Desarrollo Local?

19. Ha partioipado de proyeotoe o aooiones para el Desarrollo Local?

20. Cómo fue el resultado.

Excelente Mury bueno

Bueno Regular

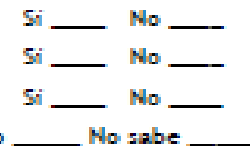

VII. EL DESARROLLO ECONÖMICO LOCAL

21. Conoce qué es Desarrollo Económico Local?

22. Considera que hay diferenciaz entre el Desarrollo Looal y el Dezarrollo Económioo Looal?

23. Conooe si alguna persona o entidad ha promovido aooiones para el Dezarrollo Eoonömioo Looal?

24. Ha partioipado de proyeotos o aooiones para el Desarrollo Eoonómioo Looal?

25. Cómo fue el resultado.

Excelente Muy bueno

Bueno

Regular

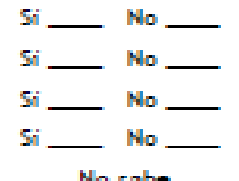

VIII. PROMOCIÓN DEL DESARROLLO ECONÓMICO LOCAL

26. Cree en los proyeotos y resultados que promueven el Desarrollo Económioo Looal?

27. Le gustaria aprender o conooer ampliamente sobre el Desarrollo Eoonómico Local?

28. Apoyaria procesoe que promuevan el Desarrollo Eoonómico Local para el munioipio?

29. Cree que implementar Desarrollo Económico Local le ayudaria a mejorar el Desarrollo Local?

30. Considera que el munioipio necesita procesoa de Desarrollo Eoonómioo Looal?

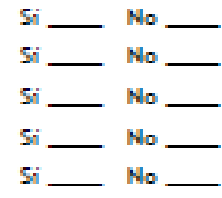




\section{Anexo D. Tabulación de Respuestas}

\begin{tabular}{|c|c|c|c|c|c|c|c|c|c|c|c|}
\hline \multirow[b]{2}{*}{ N. } & \multicolumn{11}{|c|}{ INFORMACIÓN SOBRE LA DIMENSIOÓN SOCIAL } \\
\hline & Salud & Educación & Vivienda & $\begin{array}{c}\text { Servicios } \\
\text { domiciliario } \\
\mathrm{s}\end{array}$ & $\begin{array}{l}\text { Atención a } \\
\text { la Juventud }\end{array}$ & $\begin{array}{c}\text { Protección a } \\
\text { la niñez }\end{array}$ & $\begin{array}{c}\text { Protección a } \\
\text { la tercera } \\
\text { edad }\end{array}$ & $\begin{array}{l}\text { Respeto a } \\
\text { derechos } \\
\text { humanos }\end{array}$ & Seguridad & $\begin{array}{c}\text { Fomento de } \\
\text { la cultura }\end{array}$ & GENERAL \\
\hline 1 & 2 & 2 & 2 & 2 & 2 & 3 & 3 & 2 & 3 & 2 & 2 \\
\hline 2 & 3 & 2 & 3 & 2 & 3 & 3 & 3 & 2 & 2 & 2 & 3 \\
\hline 3 & 2 & 2 & 3 & 2 & 1 & 3 & 3 & 3 & 3 & 3 & 3 \\
\hline 4 & 2 & 3 & 3 & 2 & 3 & 5 & 5 & 2 & 3 & 5 & 3 \\
\hline 5 & 3 & 3 & 5 & 3 & 2 & 3 & 2 & 5 & 3 & 2 & 3 \\
\hline 6 & 3 & 3 & 3 & 4 & 4 & 4 & 3 & 2 & 3 & 2 & 3 \\
\hline 7 & 3 & 3 & 2 & 3 & 2 & 2 & 1 & 2 & 3 & 2 & 2 \\
\hline 8 & 3 & 3 & 2 & 3 & 3 & 3 & 3 & 2 & 3 & 2 & 3 \\
\hline 9 & 5 & 4 & 4 & 3 & 3 & 3 & 3 & 3 & 4 & 2 & 4 \\
\hline 10 & 1 & 0 & 1 & 1 & 3 & 3 & 3 & 2 & 3 & 0 & 2 \\
\hline 11 & 2 & 3 & 2 & 3 & 5 & 5 & 2 & 2 & 5 & 2 & 3 \\
\hline 12 & 3 & 2 & 2 & 3 & 3 & 3 & 3 & 3 & 2 & 2 & 3 \\
\hline 13 & 2 & 2 & 3 & 3 & 2 & 2 & 1 & 2 & 3 & 2 & 2 \\
\hline 14 & 3 & 3 & 3 & 3 & 3 & 3 & 3 & 3 & 2 & 2 & 3 \\
\hline 15 & 2 & 3 & 3 & 3 & 2 & 2 & 2 & 3 & 2 & 2 & 3 \\
\hline 16 & 2 & 3 & 3 & 3 & 2 & 3 & 3 & 3 & 2 & 2 & 3 \\
\hline 17 & 5 & 4 & 4 & 4 & 4 & 4 & 3 & 3 & 4 & 2 & 3 \\
\hline 18 & 3 & 3 & 3 & 3 & 3 & 3 & 3 & 4 & 3 & 2 & 3 \\
\hline 19 & 3 & 3 & 2 & 3 & 3 & 3 & 3 & 2 & 2 & 2 & 2 \\
\hline 20 & 4 & 4 & 4 & 4 & 4 & 4 & 2 & 2 & 4 & 2 & 4 \\
\hline 21 & 2 & 3 & 3 & 3 & 4 & 3 & 2 & 3 & 5 & 4 & 3 \\
\hline 22 & 3 & 3 & 3 & 5 & 5 & 5 & 5 & 5 & 5 & 5 & 4 \\
\hline 23 & 2 & 2 & 1 & 2 & 2 & 3 & 2 & 1 & 2 & 3 & 3 \\
\hline
\end{tabular}

\begin{tabular}{|c|c|c|c|c|c|c|c|c|c|c|c|c|}
\hline \multirow{7}{*}{$\begin{array}{l}\text { Información Base para elaborar } \\
\text { el Indice de Confianza } \\
\text { (cantidades) }\end{array}$} & 0 - No sabe & - & 1 & - & - & - & - & - & - & - & 1 & \\
\hline & 1 - Malo & 1 & - & 2 & 1 & 1 & - & 2 & 1 & - & - & \\
\hline & 2-Regular & 9 & 6 & 6 & 5 & 7 & 3 & 6 & 11 & 7 & 17 & 5 \\
\hline & 3 - Bueno & 10 & 13 & 11 & 13 & 9 & 14 & 13 & 8 & 10 & 2 & 15 \\
\hline & 4 - Muy Bueno & 1 & 3 & 3 & 3 & 4 & 3 & - & 1 & 3 & 1 & 3 \\
\hline & 5 - Excelente & 2 & - & 1 & 1 & 2 & 3 & 2 & 2 & 3 & 2 & - \\
\hline & Total & 23 & 23 & 23 & 23 & 23 & 23 & 23 & 23 & 23 & 23 & 23 \\
\hline
\end{tabular}




\begin{tabular}{|c|c|c|c|c|c|c|c|c|c|c|c|}
\hline \multirow[b]{2}{*}{ N. } & \multicolumn{11}{|c|}{ INFORMACIÓN SOBRE LA DIMENSIÓN ECONÓNCA } \\
\hline & $\begin{array}{c}\text { Oportunidad } \\
\text { a los } \\
\text { negocios }\end{array}$ & $\begin{array}{l}\text { Incentivo a } \\
\text { la Inversión }\end{array}$ & \begin{tabular}{|c|} 
Alternativas \\
de Empleo
\end{tabular} & $\begin{array}{l}\text { Niveles de } \\
\text { Ingresos }\end{array}$ & $\begin{array}{c}\text { Organizació } \\
\text { n del } \\
\text { Comercio }\end{array}$ & $\begin{array}{l}\text { Oferta } \\
\text { turistica }\end{array}$ & $\begin{array}{c}\text { Calidad de } \\
\text { la } \\
\text { producción }\end{array}$ & $\begin{array}{c}\text { Diversidad } \\
\text { de la oferta } \\
\text { Pcc }\end{array}$ & $\begin{array}{c}\text { Estado de la } \\
\text { Infraestructu } \\
\text { ra }\end{array}$ & $\begin{array}{c}\text { Apoyo a la } \\
\text { asociativida } \\
\text { d }\end{array}$ & GENERAL \\
\hline 1 & 3 & 3 & 3 & 3 & 2 & 2 & 0 & 0 & 2 & 1 & 3 \\
\hline 2 & 3 & 3 & 2 & 2 & 3 & 2 & 2 & 2 & 3 & 3 & 3 \\
\hline 3 & 5 & 4 & 3 & 3 & 3 & 4 & 4 & 4 & 3 & 3 & 3 \\
\hline 4 & 0 & 0 & 3 & 3 & 2 & 2 & 0 & 0 & 0 & 3 & 2 \\
\hline 5 & 5 & 5 & 3 & 2 & 2 & 3 & 5 & 4 & 2 & 5 & 3 \\
\hline 6 & 3 & 2 & 2 & 2 & 3 & 2 & 3 & 3 & 2 & 2 & 2 \\
\hline 7 & 4 & 3 & 2 & 2 & 3 & 2 & 3 & 2 & 4 & 2 & 3 \\
\hline 8 & 2 & 2 & 2 & 2 & 3 & 2 & 3 & 2 & 3 & 2 & 3 \\
\hline 9 & 3 & 3 & 3 & 2 & 3 & 2 & 3 & 3 & 4 & 2 & 3 \\
\hline 10 & 4 & 0 & 1 & 2 & 2 & 2 & 2 & 1 & 2 & 3 & 2 \\
\hline 11 & 2 & 3 & 2 & 2 & 5 & 2 & 3 & 2 & 4 & 2 & 2 \\
\hline 12 & 2 & 2 & 2 & 2 & 3 & 2 & 2 & 2 & 3 & 3 & 2 \\
\hline 13 & 2 & 3 & 2 & 2 & 3 & 1 & 0 & 2 & 3 & 0 & 2 \\
\hline 14 & 3 & 2 & 2 & 2 & 3 & 3 & 4 & 4 & 4 & 3 & 3 \\
\hline 15 & 2 & 2 & 2 & 2 & 3 & 2 & 3 & 3 & 2 & 0 & 3 \\
\hline 16 & 3 & 2 & 2 & 3 & 3 & 2 & 4 & 4 & 4 & 3 & 3 \\
\hline 17 & 3 & 3 & 3 & 3 & 3 & 3 & 2 & 2 & 4 & 2 & 3 \\
\hline 18 & 3 & 3 & 3 & 2 & 3 & 2 & 2 & 2 & 4 & 2 & 3 \\
\hline 19 & 2 & 2 & 2 & 2 & 3 & 2 & 2 & 0 & 2 & 3 & 2 \\
\hline 20 & 3 & 3 & 3 & 3 & 3 & 2 & 2 & 2 & 3 & 2 & 3 \\
\hline 21 & 3 & 5 & 3 & 2 & 3 & 2 & 2 & 2 & 3 & 1 & 2 \\
\hline 22 & 3 & 5 & 5 & 4 & 3 & 3 & 4 & 3 & 5 & 4 & 3 \\
\hline 23 & 3 & 1 & 3 & 3 & 3 & 2 & 2 & 2 & 1 & 1 & 1 \\
\hline
\end{tabular}

\begin{tabular}{|c|c|c|c|c|c|c|c|c|c|c|c|}
\hline 0 - No sabe & 1 & 2 & - & - & - & - & 3 & 3 & 1 & 2 & - \\
\hline 1 - Malo & - & 1 & 1 & - & - & 1 & - & 1 & 1 & 3 & 1 \\
\hline 2-Regular & 6 & 7 & 11 & 15 & 4 & 17 & 9 & 11 & 6 & 8 & 8 \\
\hline 3-Bueno & 12 & 9 & 10 & 7 & 18 & 4 & 6 & 4 & 7 & 8 & 14 \\
\hline 4-Muy Bueno & 2 & 1 & - & 1 & - & 1 & 4 & 4 & 7 & 1 & - \\
\hline 5 - Excelente & 2 & 3 & 1 & - & 1 & - & 1 & - & 1 & 1 & - \\
\hline Total & 23 & 23 & 23 & 23 & 23 & 23 & 23 & 23 & 23 & 23 & 23 \\
\hline
\end{tabular}




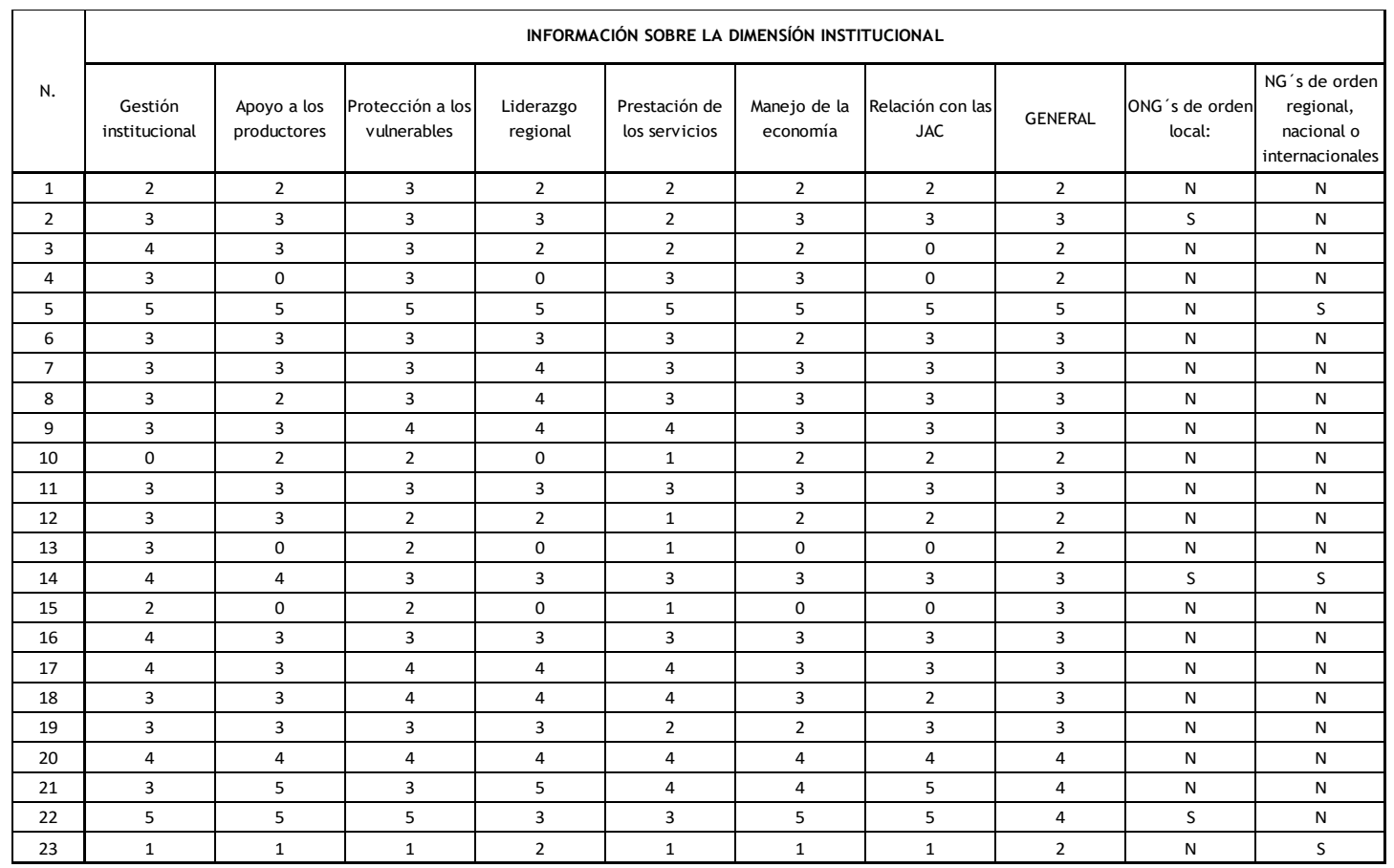

\begin{tabular}{|c|c|c|c|c|c|c|c|c|c|c|c|}
\hline \multirow[b]{2}{*}{ Desempeño } & \multicolumn{8}{|c|}{ DIMENSIÓN INSTITUCIONAL } & & & \\
\hline & $\begin{array}{c}\text { Gestión } \\
\text { institucional }\end{array}$ & $\begin{array}{l}\text { Apoyo a los } \\
\text { productores }\end{array}$ & $\begin{array}{c}\text { Protección a los } \\
\text { vulnerables }\end{array}$ & $\begin{array}{l}\text { Liderazgo } \\
\text { regional }\end{array}$ & $\begin{array}{l}\text { Prestación de } \\
\text { los servicios }\end{array}$ & $\begin{array}{l}\text { Manejo de la } \\
\text { economía }\end{array}$ & $\begin{array}{c}\text { Relación con las } \\
\text { JAC }\end{array}$ & GENERAL & & & \\
\hline 0 - No sabe & $4 \%$ & $13 \%$ & $0 \%$ & $17 \%$ & $0 \%$ & $9 \%$ & $17 \%$ & $0 \%$ & & & \\
\hline 1 - Malo & $4 \%$ & $4 \%$ & $4 \%$ & $0 \%$ & $22 \%$ & $4 \%$ & $4 \%$ & $0 \%$ & & & \\
\hline 2 - Regular & $9 \%$ & $13 \%$ & $17 \%$ & $17 \%$ & $17 \%$ & $26 \%$ & $17 \%$ & $30 \%$ & No & $87 \%$ & $87 \%$ \\
\hline 3 - Bueno & $52 \%$ & $48 \%$ & $52 \%$ & $30 \%$ & $35 \%$ & $43 \%$ & $43 \%$ & $52 \%$ & & & \\
\hline 4 - Muy Bueno & $22 \%$ & $9 \%$ & $17 \%$ & $26 \%$ & $22 \%$ & $9 \%$ & $4 \%$ & $13 \%$ & $\mathrm{Si}$ & $13 \%$ & $13 \%$ \\
\hline 5 - Excelente & $9 \%$ & $13 \%$ & $9 \%$ & $9 \%$ & $4 \%$ & $9 \%$ & $13 \%$ & $4 \%$ & & & \\
\hline Total & $100 \%$ & $100 \%$ & $100 \%$ & $100 \%$ & $100 \%$ & $100 \%$ & $100 \%$ & $100 \%$ & & & \\
\hline
\end{tabular}




\begin{tabular}{|c|c|c|c|c|c|c|c|c|c|c|c|c|c|c|}
\hline \multirow[b]{2}{*}{ N. } & \multicolumn{4}{|c|}{ EL DESARROLLO LOCAL } & \multicolumn{5}{|c|}{ EL DESARROLLO ECONÓMICO LOCAL } & \multicolumn{5}{|c|}{ PROMOCIÓN DEL DESARROLLO ECONÓMICO LOCAL } \\
\hline & $\begin{array}{l}\text { Conoce qué es } \\
\text { Desarrollo Local }\end{array}$ & \begin{tabular}{|c|} 
Conoce s1 \\
persona o \\
entidad alguna \\
ha promovido \\
acciones narael
\end{tabular} & $\begin{array}{l}\text { Ha participado } \\
\text { de proyectos } 0 \\
\text { acciones para el } \\
\text { Desarrollo Local } \\
\end{array}$ & RESULTADO & \begin{tabular}{|c|} 
Conoce qué es \\
Desarrollo \\
Económico \\
Local \\
\end{tabular} & \begin{tabular}{|c|} 
Considera que \\
hay diferencias \\
entre el \\
Desarrollo Local \\
vel Desarrollo
\end{tabular} & \begin{tabular}{|c|} 
Conoce st \\
persona o \\
entidad alguna \\
ha promovido \\
acciones narael
\end{tabular} & \begin{tabular}{|c|} 
Ha participado \\
de proyectos 0 \\
acciones para el \\
Desarrollo \\
Fconómico \\
\end{tabular} & RESULTADO & \begin{tabular}{|c|} 
Cree en los \\
proyectosy \\
resultados que \\
promueven el \\
Desarrollo \\
\end{tabular} & $\begin{array}{l}\text { Le gustana } \\
\text { aprender } 0 \\
\text { conocer } \\
\text { ampliamente } \\
\text { sabre el } \\
\end{array}$ & \begin{tabular}{|c|} 
Apoyarana \\
procesos que \\
promuevan el \\
Desarrollo \\
Económico \\
\end{tabular} & $\begin{array}{l}\text { Cree que } \\
\text { implementar } \\
\text { Desarrollo } \\
\text { Económico } \\
\text { localle }\end{array}$ & $\begin{array}{c}\text { Considera que } \\
\text { el municipio } \\
\text { necesita } \\
\text { procesos de } \\
\text { Desarrollo }\end{array}$ \\
\hline 1 & $\mathrm{~s}$ & s & $\mathrm{N}$ & 3 & $s$ & $s$ & $s$ & $\mathrm{~N}$ & 3 & s & s & s & s & s \\
\hline 2 & $\mathrm{~s}$ & $\mathrm{~s}$ & $\mathrm{~s}$ & 3 & $\mathrm{~s}$ & $\mathrm{~s}$ & $\mathrm{~s}$ & $\mathrm{~s}$ & 3 & $\mathrm{~s}$ & $\mathrm{~s}$ & $\mathrm{~s}$ & $\mathrm{~s}$ & $\mathrm{~s}$ \\
\hline 3 & $\mathrm{~s}$ & $\mathrm{~s}$ & $\mathrm{~s}$ & 3 & $\mathrm{~s}$ & $\mathrm{~N}$ & $\mathrm{~N}$ & $\mathrm{~N}$ & 0 & $\mathrm{~s}$ & $\mathrm{~s}$ & $\mathrm{~s}$ & $\mathrm{~s}$ & $\mathrm{~s}$ \\
\hline 4 & $\mathrm{~N}$ & & & & $\mathrm{~N}$ & & & & & & & & & \\
\hline 5 & $\mathrm{~s}$ & $\mathrm{~s}$ & $\mathrm{~s}$ & 5 & $s$ & $\mathrm{~N}$ & $\mathrm{~s}$ & $\mathrm{~s}$ & 5 & $\mathrm{~s}$ & $\mathrm{~s}$ & $\mathrm{~s}$ & $\mathrm{~s}$ & $\mathrm{~s}$ \\
\hline 6 & $\mathrm{~s}$ & $\mathrm{~s}$ & $\mathrm{~s}$ & 4 & $\mathrm{~s}$ & $\mathrm{~s}$ & $\mathrm{~s}$ & $\mathrm{~s}$ & 4 & $\mathrm{~s}$ & $\mathrm{~s}$ & $\mathrm{~s}$ & $\mathrm{~s}$ & $\mathrm{~s}$ \\
\hline 7 & $\mathrm{~N}$ & & & & $\mathrm{~N}$ & & & & & & $\mathrm{~s}$ & & & \\
\hline 8 & $\mathrm{~s}$ & $\mathrm{~s}$ & $\mathrm{~N}$ & 0 & $\mathrm{~s}$ & $\mathrm{~s}$ & $\mathrm{~s}$ & $\mathrm{~N}$ & 0 & $\mathrm{~s}$ & $\mathrm{~s}$ & $\mathrm{~s}$ & $\mathrm{~s}$ & $\mathrm{~s}$ \\
\hline 9 & $S$ & $S$ & $S$ & 3 & $S$ & $S$ & $S$ & $S$ & 3 & $S$ & $S$ & $S$ & $S$ & $S$ \\
\hline 10 & $\mathrm{~N}$ & & & & $\mathrm{~N}$ & & & & & & $\mathrm{~s}$ & & & \\
\hline 11 & $\mathrm{~s}$ & $\mathrm{~N}$ & $\mathrm{~N}$ & 0 & $\mathrm{~s}$ & $\mathrm{~s}$ & $\mathrm{~N}$ & $\mathrm{~N}$ & 0 & $\mathrm{~s}$ & $\mathrm{~s}$ & $S$ & $\mathrm{~s}$ & $\mathrm{~s}$ \\
\hline 12 & $\mathrm{~N}$ & & & & $\mathrm{~N}$ & & & & & & $S$ & & & \\
\hline 13 & $\mathrm{~N}$ & , & & & $\mathrm{N}$ & & & & & & $S$ & & & \\
\hline 14 & $S$ & $S$ & $S$ & 3 & $S$ & $S$ & $S$ & $S$ & 3 & $S$ & $S$ & $S$ & $S$ & $S$ \\
\hline 15 & $S$ & $S$ & $S$ & 3 & $S$ & $S$ & $S$ & $S$ & 3 & $S$ & $S$ & $S$ & $S$ & $S$ \\
\hline 16 & $S$ & $\mathrm{~N}$ & $\mathrm{~N}$ & 0 & $S$ & $\mathrm{~N}$ & $\mathrm{~N}$ & $\mathrm{~N}$ & 0 & $S$ & $S$ & $S$ & $S$ & $S$ \\
\hline 17 & $S$ & $S$ & $S$ & 3 & $S$ & $S$ & $S$ & $S$ & 4 & $\mathrm{~S}$ & S & $S$ & $\mathrm{~S}$ & $\mathrm{~S}$ \\
\hline 18 & $S$ & $S$ & $S$ & 4 & $S$ & $S$ & $S$ & $S$ & 4 & $S$ & $S$ & $S$ & $S$ & $S$ \\
\hline 19 & $S$ & $S$ & $\mathrm{~N}$ & 0 & $S$ & $S$ & $\mathrm{~N}$ & $\mathrm{~N}$ & 0 & $S$ & $S$ & $S$ & $S$ & $S$ \\
\hline 20 & $\mathrm{~s}$ & $\mathrm{~s}$ & $\mathrm{~s}$ & 4 & $\mathrm{~s}$ & $\mathrm{~s}$ & $\mathrm{~s}$ & $\mathrm{~s}$ & 4 & $S$ & $\mathrm{~s}$ & $\mathrm{~s}$ & $\mathrm{~s}$ & $S$ \\
\hline 21 & $S$ & $S$ & $S$ & 3 & $S$ & $S$ & $S$ & $S$ & 4 & $S$ & $S$ & $S$ & $S$ & $S$ \\
\hline 22 & $\mathrm{~S}$ & $\mathrm{~S}$ & $\mathrm{~N}$ & 0 & $\mathrm{~S}$ & $\mathrm{~S}$ & $S$ & $\mathrm{~N}$ & 4 & $\mathrm{~S}$ & $\mathrm{~S}$ & $S$ & $\mathrm{~S}$ & $\mathrm{~S}$ \\
\hline 23 & $S$ & $S$ & $S$ & 2 & $S$ & $S$ & $\mathrm{~N}$ & $\mathrm{~N}$ & 0 & $\mathrm{~N}$ & $S$ & $S$ & $S$ & $S$ \\
\hline
\end{tabular}

\begin{tabular}{|l|l|l|l|l|l|l|l|l|}
\hline & & & & $33 \%$ & & & \\
\hline
\end{tabular}


Anexo E. Cálculos de Cronbach (Fiabilidad Variables Dimensión Social)

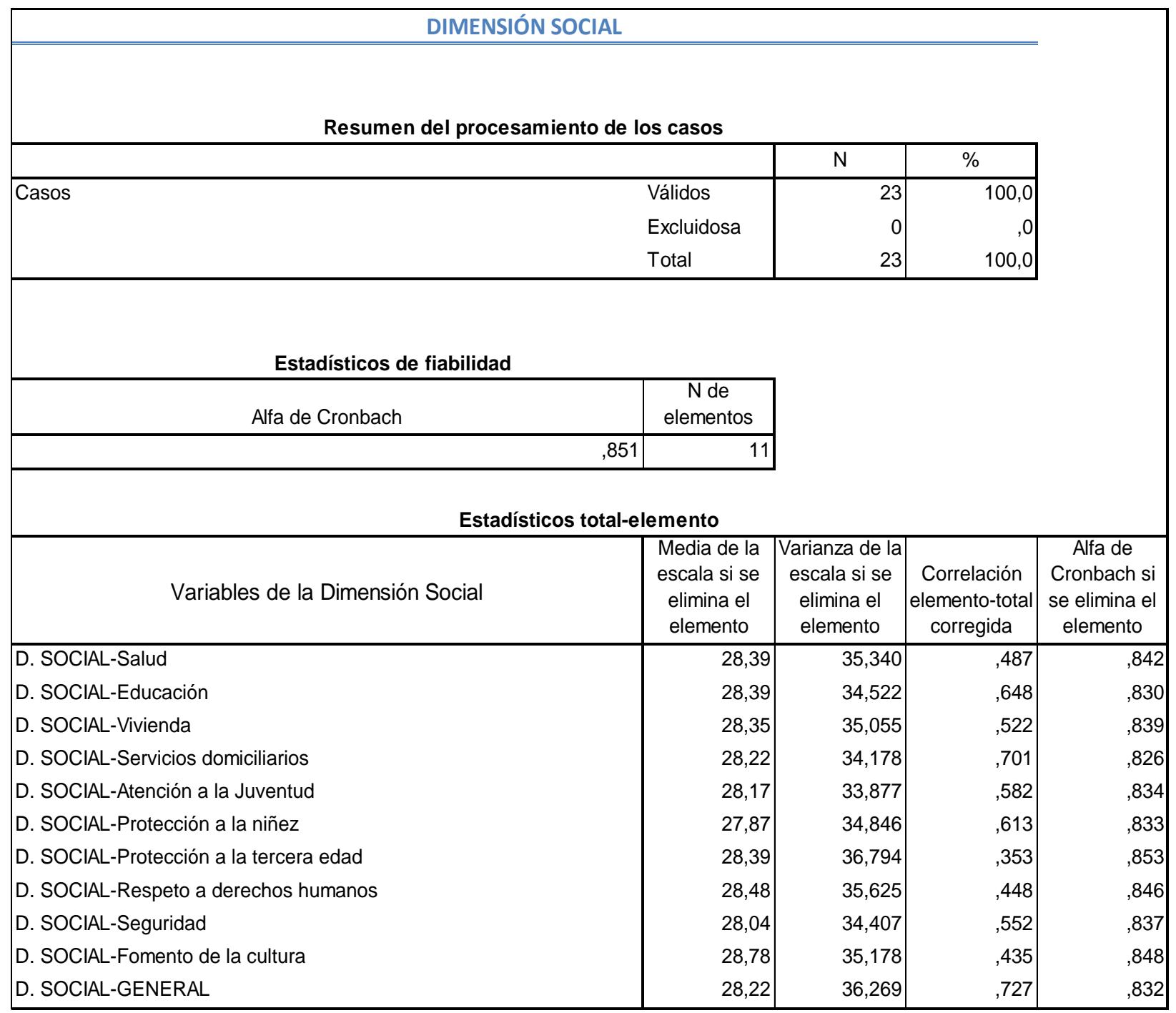


Anexo F. Cálculos de Cronbach (Fiabilidad Variables Dimensión Económica)

\begin{tabular}{|c|c|c|c|c|}
\hline \multicolumn{4}{|l|}{ DIMENSIÓN ECONÓMICA } & \\
\hline \multicolumn{4}{|c|}{ Resumen del procesamiento de los casos } & \\
\hline & & $\mathrm{N}$ & $\%$ & \\
\hline Casos & Válidos & 23 & 100,0 & \\
\hline & Excluidosa & 0 &, 0 & \\
\hline & Total & 23 & 100,0 & \\
\hline \multicolumn{2}{|l|}{ Estadísticos de fiabilidad } & & & \\
\hline Alfa de Cronbach & $\begin{array}{c}\mathrm{N} \text { de } \\
\text { elementos }\end{array}$ & & & \\
\hline ,820 & 11 & & & \\
\hline \multicolumn{5}{|c|}{ Estadísticos total-elemento } \\
\hline Variables de la Dimensión Económica & \begin{tabular}{|c|} 
Media de la \\
escala si se \\
elimina el \\
elemento
\end{tabular} & \begin{tabular}{|c|} 
Varianza de la \\
escala si se \\
elimina el \\
elemento
\end{tabular} & \begin{tabular}{|c|} 
Correlación \\
elemento-total \\
corregida
\end{tabular} & $\begin{array}{c}\text { Alfa de } \\
\text { Cronbach si } \\
\text { se elimina el } \\
\text { elemento }\end{array}$ \\
\hline D. ECONÓMICA-Oportunidad a los negocios & 25,13 & 34,573 & ,551 & ,799 \\
\hline D. ECONÓMICA-Incentivo a la Inversión & 25,35 & 31,601 & ,610 & ,793 \\
\hline D. ECONÓMICA-Alternativas de Empleo & 25,48 & 38,261 & ,374 & ,815 \\
\hline D. ECONÓMICA-Niveles de Ingresos & 25,61 & 40,794 & , 189 & ,825 \\
\hline D. ECONÓMICA-Organización del Comercio & 25,09 & 41,356 & , 109 & ,830 \\
\hline D. ECONÓMICA-Oferta turística & 25,78 & 37,178 & ,685 & ,798 \\
\hline D. ECONÓMICA-Calidad de la producción & 25,52 & 30,170 & ,741 & ,775 \\
\hline D. ECONÓMICA-Diversidad de la oferta Pcc & 25,78 & 31,996 & ,668 &, 785 \\
\hline D. ECONÓMICA-Estado de la Infraestructura & 25,09 & 33,628 &, 560 &, 798 \\
\hline D. ECONÓMICA-Apoyo a la asociatividad & 25,74 & 35,838 & ,378 & ,818 \\
\hline D. ECONÓMICA-GENERAL & 25,43 & 38,348 &, 527 & ,807 \\
\hline
\end{tabular}




\section{Anexo G. Cálculos de Cronbach (Fiabilidad Variables Dimensión Institucional)}

\begin{tabular}{|c|c|c|c|}
\hline \multicolumn{4}{|c|}{ DIMENSIÓN INSTITUCIONAL } \\
\hline \multicolumn{4}{|c|}{ Resumen del procesamiento de los casos } \\
\hline & & $\mathrm{N}$ & $\%$ \\
\hline \multirow[t]{3}{*}{ Casos } & Válidos & 23 & 100,0 \\
\hline & Excluidosa & 0 &, 0 \\
\hline & Total & 23 & 100,0 \\
\hline
\end{tabular}

\section{Estadísticos de fiabilidad}

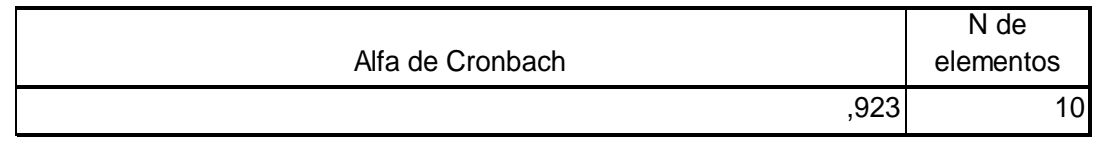

\section{Estadísticos total-elemento}

\begin{tabular}{|c|c|c|c|c|}
\hline Variables de la Dimensión Institucional & $\begin{array}{c}\text { Media de la } \\
\text { escala si se } \\
\text { elimina el } \\
\text { elemento }\end{array}$ & \begin{tabular}{|c|} 
Varianza de la \\
escala si se \\
elimina el \\
elemento
\end{tabular} & \begin{tabular}{|c|} 
Correlación \\
elemento-total \\
corregida
\end{tabular} & $\begin{array}{c}\text { Alfa de } \\
\text { Cronbach si } \\
\text { se elimina el } \\
\text { elemento }\end{array}$ \\
\hline D.INSTITUCIONAL-Gestión institucional & 19,61 & 62,885 & ,672 & 917 \\
\hline D.INSTITUCIONAL-Apoyo a los productores & 19,96 & 55,316 & ,865 & ,906 \\
\hline D.INSTITUCIONAL-Protección a los vulnerables & 19,61 & 62,885 & ,820 & 911 \\
\hline D.INSTITUCIONAL-Liderazgo regional & 19,96 & 54,862 & ,826 & ,910 \\
\hline D.INSTITUCIONAL-Prestación de los servicios & 20,00 & 59,727 & ,819 & ,909 \\
\hline D.INSTITUCIONAL-Manejo de la economía & 20,04 & 57,498 & ,888 & ,904 \\
\hline D.INSTITUCIONAL-Relación con las JAC & 20,17 & 54,423 & ,855 & ,907 \\
\hline D.INSTITUCIONAL-GENERAL & 19,78 & 64,723 & ,845 & ,912 \\
\hline D.INSTITUCIONAL-ONG's de orden local: & 22,57 & 74,439 & ,265 & ,932 \\
\hline D.INSTITUCIONAL-NG's de orden regional, nacional o internacionales & 22,57 & 75,166 &, 142 & ,934 \\
\hline
\end{tabular}




\section{Anexo H. Cálculos CATPCA Ponderados Dimensión Social}

\begin{tabular}{|l|r|r|}
\hline \multicolumn{3}{|c|}{ DIMENSIÓN SOCIAL } \\
\hline \hline \multicolumn{3}{|c|}{ Resumen del modelo } \\
\hline
\end{tabular}

\begin{tabular}{|c|c|c|c|c|c|c|c|c|}
\hline \multicolumn{9}{|c|}{ Varianza explicada } \\
\hline & \multicolumn{4}{|c|}{ Coordenadas de centroide } & \multicolumn{4}{|c|}{ Total (coordenadas del vector) } \\
\hline & \multicolumn{3}{|c|}{ Dimensión } & \multirow[b]{2}{*}{ Media } & \multicolumn{3}{|c|}{ Dimensión } & \multirow[b]{2}{*}{ Total } \\
\hline & 1 & 2 & 3 & & 1 & 2 & 3 & \\
\hline D. SOCIAL-Salud & , 180 &, 791 &, 106 & 359 & , 160 &, 788 & 003 & 951 \\
\hline D. SOCIAL-Educación & 239 & ,791 & 009 & 346 & , 161 &, 774 & 007 & ,942 \\
\hline D. SOCIAL-Vivienda & 215 & 810 &, 546 &, 524 & , 143 & 642 & ,114 & ,899 \\
\hline D. SOCIAL-Servicios domiciliarios & 666 & ,479 & 093 &, 413 & ,594 & , 155 & ,065 & ,814 \\
\hline D. SOCIAL-Atención a la Juventud &, 576 & 326 & ,268 & 390 & ,563 & 022 & ,203 & ,788 \\
\hline D. SOCIAL-Protección a la niñez & ,617 & , 488 & , 151 & , 419 & ,557 & , 196 & 124 & 877 \\
\hline D. SOCIAL-Protección a la tercera edad &, 589 & 307 & 007 & ,301 & ,542 & 279 & ,001 &, 822 \\
\hline D. SOCIAL-Respeto a derechos humanos &, 326 & , 143 &, 535 & ,335 & ,312 & ,047 &, 504 & 863 \\
\hline D. SOCIAL-Seguridad & ,568 & ,819 & |111 & , 499, & ,551 & 205 & 084 & ,840 \\
\hline D. SOCIAL-Fomento de la cultura &, 526 & ,317 & 031 & 291 &, 511 & ,300 & 001 & , 811 \\
\hline D. SOCIAL-GENERAL & ,630 & 143 & ,018 & ,264 & ,629 & 141 & 017 & ,787 \\
\hline Total activo & 5,130 & 5,415 & 1,875 & 4,140 & 4,723 & 3,548 & 1,124 & 9,395 \\
\hline
\end{tabular}

\begin{tabular}{|l|r|r|r|}
\hline & \multicolumn{3}{|c|}{ Dimensión } \\
\cline { 2 - 4 } & \multicolumn{1}{|c|}{1} & \multicolumn{1}{|c|}{2} & \multicolumn{1}{|c|}{3} \\
\hline D. SOCIAL-Servicios domicliarios &, 952 &,- 522 &, 453 \\
\hline D. SOCIAL-GENERAL &, 980 &, 498 &, 233 \\
\hline D. SOCIAL-Protección a la tercera edad &, 909 & -701 &, 066 \\
D. SOCIAL-Fomento de la cultura &, 883 & -726 &, 046 \\
\hline D. SOCIAL-Seguridad &, 917 &, 601 &,- 511 \\
\hline D. SOCIAL-Protección a la niñez &, 922 &,- 588 &,- 623 \\
\hline D. SOCIAL-Atención a la Juventud &, 927 &,- 198 & -796 \\
\hline D. SOCIAL-Vlivienda &, 468 & 1,063 &, 597 \\
\hline D. SOCIAL-Salud &, 494 & 1,178 &,- 103 \\
D. SOCIAL-Educación &, 495 & 1,168 &,- 144 \\
\hline D. SOCIAL-Respeto a derechos humanos &, 690 &,- 287 & 1,256 \\
\hline
\end{tabular}




\section{Anexo I. Cálculos CATPCA Ponderados Dimensión Económica}

\begin{tabular}{|c|c|c|c|c|c|c|c|c|c|c|}
\hline \multicolumn{4}{|c|}{ DIMENSIÓN ECONÓMICA } & & & & & & & \\
\hline \multicolumn{4}{|c|}{ Resumen del modelo } & & & & & & & \\
\hline \multirow[t]{7}{*}{ Dimensión } & & \multirow[b]{2}{*}{$\begin{array}{l}\text { Alfa de } \\
\text { Cronbach }\end{array}$} & $\begin{array}{l}\text { Varianza } \\
\text { explicada }\end{array}$ & & & & & & & \\
\hline & & & \begin{tabular}{|c|} 
Total \\
(Autovalores)
\end{tabular} & & & & & & & \\
\hline & 1 & .837 & 4,173 & & & & & & & \\
\hline & 2 & ,704 & 2,780 & & & & & & & \\
\hline & 3 & 617 & 2,277 & & & & & & & \\
\hline & 4 & ,229 & 1,263 & & & & & & & \\
\hline & Total & ,995 & 10,493 & & & & & & & \\
\hline \multicolumn{11}{|c|}{ Varianza explicada } \\
\hline & \multicolumn{5}{|c|}{ Coordenadas de centroide } & \multicolumn{5}{|c|}{ Total (coordenadas del vector) } \\
\hline & \multicolumn{4}{|c|}{ Dimensión } & & \multicolumn{4}{|c|}{ Dimensión } & \multirow[b]{2}{*}{ Total } \\
\hline & 1 & 2 & 3 & 4 & Media & 1 & 2 & 3 & 4 & \\
\hline D. ECONÓMICA-Oportunidad a los negocios & ,452 & 211 & ,231 & ,112 & 251 &, 446 & 166 & ,207 & ,003 &, 822 \\
\hline D. ECONÓMICA-Incentivo a la Inversión & ,657 & 884 & 200 & ,228 & ,492 & 201 & ,763 & 031 & 005 & 1,000 \\
\hline D. ECONÓMICA-Alternativas de Empleo & 279 & 134 &, 744 &, 330 &, 372 & 264 & 001 &, 715 & 006 & 987 \\
\hline D. ECONÓMICA-Niveles de Ingresos & ,265 & ,158 & ,737 & 036 & 299 & 264 & 001 & ,715 &, 006 & .987 \\
\hline D. ECONÓMICA-Organización del Comercio & ,073 & 016 & , 170 & ,976 &, 309 & ,065 & ,005 & , 170 & ,975 & 1,215 \\
\hline D. ECONÓMICA-Oferta turística & ,624 & 095 & , 116 &, 195 & 257 & 603 & 087 & 001 & , 125 &, 816 \\
\hline D. ECONÓMICA-Calidad de la producción & ,778 & 177 & , 133 & ,201 &, 322 & ,769 & 119 & 039 & ,000 &, 927 \\
\hline D. ECONÓMICA-Diversidad de la oferta PcC & ,497 & 112 & ,411 & ,322 & ,336 & 408 & 101 & 269 & 081 & 858 \\
\hline D. ECONÓMICA-Estado de la Infraestructura & , 455 &, 775 &, 760 &, 334 &, 581 & 275 &, 724 & ,001 & 001 & 1,000 \\
\hline D. ECONÓMICA-Apoyo a la asociatividad & , 717 &, 313 &, 863 & , 175 &, 517 & 680 & 045 & 091 & 061 & 878 \\
\hline D. ECONÓMICA-GENERAL & ,304 & ,797 & 037 & , 125 &, 316 & , 198 &, 768 & 036 & 000 & 1,002 \\
\hline Total activo & 5,101 & 3,673 & 4,404 & 3,032 & 4,052 & 4,173 & 2,780 & 2,277 & 1,263 & 10,493 \\
\hline
\end{tabular}

\section{Saturaciones en componentes}

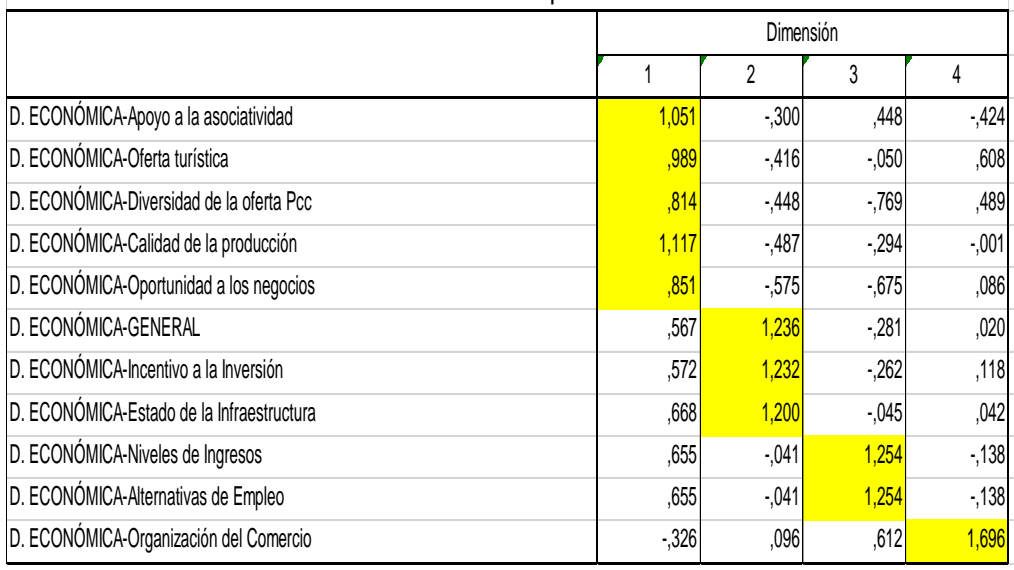




\section{Anexo J. Cálculos CATPCA Ponderados Dimensión Institucional}

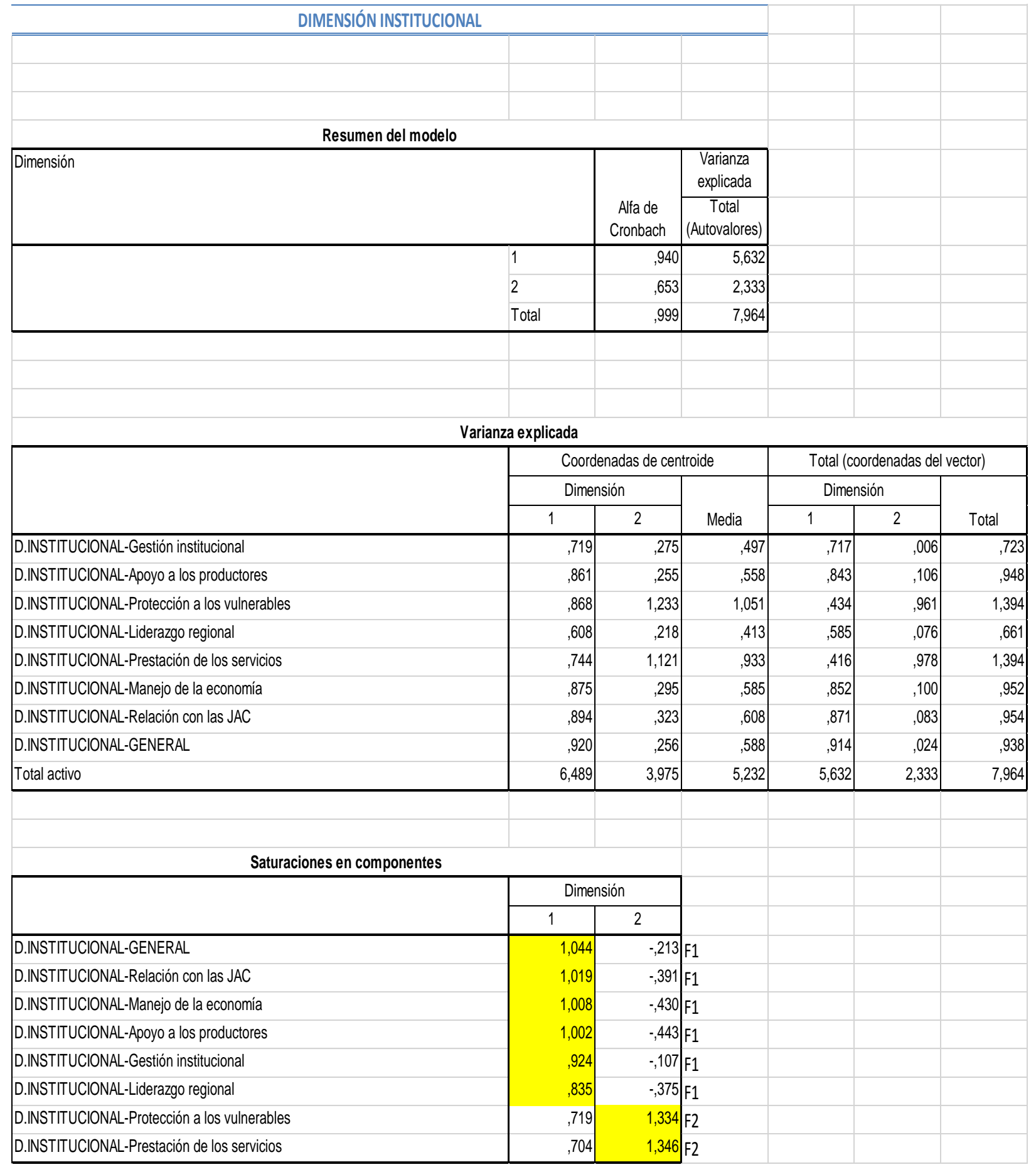




\section{Anexo K. Consolidado de los Cálculos Ponderados para cada Dimensión}

CONSOLIDADO DE LOS CALCULOS PONDERADOS POR DIMENSIÓN Y GENERAL

\begin{tabular}{|c|c|c|c|c|c|c|c|c|c|c|c|c|c|c|}
\hline N. & Encuestado & $\begin{array}{l}\text { Primer } \\
\text { factor D. } \\
\text { SOCIAL }\end{array}$ & $\begin{array}{l}\text { Segundo } \\
\text { factor D. } \\
\text { SOCIAL }\end{array}$ & $\begin{array}{l}\text { Tercero } \\
\text { factor D. } \\
\text { SOCIAL }\end{array}$ & $\begin{array}{l}\text { Primer } \\
\text { factor D. } \\
\text { ECONÓM } \\
\text { CA }\end{array}$ & $\begin{array}{l}\text { Segundo } \\
\text { factor D. } \\
\text { ECONóml } \\
\text { CA }\end{array}$ & $\begin{array}{l}\text { Tercero } \\
\text { factor D. } \\
\text { ECONÓMI } \\
\text { CA }\end{array}$ & $\begin{array}{l}\text { Cuarto } \\
\text { factor D. } \\
\text { ECONÓMl } \\
\text { CA }\end{array}$ & $\begin{array}{l}\text { Primer } \\
\text { factor } \\
\text { D.INSTITU } \\
\text { CIONAL }\end{array}$ & $\begin{array}{l}\text { Segundo } \\
\text { factor } \\
\text { D.INSTITU } \\
\text { CIONAL }\end{array}$ & $\begin{array}{l}\text { Indice } \\
\text { desarrollo } \\
\text { social }\end{array}$ & $\begin{array}{l}\text { Indice } \\
\text { económico }\end{array}$ & $\begin{array}{l}\text { Indice } \\
\text { desarrollo } \\
\text { institucion } \\
\text { al }\end{array}$ & $\begin{array}{l}\text { Indice } \\
\text { General } \\
\text { DEL }\end{array}$ \\
\hline 1 & ASOMAIZ & 4,9 & 4,0 & & 0 & 3 & 4 & & 1,0 & $5,($ & 4,4 & 4,1 & 4,3 & 4,9 \\
\hline 2 & AMEN & 5,2 & 5,3 & & 0 & 8 & 0 & 0 & 0 & 5, & 5,1 & 5,1 & 5,7 & 6,5 \\
\hline 3 & SOCIEDAD CIVIL & 5,1 & 4,6 & & 0 & 6, & 7] & 0 & 4,3 & $5,($ & 5,0 & 6,9 & 4,5 & 6,6 \\
\hline 4 & AMEN & 7,4 & 5,3 & & 0 & 1 & 4 & 0 & 1,0 & 6, & 6,2 & 3,0 & 3,7 & 4,3 \\
\hline 5 & AMEN & 5,2 & 7,3 & 3 & 0 & 8 & 7 & 0 & 10, & 10, & 6,5 & 6,9 & 10,0 & 8,4 \\
\hline 6 & JAC & 6,6 & 6,0 & & 0 & 4, & 0 & 0 & ;, & 6, & 6,1 & 4,7 & 5,8 & 6,6 \\
\hline 7 & ASOCIACIÓN DESPLAZADOS & 4,3 & 5,4 & & 0 & 6, & 7 & 0 & 0 & 6, & 4,7 & 5,4 & 6,2 & 5,4 \\
\hline 8 & $J A C$ & 5,7 & 5,4 & & 0 & 5 & 3 & 0 & 5,9 & 6, & 5,4 & 4,8 & 6,0 & 4,9 \\
\hline 9 & ORGANZZACIÓN RURAL & 6,3 & 8,7 & & 0 & 6, & 7 & 0 & 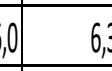 & 8,4 & 7,2 & 5,6 & 6,8 & 7,4 \\
\hline 10 & CONSEJO CONSULTIVO & 4,3 & 1,3 & & 0 & 8 & 7 & 0 & 1,0 & 3,4 & 3,1 & 3,8 & 2,9 & 3,2 \\
\hline 11 & CONSEJO CONSULTIVO & 7,2 & 4,7 & & 0 & 5 & 0 & 0 & 1,0 & 6, & 5,8 & 5,4 & 6,0 & 4,3 \\
\hline 12 & CONSEJO CONSULTIVO & 5,5 & 4,7 & & 0 & 4, & 7 & 0 & 3,0 & 3,4 & 5,2 & 4,6 & 4,2 & 4,7 \\
\hline 13 & CONSEJO CONSULTIVO & 4,3 & 4,6 & & 0 & 8 & 3 & 0 & 3,0 & 3,4 & 4,4 & 3,7 & 2,1 & 3,4 \\
\hline 14 & CONSEJO CONSULTIVO & 5,5 & 6,0 & & 0 & 8 & 0 & 0 & 0 & 6,1 & 5,7 & 5,9 & 6,5 & 7,0 \\
\hline 15 & CONSEJO CONSULTIVO & 4,6 & 5,3 & & 0 & 4, & 7 & 0 & 1,7 & 3,4 & 5,0 & 4,4 & 2,1 & 5,4 \\
\hline 16 & CONSEJO CONSULTIVO & 5,2 & 5,3 & & 0 & 4 & 0 & 0 & 3,0 & 6, & 5,3 & 5,9 & 6,2 & 4,4 \\
\hline 17 & CONSEJO CONSULTIVO & 6,9 & 8,7 & & 0 & 6, & 7 & 0 & 6,6 & 8,0 & 7,5 & 5,7 & 7,0 & 7,5 \\
\hline 18 & CONSEJO CONSULTIVO & 5,7 & 6,0 & & 0 & 4 & 7 & 3,0 & 0 & 8,4 & 6,1 & 5,3 & 6,5 & 7,0 \\
\hline 19 & ALCALD́́A & 5,1 & 5,4 & & 0 & 8 & 0 & 1,0 & 0 & 5, & 5,1 & 4,1 & 5,5 & 4,5 \\
\hline 20 & ALCALDÍA & 6,9 & 8,6 & & 4 & 6, & 0 & 5,0 & 0 & 8,1 & 7,0 & 5,3 & 8,0 & 7,6 \\
\hline 21 & ALCALD́́A & 6,8 & 5,3 & & 0 & 9 & 7 & 3,0 &, 0 & 7,4 & 6,2 & 5,1 & 8,2 & 7,4 \\
\hline 22 & ALCALDÍA & 9,7 & 6,0 & & 0 & 8, & 7 & 3,0 & 0 & 8,1 & 8,3 & 7,7 & 8,8 & 7,0 \\
\hline 23 & CONCEJO MUNCIPAL & 4,9 & 3,4 & & 0 & 2, & 0 & 5,0 &, 0 & 2,4 & 4,0 & 4,1 & 2,5 & 4,3 \\
\hline
\end{tabular}

\begin{tabular}{|c|r|r|r|r|r|r|r|r|r|r|r|r|r|}
\hline Promedio & 5,79 & 5,51 & 5,30 & 4,80 & 5,42 & 4,91 & 5,83 & 5,54 & 5,78 & 5,62 & 5,11 & 5,61 & 5,7630 \\
\hline Promedio Mínimo & 4,30 & 1,32 & 2,00 & 1,79 & 1,35 & 3,00 & 4,00 & 1,67 & 2,00 & 3,13 & 3,00 & 2,05 & 3,24 \\
\hline Promedio Máximo & 9,70 & 8,69 & 10,00 & 8,84 & 8,65 & 9,00 & 10,00 & 10,00 & 10,00 & 8,33 & 7,71 & 10,00 & 8,35 \\
\hline
\end{tabular}




\section{Anexo L. Consolidado Conocimiento en Desarrollo Local y Desarrollo Económico Local}

\begin{tabular}{|c|c|c|c|c|c|c|c|c|c|c|c|c|c|c|c|c|c|c|c|}
\hline \multirow[b]{2}{*}{ N. } & & \multicolumn{5}{|c|}{ EL DESARROLLO LOCAL } & & \multicolumn{6}{|c|}{ EL DESARROLLO ECONÓMICO LOCAL } & & \multicolumn{5}{|c|}{ PROMOCIÓN DEL DESARROLLO ECONÓMICO LOCAL } \\
\hline & & $\begin{array}{l}\text { Conoce quée es } \\
\text { Desarrollo Local }\end{array}$ & \begin{tabular}{c|c|} 
& Conoce si \\
sersona o \\
sentidad alyuna \\
al ha promovido \\
acciones para el \\
Desarrollo Local
\end{tabular} & \begin{tabular}{|l|} 
Ha participado \\
de proyectos o \\
acciones para el \\
Desarrollo Local
\end{tabular} & & $\begin{array}{l}\text { Cómo fue el } \\
\text { resultado }\end{array}$ & & $\begin{array}{c}\text { Conoce qué es } \\
\text { Desarrollo } \\
\text { Económico } \\
\text { Local }\end{array}$ & $\begin{array}{c}\text { Considera que } \\
\text { hay diferencias } \\
\text { entre el } \\
\text { Desarrollo Local } \\
\text { ye Desarrollo } \\
\text { Econónico } \\
\text { Local }\end{array}$ & \begin{tabular}{|c} 
Conoce si \\
persona o \\
entidad alguna \\
ha promovido \\
acciones para el \\
Desarrollo \\
Económico \\
Local
\end{tabular} & \begin{tabular}{|c|} 
Ha participado \\
de proyectos 0 \\
acciones para el \\
Desarrollo \\
Económico \\
Local \\
\end{tabular} & & $\begin{array}{c}\text { Cómo fue el } \\
\text { resultado }\end{array}$ & & \begin{tabular}{|c|} 
Cree en los \\
proyectosy \\
resultados que \\
promuevenel \\
Desarrollo \\
Económico \\
Local
\end{tabular} & \begin{tabular}{|c|} 
Le gustaría \\
aprender o \\
conocer \\
ampliamente \\
sobre el \\
Desarrollo \\
Económico \\
Local
\end{tabular} & \begin{tabular}{|c} 
Apoyaría \\
procesoso que \\
promuevanel \\
Desarrollo \\
Económico \\
Local para el \\
municipio
\end{tabular} & \begin{tabular}{|c|} 
Cree que \\
implementar \\
Desarrollo \\
Económico \\
Local le \\
ayudaría a \\
mejorar el \\
Desarrollo Local
\end{tabular} & $\begin{array}{c}\text { Considera que } \\
\text { el municipio } \\
\text { necesita } \\
\text { procesos de } \\
\text { Desarrollo } \\
\text { Económico } \\
\text { Local. }\end{array}$ \\
\hline 1 & & $\mathrm{~s}$ & s & $\mathrm{N}$ & & 3 & & $\mathrm{~s}$ & s & s & $\mathrm{N}$ & & 3 & & s & $s$ & s & $\mathrm{s}$ & s \\
\hline 2 & & $s$ & $s$ & $s$ & & 3 & & $s$ & $s$ & $s$ & $s$ & & 3 & & $s$ & $s$ & $s$ & $s$ & $s$ \\
\hline 3 & & $s$ & $s$ & $s$ & & 3 & & $s$ & $\mathrm{~N}$ & $\mathrm{~N}$ & $\mathrm{~N}$ & & 0 & & $s$ & $s$ & $s$ & $s$ & $s$ \\
\hline 4 & & $\mathrm{~N}$ & & & & & & $\mathrm{~N}$ & & & & & & & & & & & \\
\hline 5 & & $\mathrm{~s}$ & $\mathrm{~s}$ & $\mathrm{~s}$ & & 5 & & $\mathrm{~s}$ & $\mathrm{~N}$ & $\mathrm{~s}$ & $\mathrm{~s}$ & & 5 & & $\mathrm{~s}$ & $\mathrm{~s}$ & $\mathrm{~s}$ & $\mathrm{~s}$ & $\mathrm{~s}$ \\
\hline 6 & & $s$ & $s$ & $s$ & & 4 & & $s$ & $s$ & $s$ & $s$ & & 4 & & $s$ & $s$ & $s$ & $s$ & $s$ \\
\hline 7 & & $\mathrm{~N}$ & & & & & & $\mathrm{~N}$ & & & & & & & & s & & & \\
\hline 8 & & $s$ & $s$ & $\mathrm{~N}$ & & 0 & & $s$ & $s$ & $s$ & $\mathrm{~N}$ & & 0 & & $s$ & $s$ & $s$ & $s$ & $s$ \\
\hline 9 & & $s$ & $s$ & $s$ & & 3 & & $s$ & $s$ & $s$ & $s$ & & 3 & & $s$ & $s$ & $s$ & $s$ & $s$ \\
\hline 10 & & $\mathrm{~N}$ & & & & & & $\mathrm{~N}$ & & & & & & & & s & & & \\
\hline 11 & & $s$ & $\mathrm{~N}$ & $\mathrm{~N}$ & & 0 & & $s$ & $s$ & $\mathrm{~N}$ & $\mathrm{~N}$ & & 0 & & $s$ & $s$ & $s$ & $s$ & $s$ \\
\hline 12 & & $\mathrm{~N}$ & & & & & & $\mathrm{~N}$ & & & & & & & & $S$ & & & \\
\hline 13 & & $\mathrm{~N}$ & & & & & & $\mathrm{~N}$ & & & & & & & & $s$ & & & \\
\hline 14 & & $\mathrm{~s}$ & $\mathrm{~s}$ & $s$ & & 3 & & $\mathrm{~s}$ & $\mathrm{~s}$ & $s$ & $\mathrm{~s}$ & & 3 & & $\mathrm{~s}$ & $s$ & $\mathrm{~s}$ & $\mathrm{~s}$ & $\mathrm{~s}$ \\
\hline 15 & & $s$ & $s$ & $s$ & & 3 & & $s$ & $s$ & $s$ & $s$ & & 3 & & $s$ & $s$ & $s$ & $s$ & $s$ \\
\hline 16 & & $s$ & $\mathrm{~N}$ & $\mathrm{~N}$ & & 0 & & $s$ & $\mathrm{~N}$ & $\mathrm{~N}$ & $\mathrm{~N}$ & & 0 & & $s$ & $S$ & $s$ & $s$ & $s$ \\
\hline 17 & & $S$ & $s$ & $s$ & & 3 & & $s$ & $\mathrm{~s}$ & $s$ & $s$ & & 4 & & $\mathrm{~s}$ & s & $\mathrm{s}$ & $\mathrm{s}$ & s \\
\hline 18 & & $s$ & $s$ & $s$ & & 4 & & $s$ & $S$ & $s$ & $s$ & & 4 & & $s$ & $s$ & $s$ & $s$ & $s$ \\
\hline 19 & & $s$ & 5 & $\mathrm{~N}$ & & 0 & & $S$ & $S$ & $\mathrm{~N}$ & $\mathrm{~N}$ & & 0 & & $s$ & $s$ & $s$ & $S$ & $s$ \\
\hline 20 & & $s$ & $\mathrm{~s}$ & $s$ & & 4 & & $s$ & $S$ & $s$ & $s$ & & 4 & & $s$ & $S$ & $s$ & $s$ & $s$ \\
\hline 21 & & $s$ & $s$ & $s$ & & 3 & & $s$ & $s$ & $s$ & $s$ & & 4 & & $s$ & $s$ & $s$ & $s$ & $\mathrm{~s}$ \\
\hline 22 & & $s$ & $s$ & $\mathrm{~N}$ & & 0 & & $s$ & $\mathrm{~s}$ & $s$ & $\mathrm{~N}$ & & 4 & & $s$ & $\mathrm{~s}$ & $s$ & $S$ & $\mathrm{~s}$ \\
\hline 23 & & $s$ & $s$ & $s$ & & 2 & & $s$ & $s$ & $\mathrm{~N}$ & $\mathrm{~N}$ & & 0 & & $\mathrm{~N}$ & $s$ & $s$ & $s$ & $s$ \\
\hline & & & & & & & & & & & & & & & & & & & \\
\hline & & & & & & & & & & & & & & & & & & & \\
\hline & \multicolumn{6}{|c|}{ Conocimiento sobre el Desarrollo Local } & \multicolumn{7}{|c|}{ Conocimiento sobre el Desarrollo Económico Local } & \multicolumn{6}{|c|}{ Promoción del Desarrollo Económico Local } \\
\hline & $\begin{array}{l}\text { Opción de } \\
\text { respuesta }\end{array}$ & $\begin{array}{l}\text { Conoce qué es } \\
\text { Desarrollo Local }\end{array}$ & s $\begin{array}{c}\text { Conoce si } \\
\text { persona o } \\
\text { entidad alguna } \\
\text { al } \\
\text { ha promovido } \\
\text { acciones para el } \\
\text { Desarallo Local }\end{array}$ & $\begin{array}{l}\text { Ha participado } \\
\text { de proyectos o } \\
\text { acciones para el } \\
\text { Desarrollo Local }\end{array}$ & Opción de respuesta & $\begin{array}{l}\text { Cómo fue el } \\
\text { resultado }\end{array}$ & $\begin{array}{l}\text { Opción de } \\
\text { respousta }\end{array}$ & $\begin{array}{c}\text { Conoce qué es } \\
\text { Desarrollo } \\
\text { Económico } \\
\text { Local }\end{array}$ & \begin{tabular}{|c|} 
Considera que \\
hay diferencias \\
entre el \\
Desarrollo Local \\
yel Desarrollo \\
Económico \\
Local
\end{tabular} & \begin{tabular}{|c} 
Conoce si \\
persona o \\
entidad alyuna \\
ha promovido \\
acciones para el \\
Desarrollo \\
Económico \\
Local \\
\end{tabular} & \begin{tabular}{|c|} 
Ha participado \\
de proyectoso \\
acciones para el \\
Desarrollo \\
Económico \\
Local \\
\end{tabular} & $\begin{array}{l}\text { Opción de } \\
\text { respuesta }\end{array}$ & $\begin{array}{c}\text { Cómo fue el } \\
\text { resultado }\end{array}$ & $\begin{array}{l}\text { Opción de } \\
\text { respuesta }\end{array}$ & \begin{tabular}{|c|} 
Cree en los \\
proyectosy \\
resultados que \\
promueven el \\
Desarrollo \\
Económico \\
Local \\
\end{tabular} & \begin{tabular}{|c|} 
Le gustaría \\
aprender o \\
conocer \\
ampliamente \\
sobre el \\
Desarrollo \\
Económico \\
Local \\
\end{tabular} & \begin{tabular}{|c} 
Appyaria \\
procesos que \\
promuevan el \\
Desarrollo \\
Económico \\
Local para el \\
municipio \\
\end{tabular} & \begin{tabular}{|c|} 
Cree que \\
implementar \\
Desarrollo \\
Económico \\
Local le \\
ayudaría a \\
mejorar el \\
Desarrollo Local \\
\end{tabular} & $\begin{array}{c}\text { Considera que } \\
\text { el municipio } \\
\text { necesita } \\
\text { procesos de } \\
\text { Desarrollo } \\
\text { Económico } \\
\text { Local. }\end{array}$ \\
\hline & & & & & 0 - No sabe & $28 \%$ & & & & & & 0 - No sabe & $33 \%$ & & & & & & \\
\hline & & & & & 1-Malo & $0 \%$ & & & & & & 1-Malo & $0 \%$ & & & & & & \\
\hline & NO & $22 \%$ & $11 \%$ & $33 \%$ & 2-Regular & $6 \%$ & NO & $22 \%$ & $17 \%$ & $28 \%$ & $44 \%$ & 2-Regular & $0 \%$ & NO & $6 \%$ & $4 \%$ & $0 \%$ & $0 \%$ & $0 \%$ \\
\hline & & & & & 3- Bueno & $44 \%$ & & & & & & 3-Bueno & $28 \%$ & & & & & & \\
\hline & $\mathrm{Sl}$ & $78 \%$ & $89 \%$ & $67 \%$ & 4- Muy Bueno & $17 \%$ & $\mathrm{sl}$ & $78 \%$ & $83 \%$ & $72 \%$ & $56 \%$ & 4-Muy Buer & $33 \%$ & $\mathrm{Sl}$ & $94 \%$ & $96 \%$ & $100 \%$ & $100 \%$ & $100 \%$ \\
\hline & & & & & 5 - Excelente & $6 \%$ & & & & & & 5 - Excelente & $6 \%$ & & & & & & \\
\hline & Total & $100 \%$ & $100 \%$ & $100 \%$ & Total & $100 \%$ & Total & $100 \%$ & $100 \%$ & $100 \%$ & $100 \%$ & Total & $100 \%$ & Total & $100 \%$ & $100 \%$ & $100 \%$ & $100 \%$ & $100 \%$ \\
\hline
\end{tabular}

